\title{
Nanotechnology based solutions for anti-leishmanial impediments: a detailed insight
}

Humzah Jamshaid ${ }^{1}$, Fakhar ud Din ${ }^{1 *}$ (1) and Gul Majid Khan ${ }^{1,2^{*}}$

\begin{abstract}
As a neglected tropical disease, Leishmaniasis is significantly instigating morbidity and mortality across the globe. Its clinical spectrum varies from ulcerative cutaneous lesions to systemic immersion causing hyperthermic hepatosplenomegaly. Curbing leishmanial parasite is toughly attributable to the myriad obstacles in existing chemotherapy and immunization. Since the 1990s, extensive research has been conducted for ameliorating disease prognosis, by resolving certain obstacles of conventional therapeutics viz. poor efficacy, systemic toxicity, inadequate drug accumulation inside the macrophage, scarce antigenic presentation to body's immune cells, protracted length and cost of the treatment. Mentioned hurdles can be restricted by designing nano-drug delivery system (nano-DDS) of extant anti-leishmanials, phyto-nano-DDS, surface modified — mannosylated and thiolated nano-DDS. Likewise, antigen delivery with co-transportation of suitable adjuvants would be achievable through nano-vaccines. In the past decade, researchers have engineered nano-DDS to improve the safety profile of existing drugs by restricting their release parameters. Polymerically-derived nano-DDS were found as a suitable option for oral delivery as well as SLNs due to pharmacokinetic re-modeling of drugs. Mannosylated nano-DDS have upgraded macrophage internalizing of nanosystem and the entrapped drug, provided with minimal toxicity. Cutaneous Leishmaniasis (CL) was tackling by the utilization of nano-DDS designed for topical delivery including niosomes, liposomes, and transfersomes. Transfersomes, however, appears to be superior for this purpose. The nanotechnology-based solution to prevent parasitic resistance is the use of Thiolated drug-loaded and multiple drugs loaded nano-DDS. These surfaces amended nano-DDS possess augmented $\mathrm{IC}_{50}$ values in comparison to conventional drugs and un-modified nano-DDS. Phyto-nano-DDS, another obscure horizon, have also been evaluated for their anti-leishmanial response, however, more intense assessment is a prerequisite. Impoverished Cytotoxic T-cells response followed by Leishmanial antigen proteins delivery have also been vanquished using nano-adjuvants. The eminence of nano-DDS for curtailment of anti-leishmanial chemotherapy and immunization associated challenges are extensively summed up in this review. This expedited approach is ameliorating the Leishmaniasis management successfully. Alongside, total to partial eradication of this disease can be sought along with associated co-morbidities.
\end{abstract}

Keywords: Leishmaniasis, Nanotechnology, Nano-DDS, Nano-adjuvants, Drug delivery, Mannosylated thiolated nanosystem, Transferosomes, Nanovaccines, Phyto-nano-DDS

*Correspondence: fudin@qau.edu.pk; gmkhan@qau.edu.pk

${ }^{1}$ Nanomedicine Research Group, Department of Pharmacy, Quaid-IAzam University, Islamabad 45320, Pakistan

Full list of author information is available at the end of the article

\section{Leishmaniasis-a grievous medical condition}

Leishmaniasis, a neglected tropical disease, is the 3rd most challenging vector-borne disease. A huge number of cases of Leishmaniasis are reported annually all over the world. Additionally, according to the World 
Health Organization (WHO) published data, it has been reported that Leishmaniasis is endemic to approximately 100 countries of the world except for Polar Regions and Australia. Indeed, this disease is more pronounced in a tropical, subtropical, and temperate region and classified under the umbrella of neglected tropical disease as well [1-3]. According to 2012 stats, the death rate associated with visceral leishmaniasis (VL) was $10 \%-15 \%$ of the reported cases, worldwide [4]. Leishmaniasis is more prevalent in the poor population [5]. Most probably because of lower financial returns the pharmaceutical industries showed minimal concerns towards anti-leishmanials research and drug development. Worldwide, about 0.2-0.4 million cases of VL have been reported annually. However, 95\% of the new VL cases usually outbreak in Sudan, South America particularly in Brazil, Kenya, Nepal, and in Sub-continent-India, and Bangladesh. Worldwide VL burden has been reduced significantly from 2012, which was 50,000-90,000 according to a 2017 data survey. Contrary to this, the annual registered cases of CL are around 0.7-1.2 million, across the globe. This form of Leishmaniasis usually appears mainly (85\%) in Asian countries including Iraq, Iran, and Pakistan, in the South American region-in Brazil and Peru specifically, in Algeria, South Africa, Sudan, and Costa Rica [3, 6-8]. As far as Post Kalazar dermal Leishmaniasis is concerned, $50 \%$ of its new cases are reported in the East African region and 10\% in the Indian Sub-continent. In American regions, genus Lutzomyia causes the spreading of the parasite, while the genus Phlebotomus acts as a vector in the rest of the world [7]. Leishmaniasis also hit Middle-East regions evidenced by a survey, reporting 1033 new CL cases in Lebanon in 2013, as compared to only 6 registered CL cases between 20002012 [9]. In India, Bihar is the hub of Leishmaniasis most probably due to pathetic poverty conditions (income below 1.0 USD/day). Since 2005, Nepal and India undergoing a campaign and disease control programs to minimize leishmanial burden by 1 infective case per 10,000 individuals at the sub-district level $[5,10]$. A review published in 2006 stated that Leishmaniasis holds a high treatment cost of 30-1500 USD, indeed, a challenging factor for poverty. Furthermore, the indirect treatment cost for Leishmaniasis in Nepal was 53\% of the total treatment cost. The total median treatment cost per patient in Srilanka was found to be 66.85 USD while the economic loss median cost of households was found to be 61.27 USD. The VL diagnostic and management cost in Nepal is more than the median annual domestic income [11].

About 20 different species of trypanosomatid protozoans belonging to the genus Leishmania, have been reported to cause Leishmaniasis [1]. Moreover, the old and new world Leishmaniasis is characterized primarily by the causative species. Various Leishmania species such as L. tropica, L. infantum, and L. major are the primary causative means for Old World Leishmania. Whereas, L. mexicana, L. braziliensis, and L. viannia are mainly responsible for New World Leishmania [12]. $\mathrm{VL}$ is mainly caused by $L$. donovani, $L$. infantum and $L$. tropica. However, the major causative species for $C L$ are L. tropica, L. major, L. infantum, L. braziliensis, L. amazonensis, and L. guyanensis [1, 2, 12, 13]. The principal vector responsible for the mammal to human transmission of the leishmanial parasite is the Phlebotomine sandfly. On taxonomic grounds, it has been concluded by Lane that among 6 genera of the Phlebotomine subfamily, only 2 genera are chiefly associated with leishmanial dissemination. Furthermore, Phlebotomus genera are the chief vector for old world Leishmania and Lutzomyia genera are associated with New world Leishmania spreading $[1,2]$. Another possible reason for the prevalence of Leishmaniasis in the Mediterranean/tropical region is the hyperactivity of sand fly in warmer and humid areas [14].

Principle reservoirs for VL induced by $L$. donovani strain are the humans and its transmission is usually occurring from $700 \mathrm{~m}$ below sea level to the altitude of $1000 \mathrm{~m}$, particularly in the Sub-continent, Nepal, and Bhutan [15-17]. This form usually outbreaks in villages with high poverty rates and mud-walled houses. Moreover, the presence of cattle under the same roof or nearby places favored the spreading of parasites via Phlebotomus argentipes [2]. The primary reservoir of leishmanial protozoa ( $L$. infantum) is the wild mammals like hare, dogs, and the successful infection development requires the appropriate anthroponotic or zoonotic transmission of the parasite to the human host. Non-vector parasitic transmitting ways are also described which includes organ transplantation, blood products transfusion, and laboratory mishaps. However, the CL spreading by these routes is rare. Male gender, meager living facilities, and younger age below 15 are more prone to CL infection [2]. Two distinct morphological forms of Leishmania have been identified in its life cycle, which are the promastigote and amastigote. The former form is long, flagellated, and usually present extracellular in the vector, sandflies. However, the latter one is small in size, aflagellated and present inside the monocytes/macrophages of the human or mammalian host [1]. A detailed leishmanial life cycle is illustrated in Fig. 1.

Depending upon the severity of the affected macrophages, the infection ranges from asymptomatic to clinically evident disorder. The symptomatic infection is either localized to the skin or mucocutaneous junction, termed as CL and mucocutaneous Leishmaniasis 


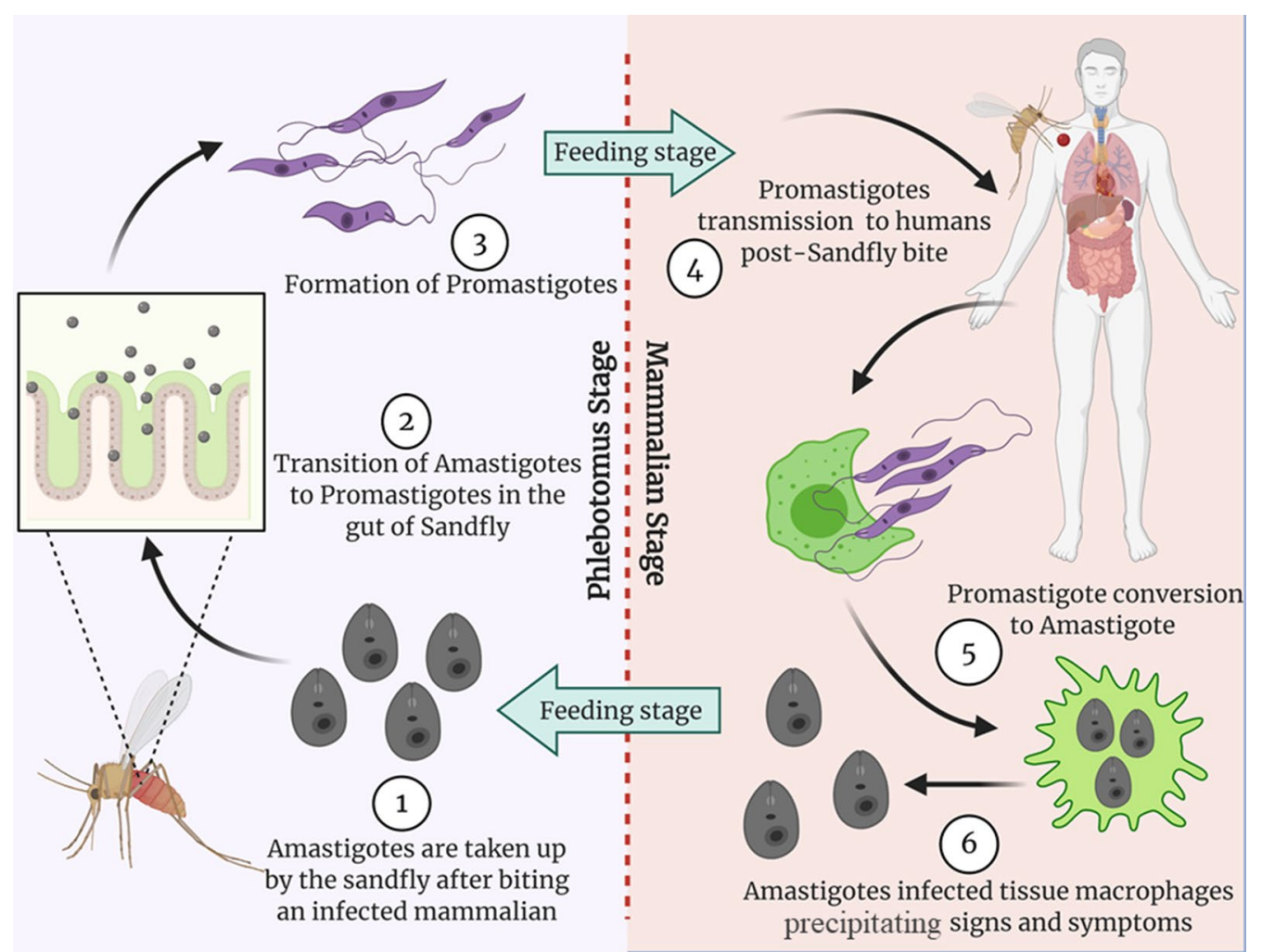

Fig. 1 Life Cycle of Leishmania and its stages; [1] Sandfly acquire amastigotes from infected mammalian host; [2] Amastigotes conversion into the promastigotes in sandfly gut; [3, 4] Transmission of promastigotes from sandfly to the healthy mammalian host by sandfly bite; [5, 6] Promastigotes conversion to amastigotes which infect the macrophages and induce a symptomatic condition

(MCL), respectively. Whereas, systemic infection is referred to as VL [18]. Thus, because of clinical signs and symptoms, Leishmaniasis is usually presented in three forms as shown in Fig. 2. VL usually manifests with irregular hyperthermic episodes accompanied with spleno-hepatomegaly and blood dyscrasia-pancytopenia and hyper gammaglobulinemia appear. Weight loss is also common in VL patients, in particular, children $[9,19]$. Wasting and acute malnutrition encounter, but it is uncertain whether a consequence of elevated parasitic burden or poverty [19]. A surge in adrenocorticotropic hormone and cortisol due to excessive cytokine release imparts skin hyperpigmentation in VL individuals, which in the Indian native language, is termed as "Kalazar-a black fever" [20]. The incubation duration of the leishmanial parasite ranges from 7 to 147 days [21]. Hence, the commencement of VL is either acute or insidious. VL infection, unfortunately, can be lethal on account of serious anemic conditions or secondary bacterial infection and sepsis [22]. Contrary to VL, CL is a non-lethal skin infection that reduces a patient's life quality, impart psychological problems and social stigmatism [23]. The lesion morphology varies with the infective species. In general, at the initial stages of infection, the papule develops which gradually transforms into an ulcerative nodule over an extended duration of few months. Lesion site is not limited to face and extremities, because in diffused CL lesion develops at various cutaneous sites, illustrated in Fig. 3 [24, 25]. Lymphatic dissemination of the parasite, however, is probable. Lesions of L. major and L tropica infection are usually self-resolving, but unfortunately, instigate permanent cutaneous scarring. CL caused by L. aethiopica is quite dangerous owing to its diffused nature, deterioration, and dissemination of lesions to mucocutaneous junctions [26]. However, MCL manifestation is life-threatening and is believed to be encountered more frequently in the immunocompromised population $[27,28]$. The major ulcer site in this form is an oronasal junction. As previously stated, MCL lesion can cause mutilation of nasal cartilage and nasal septum, which could ultimately cause nasal collapse [1,29]. To summarize the discussion, it is conclusive that Leishmaniasis is a challenging medical condition and public 


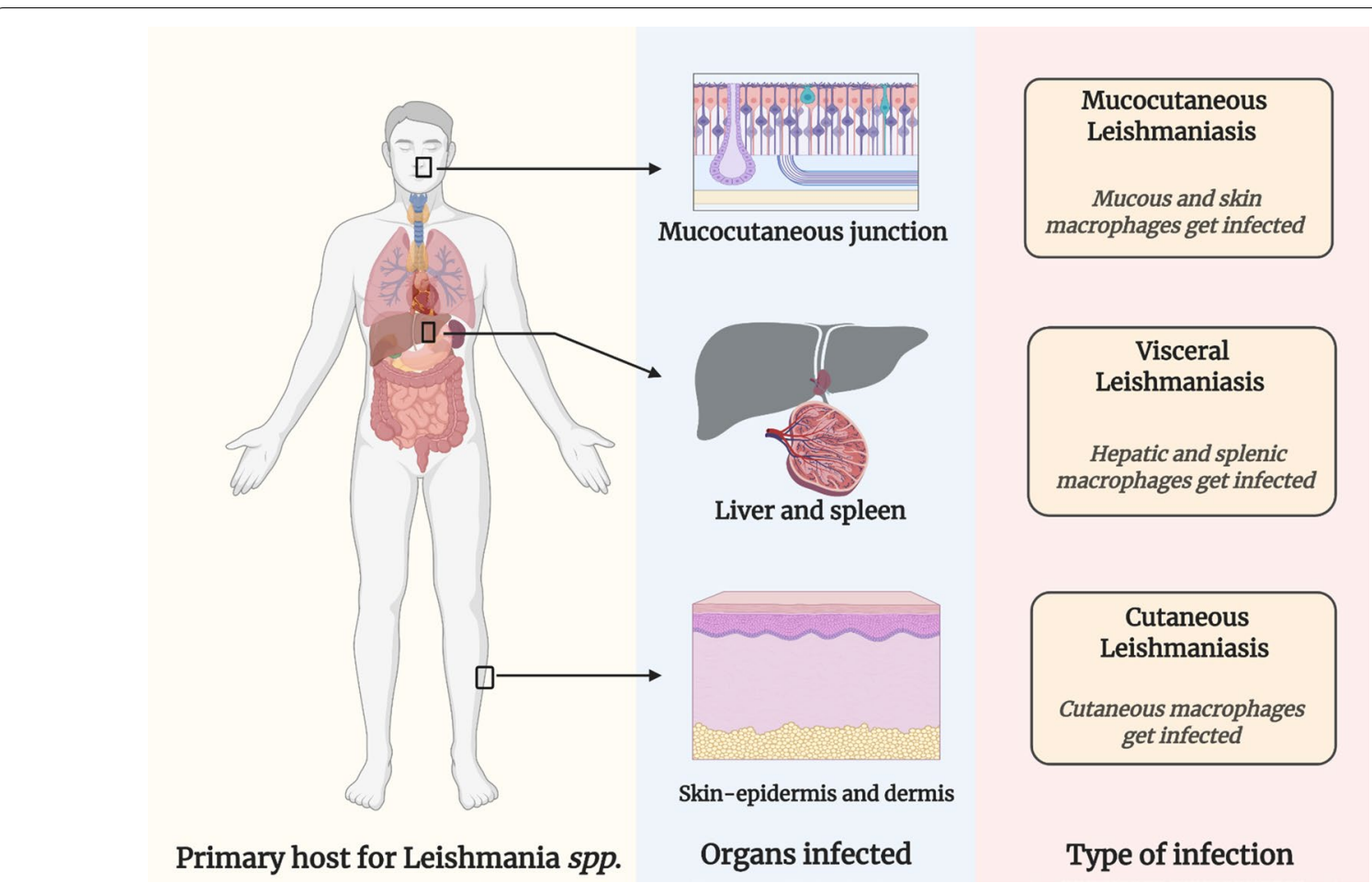

Fig. 2 Types of leishmaniasis and the organs affected; Mucocutaneous Leishmaniasis—-mucocutaneous junctions get infected, Visceral Leishmaniasis — Liver and spleen get infected, Cutaneous Leishmaniasis—skin gets infected

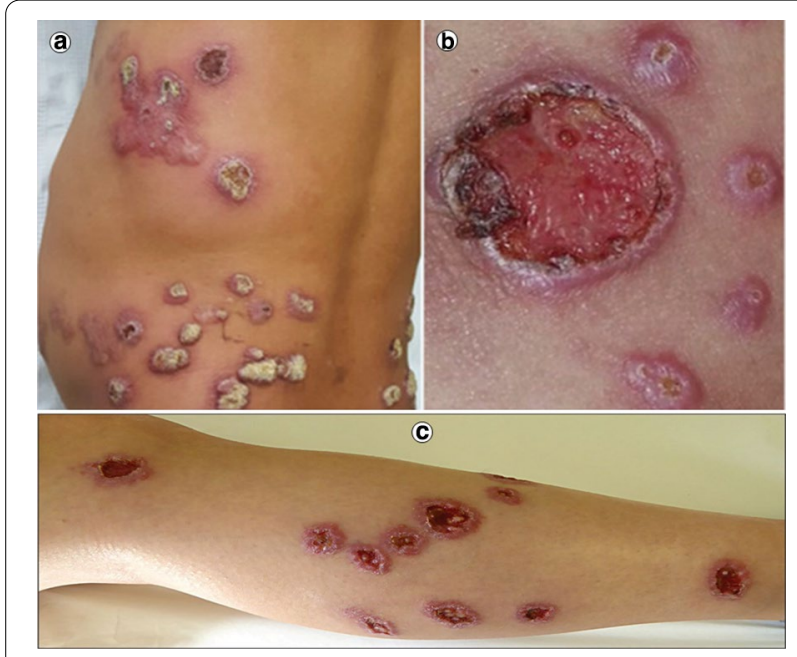

Fig. 3 a Keratitis with diffused nodular lesion [24]. b Ulcerated lesion with crusty border with non-bleeding erythematous center [24]. c Multiple CL lesions on the right leg of 27-years old women [25]

health burden, globally. At the start of the last decade, Leishmaniasis was endemic to 98 countries but now the number is raised to 100 . These facts are critical and demands global scientific attention towards mitigation of hurdles to attain its eradication.

\section{Challenges related to conventional anti-leishmanials-in the way of disease eradication}

Resistance emergence-a major setback for Leishmaniasis management

There is no vaccine yet approved for Leishmaniasis prevention, but undergoing clinical trials [30]. Thus, the mainstay of treatment; for all forms of Leishmaniasis, relies on chemotherapeutic agents. Despite the extensive research on anti-leishmanial chemotherapy in the past 7 decades, satisfactory treatment has yet to be approved. Although, WHO has recommended the use of Meglumine Antimonate (MA) for all forms of Leishmaniasis, still it encourages the investigation of new anti-leishmanial agents because of multiple limitations. Nowadays, both of the above-mentioned cornerstones of leishmanial chemotherapy have gone resistant and not properly responding in terms of parasitic eradication [31]. In various regions of India, particularly in Bihar, numerous resistant cases of $L$. donovani have been reported. Consequently, numerous studies have been conducted and recommended the adoption of Amphotericin B (Amp-B) as an alternative first-line agent for resistant Kalazar (VL) cases [32]. Approval of Liposomal Amp-B (L-Amp-B), however, is presently being opted as a suitable alternative 
to antimonate therapy, particularly for VL. An unusual case of Amp-B resistance has been reported in India, according to the recently published case report [33]. Miltefosine (MFS) is the first oral anti-leishmanial agent approved by the Food and Drug Administration
(FDA) for the management of CL, caused by L. donovani, and for some resistant cases of VL, it is merely, a ray of hope [34]. Despite the fact of its discovery, two MFS resistant cases have been reported in India [35]. The proposed mechanisms by which the leishmanial

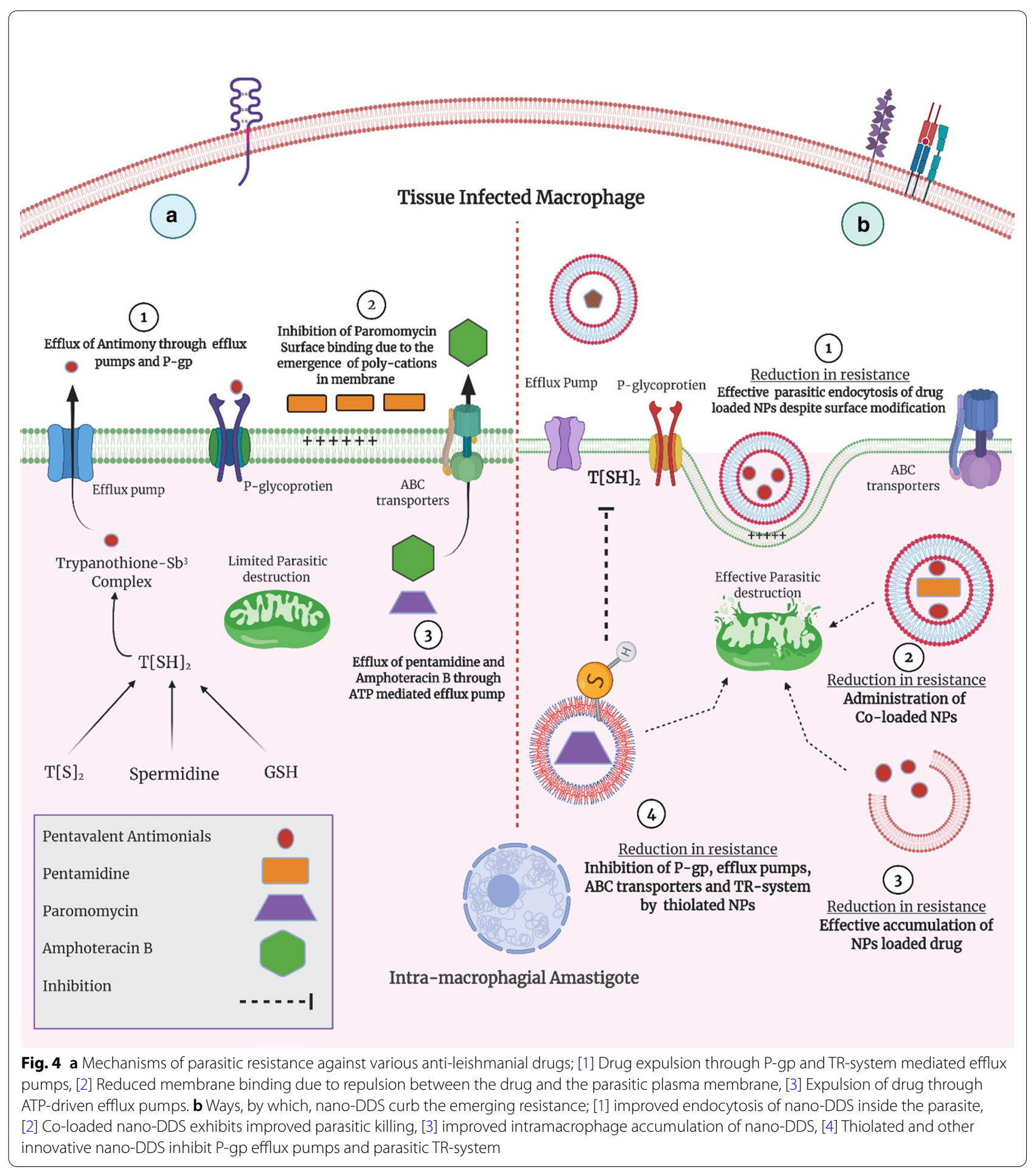


amastigote exhibit resistance against various agents has been graphically illustrated in Fig. 4a, b.

Two major mechanisms are involved in the emergence of resistant leishmanial strains, the $\mathrm{ABC}$ transporters (setup in the parasitic membrane) and thiol conjugated system (present in the cytosol). These ATP-binding cassette $(A B C)$ transporters are also shown to minimize intra-parasitic drug accumulation accompanied by their rapid expulsion. ABCC3 transported is found to be associated with antimony resistance and these pumps work more efficiently to pump out thiol conjugated metal moieties. Pentamidine (PTM) resistance, evaluated in previous studies, was considered to be due to Pentamidine resistant protein-1 (PRP1) transporter [36]. In addition, due to various efflux pumps, P-glycoprotein (P-gp) and ATP mediated efflux pump, the drug residence time inside the parasite gets lowered which could ultimately lead to treatment failure. Thiol conjugation-Trypanosomatid Trypanothione reductase system (TR-system), also referred to as $\mathrm{T}[\mathrm{SH}]_{2}$, which is merely an anti-oxidant system of the parasite also, unfortunately, plays a crucial role in neutralization and expulsion of drug [36, 37]. Moreover, the reason for Paromomycin (PMC) resistance is the reduced initial cationic drug binding with negatively charged leishmanial glycocalyx which would ultimately minimize the endocytosis as well as intraparasitic accumulation of PMC. However, the detailed molecular mechanism of PMC resistance is yet to be discovered [38].

\section{Chemotherapeutic toxicity-hindrance in medication adherence}

In addition to resistance emergence, MA has several other complications as well, such as large doses are required to meet up with the rapid parasitic clearance [39]. This possibly could lead to MA toxicity-renal failure, pancreatitis, and cardiomyopathy. Another reason for the decline in its use is its systemic toxicity. Sodium Stibogluconate (SSG), another pentavalent antimonate, has also been associated with systemic and local toxicity. Infected patients, undergoing SSG treatment, usually encounter pain at the site of injection as well as nausea and vomiting $[40,41]$.

Despite the effectiveness of Amphotericin-B (AmpB) against fungal and leishmanial infections, its use has been restricted due to its systemic undesirable events and toxicity. Infusion-related adverse effects and nephrotoxicity are its major limiting parameters [42]. Pentamidine (PTM) therapy is often accompanied by problems such as painful necrotic injection site lesions, nephrotoxicity, and hypoglycemia; the main reasons for its poor adherence and associated lower cure rates [43, 44]. The discovery of anti-leishmanial activity of MFS is, merely, a novelty because it is the first oral anti-leishmanial drug for the treatment of Leishmaniasis [45, 46]. Although MFS is approved for oral treatment in Leishmaniasis, still some undesirable events such as gastrointestinal distress, hemolysis and nephrotoxicity are its major dose-limiting parameters and are the reason for poor patient compliance [47-49].

\section{Anti-leishmanials with meager GIT absorption}

All 1st line anti-leishmanial drugs are injectable except MFS. Older anti-leishmanials; MA and SSG, are unable to cross the intestinal epithelial membrane, thus exhibit very poor oral absorption, illustrated in Fig. $5 \mathrm{a}$, b. As a result, they are given as injectable and the preferred route of administration is intravenous and intra-lesioned. Amp-B, despite its good effectiveness against fungal and leishmanial infections, is administered intravenously and it eventually causes infusion-related side effects and nephrotoxicity [42]. Amp-B demonstrated passive diffusion for its intestinal absorption. However, due to its high molecular weight (924.08 Daltons), its intestinal passive diffusion was minimal. Moreover, it is also susceptible to damage caused by the acidic $\mathrm{pH}$ of the stomach [50, 51]. To tackle this challenging situation, several Amp-B nano-DDS have been designed (discussed in "Promising nano-DDS-capable for oral delivery of injectable antileishmanials" section). PTM is an aromatic diamidine available only in injectable form because of its stunted oral absorption. Chemically, it possesses two strong amide groups which is the major contributory factor towards its poor intestinal absorption [52, 53]. PMC, an aminoglycoside antibiotic, is a new treatment modality for Leishmaniasis and undergoing clinical studies. However, apart from its associated benefits, it also has limitations to be administered through parenteral, topical, or transdermal route only [54].

\section{Additional miscellaneous chemotherapy drawbacks}

In the pursuance of a recommendation by WHO to use topical agents for uncomplicated CL, a few anti-leishmanials were fabricated to be applied topically to passively target the cutaneous parasites. This route is also beneficial for minimal systemic exposure and unnecessary drug metabolism [55]. Minimal cutaneous absorption of some anti-leishmanials is troublesome because the parasite resides in the deep cutaneous layer. To effectively treat $\mathrm{CL}$, the drug must cross the epidermal barrier and internalize inside skin macrophages, but existing conventional dosage forms are unable to meet this condition [13]. Several other drugs possess leishmanial killing potential, but not enough to cause total parasite eradication, and are used as "off-label drugs". Though they are safer drugs, however, to attain effective parasite 


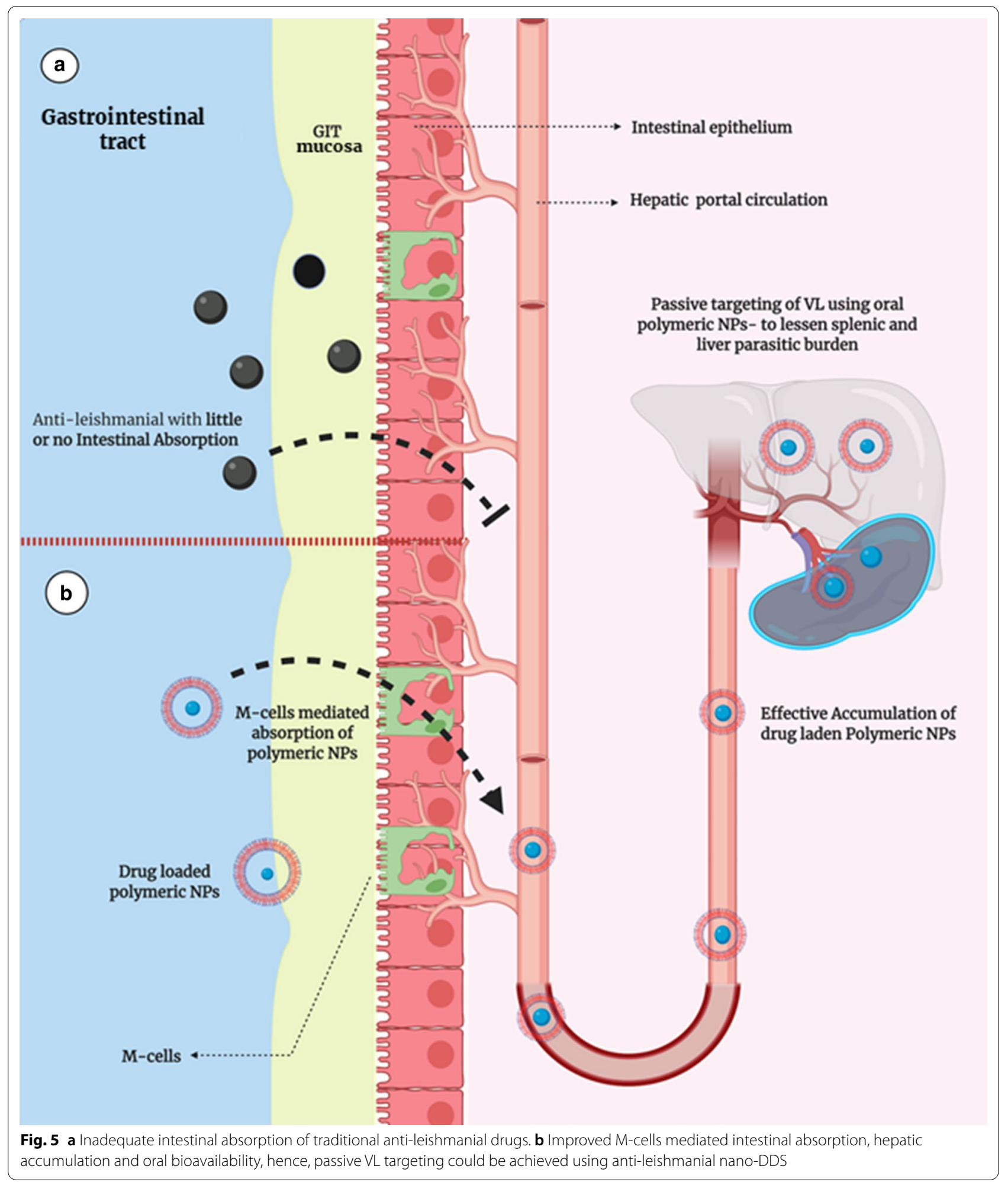

eradication and disease remission, combined administration with 1st line anti-leishmanials is necessary. These agents include several anti-fungal azoles such as fluconazole and ketoconazole, rifampicin, stimaquine, and
immunomodulators-Resiquimod (RMQ) and Imiquimod (IMQ) $[40,56]$. The existing chemotherapy together with its associated obstacles is mentioned in Table 1. 
Table 1 Anti-leishmanial chemotherapy and associated limitations

\begin{tabular}{|c|c|c|c|c|c|}
\hline Drugs & FDA approval & Administration route & Possible associated challenges & $\begin{array}{l}\text { FDA } \\
\text { approved } \\
\text { nano- } \\
\text { formulation }\end{array}$ & References \\
\hline Meglumine antimonate & Not approved & IV/IM/IL & $\begin{array}{l}\text { Systemic adverse effects (Acute pan- } \\
\text { creatitis, Acute renal failure, hepatitis \& } \\
\text { cardiotoxicity) }^{\text {Resistance development }}{ }^{\mathrm{a}} \\
\text { Poor oral absorption }\end{array}$ & No & {$[31,40,41,52]$} \\
\hline Sodium stibogluconate & Not approved & IV/IM/IL & $\begin{array}{l}\text { Systemic adverse events (Infusion-related } \\
\text { toxicity (pain, nausea \& Vomiting) with } \\
\text { respiratory distress, vomiting) } \\
\text { Resistance development }{ }^{\mathrm{a}} \\
\text { Poor oral absorption }\end{array}$ & No & \\
\hline Amphotericin B & $\begin{array}{l}\text { Approved for } V L \text { caused } \\
\text { by any species } \\
\text { Particularly in Antimoni- } \\
\text { als unresponsive cases }\end{array}$ & IV & $\begin{array}{l}\text { Systemic adverse effects (Acute infusion- } \\
\text { related toxicity \& Nephrotoxicity) } \\
\text { Resistance development } \\
\text { Cost of therapy }\end{array}$ & $\begin{array}{l}\text { AmBisome }^{\circledR} \\
\text { (liposomes) }\end{array}$ & \\
\hline Pentamidine (isethionate) & Not approved & $\mathrm{IM} / \mathrm{IV}$ & $\begin{array}{l}\text { Systemic adverse events (Nephrotoxicity } \\
\& \text { dysglycemia) } \\
\text { Poor oral absorption }\end{array}$ & No & \\
\hline Miltefosine & $\begin{array}{l}\text { VL caused by L. donovani } \\
C L \text { caused by L. viannia }\end{array}$ & Oral & $\begin{array}{l}\text { Systemic adverse events (Gastrointestinal } \\
\text { distress, elevated liver enzymes \& renal } \\
\text { toxicity) }\end{array}$ & No & \\
\hline Paromomycin & Not Approved & Topical/IV & $\begin{array}{l}\text { Poor oral absorption } \\
\text { Variable response against } \mathrm{CL} \\
\text { Limited skin permeation }\end{array}$ & No & \\
\hline
\end{tabular}

a Almost $100 \%$ of the cases of VL in India are un-responsive to antimonial therapy

${ }^{b}$ A very few cases have been reported yet

\section{Futile vaccination candidates-another contest to confront} Leishmaniasis

At present, myriad candidates of leishmanial vaccines are undergoing pre-clinical trials; live (genetically altered), live attenuated, killed parasitic vaccine, recombinant vaccine, recombinant protein, DNA vaccine, and antigen cocktail vaccine [57]. However, due to various obstacles, only a single vaccine candidate has been successful to reach the stage of human trials. Leish-111F has successfully completed phase-I and II clinical trials. Unluckily, it failed to exhibit a protective response in dogs as per the results of phase-III trials [57, 58]. The most probable barriers towards Leishmaniasis vaccine fabrications are marginally recoverable profit-as its heavy-budgeted program costing 300-800 million USD. Leishmania, being a disease endemic to under-developed and 3rd world countries, the vaccine industries presume to have minimal turnover and revenue generation. Inadequate effectiveness-because of minimal antigenic exposure to the body's defending lymphocytes, of trial candidates is another obstacle in the way of vaccine commercialization. Furthermore, variable virulence of different leishmanial species and broad manifesting spectrum of the disease is also hampering immunization influx towards FDA approval [57].

\section{Strategies to overcome anti-leishmanials associated limitations}

To confront the erstwhile discussed challenges accompanying the anti-leishmanial therapy and assure successful treatment of Leishmaniasis several strategies can opt. New drug development is one of the strategies used to discover, fabricate and optimize new and effective drugs. This is, however, a protracted (require 10-12 years on average) and high-budgeted approach. Besides, the risk of failure, the financial loss is also considered to be its limitations [59]. Despite these issues, scientists are using several biologically active substances as potential antileishmanial agents. Among them, edelfosine-an alkyl-phospholipid, has displayed valuable antileishmanial properties and is found more effective than MFS $[60,61]$. The number of phenolic compounds has been assessed and found to possess pronounced in vivo and in vitro anti-leishmanial activity [62]. In the struggle to find a new treatment option, the anti-leishmanial activity of calcium channel blockers, fendiline, and lidoflazine, was reported but due to unsatisfactory activity against intracellular amastigote research was unable to be continued [63]. The discovery of IMQ is however one of the scientist's successful efforts. As some of its analogs possess strong leishmanicidal properties [64]. 
The second strategy is the development of new derivatives of existing anti-leishmanial drugs for the reason to alter the pharmacokinetic (ADME) parameters, toxicity profile, and enhancing their potency. By using this technique, derivatives can be designed that have effectiveness against resistant cases. One such attempt was made, to modify the PTM using boronic acid to target the leishmanial membrane lipophosphoglycan. But the results of the study were not satisfactory [65]. In another meaningful attempt, MA with a low polymerized state has been developed which exhibited considerable oral absorption [66]. Primaquine (PMQ), having reported anti-leishmanial activity, was chemically modified by the introduction of imidazolidin-4-one and ferrocene to form peptidomimetic and organometallic derivatives of PMQ, respectively. In this study, the anti-leishmanial activity of the above-mentioned derivatives against intracellular amastigotes of $L$. infantum was reported to be less than the parent compound and the positive control, the MFS [67].

\section{Nanotechnology—a revolutionary perspective towards medical advancement}

The preferable option to hasten the limitations of antileishmanial chemotherapeutic and immunogenic agents is their nano-optimization. It is also be referred to as nano-medicine which is defined as the use of nano-technology for the sake of increasing the solubility, modifying the pharmacokinetics, reducing toxicity, and enhancing tissue targeting in contrast to the conventional options $[68,69]$. Thus, with the employment of nano-DDS, the oral bioavailability of inadequately absorbed drugs will improve along with the impartment of sustained and controlled release behavior [70, 71]. As previously mentioned, the conventional drug delivery systems are not capable of targeted delivery. Nanotechnology-based DDS have also resolved this contest as they can easily be modified using surface tuning with certain biological moieties. Those surface-attached moieties act as a guide towards the target tissue. This targeting approach is referred to as "active targeting" [72]. Another important aspect is their ability to achieve enhanced therapeutic efficacy in a shorter treatment duration, contrary to the conventional drug delivery systems [73]. Generally, in context to Leishmaniasis, the nano-DDS of conventional anti-leishmanials grapple with several limitations inclusively their resistance, toxicity, infection re-emergence, and pharmacokinetics restrictions [74, 75]. These findings are extensively discussed in next "Nanosystem with upgraded efficacy for curtailment of chemotherapeutic toxicity"; "Promising nano-DDS-capable for oral delivery of injectable anti-leishmanials"; "Targeted delivery of anti-leishmanials - unfettered access to intramacrophage parasite"; "Nanosystem based modalities to curb parasitic resistance" and "Distinctive nano-DDS for Leishmaniasis" sections of the review. Nanotechnology, in addition to drug delivery, has also shown its worth in the immunization domain. Nanocarriers offer safe and efficient trafficking of immunogenic proteins to the Antigenpresenting cells (APCs). Furthermore, nano-vaccines are also much more stable than convention vaccines even inside the blood circulation [76]. This immunization approach has also unfolded a new research horizon-an oral vaccine delivery. Numerous nano-adjuvants, under pre-clinical and clinical investigation, are discussed in detail in "Leishmanial nano-vaccines-an innovative approach towards immunization" section. Metallic Nanoparticles (NPs), in particular Gold NPs (AuNPs), dendrimers, and Quantum dots (QDs) also retain potential diagnostic applications that have been evaluated for leishmanial parasite spotting as well [77]. Despite the lack of reasonable outcomes i.e., improper selectivity, sensitivity, and erroneous (false-negative) results, research on leishmanial nano-diagnostics is still advancing. The use of nano-repellants, nano-insecticides, and biological nanoparticles for the purpose to control the vector activity is another obscure field that requires considerable attention, in particular, for leishmanial endemic countries [78]. Nano-theranostics, another forward-looking utilization of NPs for simultaneous diagnosis and treatment, are also under pre-clinical evaluation. This forthcoming modus operandi will greatly influence the treatment outcomes and recovery time, positively [77]. Among them, AmBisome $^{\circledR}$, the L-Amp-B, is the only approved anti-leishmanial nano-DDS based product, providing a non-toxic treatment for VL [79]. In this review, the nano-DDS, designed in last decades for trumping leishmanial treatment, immunization and prevention have been discussed in a comprehensible and critical manner, particularly in terms of in vivo assays. Frequently designed nano-DDS for leishmaniasis, their structure, composition, features, benefits and uses are illustrated in Fig. 6 and discussed comprehensively.

\section{Lipid-based nano-DDS}

Liposomes (LPS), artificially fabricated, spherical, vesicular nanosystem, usually constructed using natural or synthetic lipid moieties and the cholesterol, merely, to strengthen and stabilize the designed lipid bilayer. The dual incorporation of hydrophilic and lipophilic drugs in LPS make them the most suitable and worthy nanocarriers for drug delivery through a variety of routes i.e. parenteral, topical, oral, etc. [80]. LPS are also beneficial in terms of passive targeting to various APCs and tissue macrophages. Polyethylene glycol (PEG)-coated LPS are more stable and have considerably improved half-life (plasma circulation time) as compared to the 


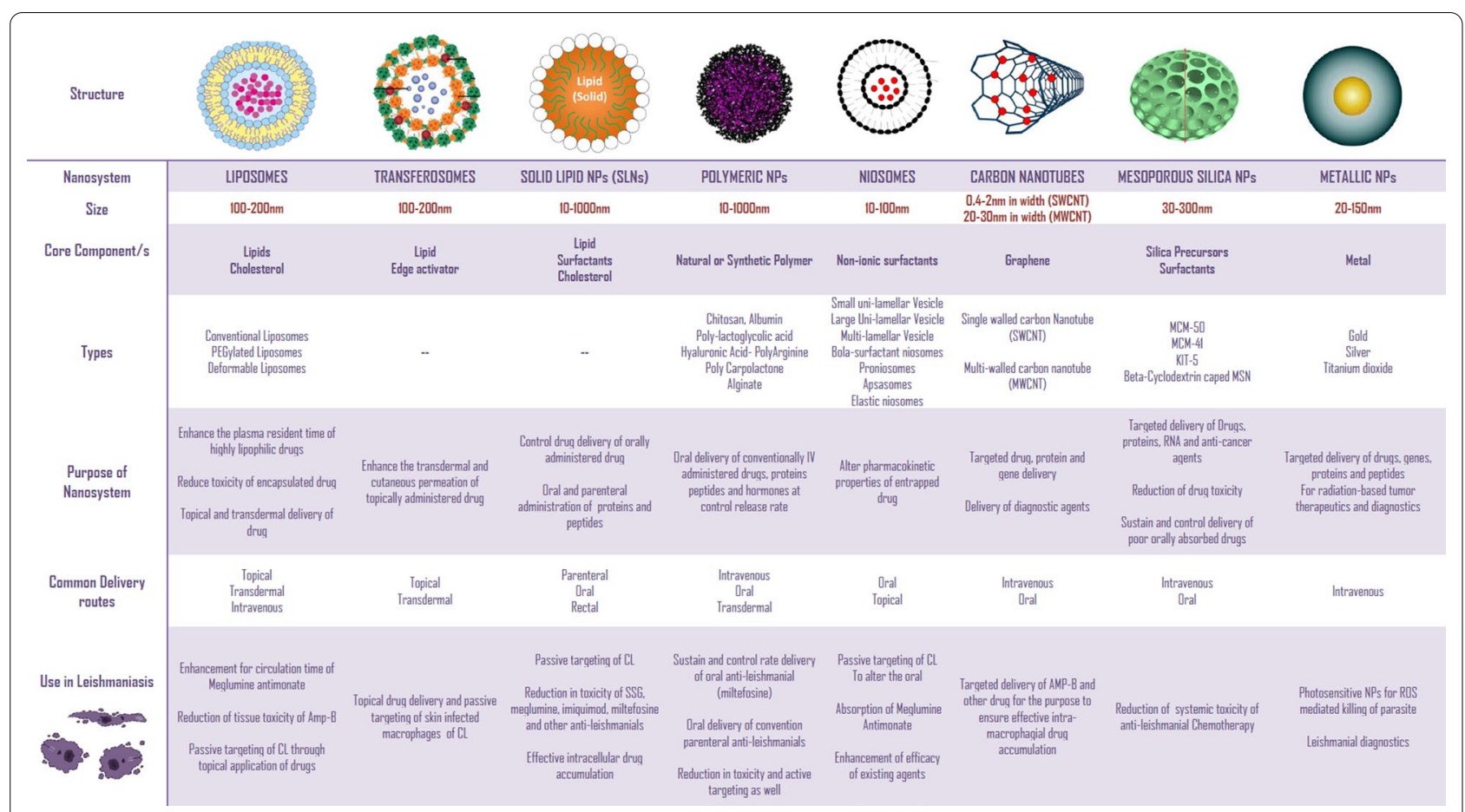

Fig. 6 Nanoparticles employed to grapple anti-leishmanials associated drawbacks

conventional LPS. Another innovative strategy to prolong the circulation time of NPs is to fasten CD47 protein that appears to interact with SPIR- $\alpha$ macrophage receptors. This interaction ultimately reduces the phagocytosis rate of NPs, hence plasma circulation time lifts [81]. Solid lipid NPs (SLNs), have the potential to entrap a vast variety of drugs, proteins, and other medicinal entities. These NPs are considerably stable owing to surfactant covering around them [82]. Due to their small size and lipid nature, they prevents the toxicity incidence of anti-leishmanial agents by limiting their release and exposure [83]. This modified lipid nano-DDS has resolved the stability issues linked with LPS, but experienced burst release of the entrapped drugs. This has hampered the SLNs usefulness towards nanomedicine [84]. Surface modification of SLNs can be effective in controlling the drug release rate [85]. Utilization of a mixture of unstructured solid and liquid lipids along with surfactants in a ratio of $1.5-5 \%$ (weight/volume) has minimized the undesirable burst release of SLNs. Nanostructured lipid carriers (NLCs), in addition, are highly stable and multi-purpose i.e. used for oral as well as dermal delivery. A valuable study has reported the NLCs potential to inhibit intestinal P-gp efflux pumps [86]. Flexible phospholipid-based nanocarriers, the Transfersomes (TFS), have been studied for passive targeting of CL [87]. These nano-DDS possess surged cutaneous penetration as proven by confocal laser scanning microscopy (CLSM) of dye-loaded TFS in numerous studies [88, 89]. In reality, this lipid structured nano-DDS was extensively investigated and utilized for the usefulness and effectiveness in leishmanial nanomedicine.

\section{Biodegradable polymeric nano-DDS}

Polymeric NPs facilitates in traversing biological barriers and membranes. The oral absorption is also facilitated through Microfold (M)-cells in the intestinal peyer's patch [90]. The provision of $\mathrm{pH}$ stability is an additional benefit for $\mathrm{pH}$-sensitive drugs. Furthermore, drug release in a sustained and controlled fashion, the elevation of bioavailability, efficacy improvement, tissue targeting, and adequate cellular uptake are all the paybacks of biopolymeric nanocarriers. Among various biodegradable polymers, poly-lacto-glycolic-acid (PLGA) is the most successfully employed polymer. After cellular hydrolysis, PLGA is catabolized into lactic acid and glycolic acid. The human body effectively metabolized these monomers; thus, it is non-toxic. PLGA is an FDA-approved polymer to be utilized in commercialized nanomedicine [91]. Another attractive aspect is the easily attainable surface modification of PLGA-NPs, to impart selectively victimize cells, tumors, and infectious microbes [92, 93]. Polycaprolactone (PCL), another hydrolyzable bio-polymer, is also often employed to synthesize polymeric nanosystem with better release properties, intestinal absorption, and selective targeting. Moreover, it has been utilized in an attempt to deliver insulin through the oral route. 
Hence, it provides extra-protection to proteins, peptides, and nucleic acids from the harsh gastrointestinal tract (GIT) atmosphere [94, 95]. Carbohydrate-based natural polymer, chitosan, is also valuable because it is associated with multiple benefits irrespective of its biocompatibility. Proteinaceous substances like cyclosporin A and insulin are easily delivered with adequate protection. Intrinsic anti-biological and anti-oxidant effects of chitosan strengthening the chitosan use as a polymer for nanoDDS [96]. Poly-lactic acid, gelatin, and dextran are other bio-polymer having applications in nanomedicine [94].

\section{Additional miscellaneous nano-DDS}

Another appropriate nano-carrier system-niosomes which are composed of non-ionic surfactants and lipids is capable to enhance the intestinal permeation of BCS class-II drugs. Moreover, these nano-formulations are also efficient in protein and vaccine delivery through the oral route. Provision of sustained and controlled release of entrapped drug and transdermal delivery of agents is also its beneficial features [97]. Mesoporous silica NPs (MSNs) can also be employed for efficient oral delivery of poor absorbable agents at sustained and controlled rate. These inorganic nano-DDS have a large surface area and pore volume, which ensures high loading efficiency [98]. Carbon nanotubes (CNTs) are the carbon-based nanosystem having condense benzene molecules spun to form a tubular structure having a length of $0.25-5 \mu \mathrm{m}$ in length and 0.4-2 $\mu \mathrm{m}$ in diameter (depending on that it is single-walled or multi-walled). They are hydrophobic and bio-toxic, and to make their utilization for nanomedicine they should be functionalized [99]. Among metallic NPs, Silver NPs (AgNPs), Titanium oxide $\left(\mathrm{TiO}_{2} \mathrm{NPs}\right)$, and AuNPs display valuable significance for leishmanial nanomedicine, particularly for the development of phyto-nano-DDS; discussed in "Distinctive nano-DDS for Leishmaniasis" section.

\section{Intracellular trafficking of nano-DDS-major mechanisms and influential factors}

An outer covering of animal cells-the plasma membrane, is composed of a phospholipid bilayer and the embedded transporting and structural proteins. The arrangement of lipid bilayer permits only small molecules to traverse the membrane. Larger molecules (size range $>1 \mu \mathrm{m}$ ), however, experience intracellular mobility through "phagocytosis" [100]. Nano-DDS are capable of crossing biological barriers owing to their size in the nanometer range [101]. The NPs having a size below $200 \mathrm{~nm}$ usually undergo pinocytosis (endocytosis) viz. caveolin-mediated endocytosis and clathrin-mediated endocytosis [102]. The detailed mechanism for NPs internalization is illustrated pictorially in Fig. 7a, b. There is another pinocytotic pathway termed "clathrin-caveolae independent endocytosis" and in nanomedicine, it is not very much familiar. Folate labeled chemotherapeutic nano-DDS usually select this pathway to reach the target tumor $[103,104]$.

Clathrin is a cellular membrane protein responsible for vesicle construction, known as "Clathrin cage", that conducts intracellular mobility of selective extracellular matters [105]. Clathrin-mediated endocytosis is a vital cellular internalization phenomenon by which cells usually uptake plasma components i.e., cholesterol, through Low-density lipoproteins (LDL) receptors and iron via Transferrin receptor $[106,107]$. The major steps of Clathrin-mediated endocytosis include-binding of a ligand with the receptor at the plasma membrane, the formation of ligand-receptor complex, mobilization of the complex at the clathrin-rich portion of the membrane, and ultimately the formation of clathrin layered vesicle. Furthermore, that vesicle fuse with cytosolic lysosomes followed by the release of entrapped drug [108]. Generally, most of the lipid-based nano-DDS (neutral and positively charged) opt for clathrin-mediated endocytosis as a mode of cellular entry so does the PLGA NPs and MSNs [109, 110]. Polylactide NPs and plus-charged chitosan NPs also attain cellular access in this way [109]. There is a profound impact of surface coating over the NPs intracellular trafficking. The surface coated, modified, and labeled NPs undergo rapid and targeted internalization through Clathrin-based endocytosis [103]. In nanomedicine, caveolin-mediated endocytosis is preferred owing to the by-passing of lysosomal fusion. Caveolinmediated endocytosis involves the formation of flasklike pits in the membrane having the size of 20-100 nm through the utilization of immobile lipid portions of the plasma membrane-the caveolin-1 [111]. Contrary to clathrin-mediated endocytosis, the NPs interaction with caveole results in formation of caveole-I vesicles which intracellularly fuse with larger caveolin-I based cytoplasmic organelle, having neutral $\mathrm{pH}$, termed as "caveosomes or multi-caveolar complex" [112], as illustrated in Fig. 7b. After few hours of residence, the static caveosomes, entrapping NPs, became dynamic and start to fuse with smooth endoplasmic reticulum through membrane invaginations. Finally, the NPs shifted into caveole free membrane vesicles and released in the cytoplasm without any damage. Fortunately, the content entrapped inside caveolae does not undergo $\mathrm{pH}$-induced degradation due to the neutral environment of caveosomes [113, 114]. Thus, this route is highly valuable for the safer delivery of nanomedicine [115]. Caveolin-mediated endocytosis is a lengthy internalization mechanism as compared to clathrin-mediated endocytosis but ensures safer intracellular delivery of NPs, as lysosomal fusion (Fig. 7a) of 


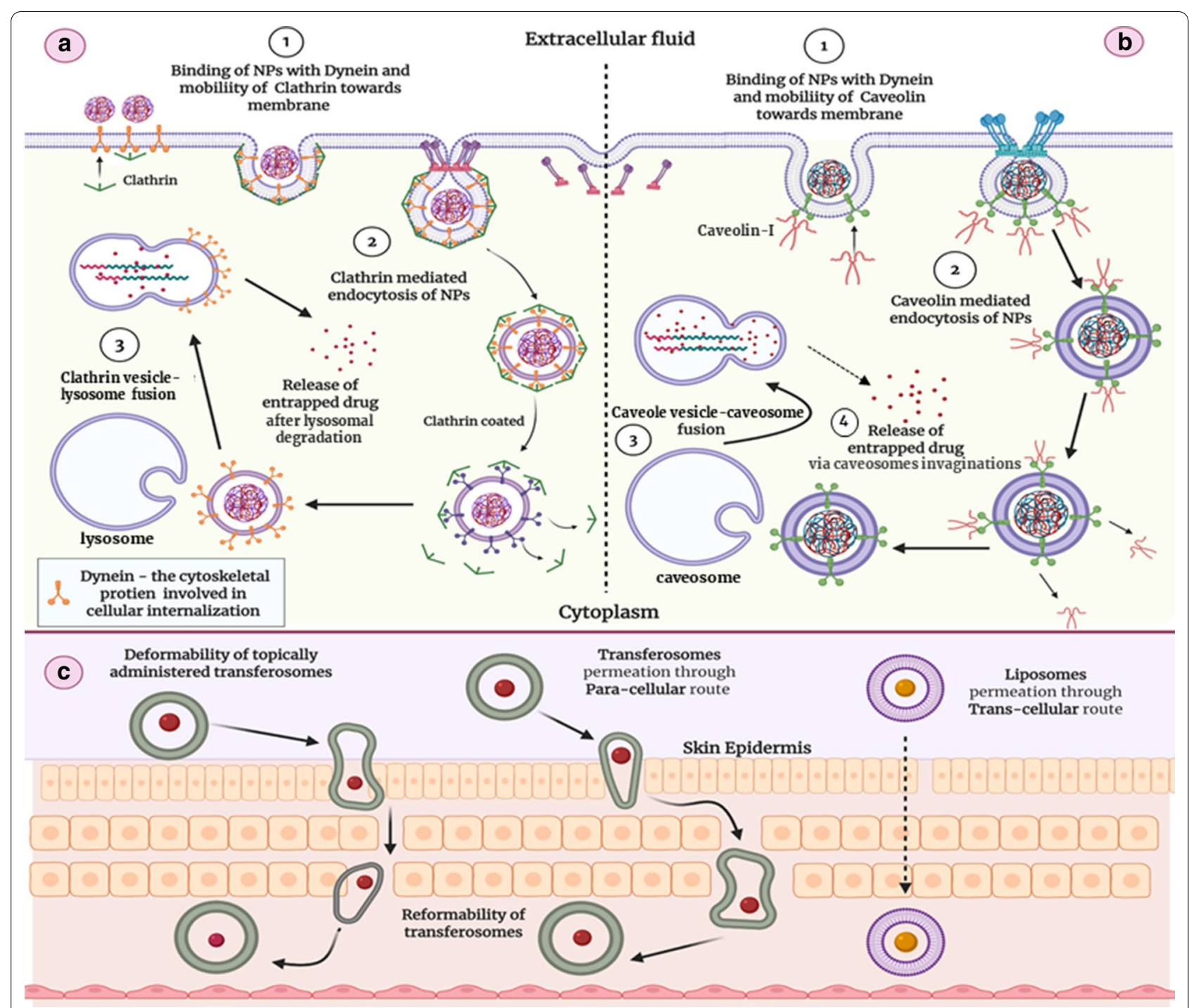

Fig. 7 a Representing the Clathrin-mediated endocytosis for NP internalization. b Caveolin-mediated endocytosis of NPs. c Skin penetration mechanisms of Transferosomes and Liposomes

membrane pinched off vesicles is replaced with caveosomes fusion (Fig. 7b). Some insightful studies have evaluated that negatively charged nanomedicine utilized this pathway to move inside the cell. Thus, by modifying the NPs surface with negatively charged substances, this non-degradable pathway can be attained. This would ensure the safer and protected delivery of medicated agents [109]. As reported earlier, negatively charged PEGylated LPS were more effective than neutral and positively charged ones. Doxil ${ }^{\circledR}$-Doxorubicin loaded negatively charged PEG covered LPS, elect endocytosis through caveolae formation [116]. Polymeric micelles with anionic core, Abraxane ${ }^{\circledR}$, negatively charged QDs, and Polysiloxane NPs take advantage of this pathway as well [109, 117-119]. NPs cellular internalization pathway can be probed by various analytic and imaging techniques including confocal fluorescence microscopy, transmission electron microscopy, atomic force microscopy, photoacoustic microscopy light scattering and scanning electron microscopy. Apart from microscopic assessments flow-cytometry, surface enhanced Raman scattering and X-ray adsorption near-edge spectroscopy are used [104].

Their cellular internalization and trafficking, however, can be manipulated by modifying its morphology (size and shape) and surface structure [120]. However, the maximal cellular uptake was observed with particles having a size of $50 \mathrm{~nm}$ [121]. Caveolin and clathrin-mediated 
endocytosis is the predominant mechanism of intracellular trafficking for NPs having a size of less than $500 \mathrm{~nm}$. The mechanism shift is encountered as the size gets increased. Thus, the particles with a size greater than $1000 \mathrm{~nm}$ undergo cellular internalization through phagocytosis [121]. With respect to shape, spherical NPs undergo significant cellular accumulation as compared to other shapes as this factor also appears to have a pivotal role in NPs uptake [122]. However, there is the availability of the data showing entirely different results, for instance, the rod-shaped NPs have better internalization than spherical-shaped nano-DDS [123]. Elasticity, the deformability, of NPs is another critical property that influences their absorption and internalization. Several studies have provided evidence that firm NPs have lesser cellular uptake than elastic NPs [103]. QDs also undergo macropinocytosis for cellular internalization [124]. Charged bearing NPs also have a critical impact on the cell internalization pathway. As discussed earlier, negatively charged NPs preferred caveolin-mediated endocytosisa lysosome bypassing route [109]. Focusing on cutaneous delivery of nano-systems, lipid-based nano-formulation is usually preferred, because of their ability to perforate through tight cutaneous junction efficiently. TFS, owing to their deformable nature, is considered as the most appropriate and recent carrier to targeted drug delivery to cutaneous macrophages-as they plump themselves to attain deeper cutaneous penetration using a transcellular route [125-127], and it is illustrated in Fig. 7c.

This evidence-based discussion, about the influencing factors and the route opted by the NPs for cellular uptake and targeting, is fundamental for understanding the role of nano-DDS in tackling the drawbacks of conventional anti-leishmanials. Ending up with a general discussion, the next portion of the review contains data and discussion about the nano-DDS approach for resolution of erstwhile discussed obstacles, encountered during the management of Leishmaniasis.

\section{Nanosystem with upgraded efficacy for curtailment of chemotherapeutic toxicity}

As mentioned earlier, nano-DDS are comparatively safer than conventional drugs. Far too many LPS nano-DDS have been designed and emerged with noteworthy results. In 1997, L-Amp-B got FDA approval and ranked as the only FDA-approved nano-formulation currently under clinical use for the treatment of Leishmaniasis [79, $128,129]$. Interestingly, the L-Amp-B was found to significantly minimize Amp-B deoxycholate nephrotoxicity with retaining comparable effectiveness [130]. MA loaded plain LPS and PEGylated LPS have fortunately undergone a high depression in drug toxicity particularly in pancreatitis and cardiomyopathy, possibly due to minimal exposure of MA with normal body tissues. Pharmacokinetic and in vivo anti-leishmanial activity evaluation was also carried out in L. infantum infected male mongrel dogs and Swiss mice VL models. Furthermore, in comparison to plain MA-LPS, MA-PEGylated-LPS retain valuable pharmacokinetic parameters-improved half-life, better accumulation in target tissues-spleen and liver, and maximal eradiation of the parasites. Higher plasma MA levels coupled with minimal tissue toxicity were encountered with MA-PEGylated-LPS. However, even after 14 days of treatment complete eradication of parasitemia was unable to be achieved with MAPEGylated-LPS. These designed PEGylated LPS of MA can opt as a suitable option to sustain drug tolerability and efficacy, for which, more extensive in vivo studies would be required [131]. The incorporation of MFS inside lipid based NPs (composed of oleic acid, cotton seed oil, phosphatidylcholine and cholesterol with size range of $100 \mathrm{~nm}$ or less and highly efficient encapsulation) has found a significant decline in MFS-induced hemolysis. The hemolytic activity of the designed nanoDDS was compared with the free drug, at two different concentrations. It has been observed that percent hemolysis occurred with $175 \mu \mathrm{M}$ MFS is $5 \%$ for nano-formulation and $73 \%$ with the plain drug. Moreover, $350 \mu \mathrm{M}$ MFS in the designed formulation and free drug showed $13 \%$ and $100 \%$ hemolysis, respectively. All the experiments in this study were conducted in vitro, hence, there is a need to evaluate the tolerability and anti-leishmanial efficacy of MFS lipid nanoparticles in the in vivo setting as well [49]. These nanocarriers were examined majorly by in vitro hemolytic assay, in vitro macrophage toxicity, GIT toxicity in the rats, and leishmanicidal assay using the BALB/c mice model. Hemolysis (\%) was reduced from $91 \%$ (for MFS solution) to $8 \%$. Values of $\mathrm{CC}_{50}$ also improved significantly to $237.4 \mu \mathrm{g} / \mathrm{ml}$, however, with MFS solution it was $39.60 \mu \mathrm{g} / \mathrm{ml}$. Furthermore, the results of animal studies were revealed to minimize MFS induced GIT epithelial and mucosal damage along with the significant reduction in leishmanial lesion size in $\mathrm{BALB} / \mathrm{c}$ mice, in contrast to the simple drug solution. However, more advanced in vivo studies-lesion and organ parasitic burden reduction, are the pre-requisite for further progressing of MFS-NLCs towards human studies [132]. IMQ, an agent with limited anti-leishmanial activity, proved to possess efficacy against CL when applied topically in form of $5 \% \mathrm{w} / \mathrm{w}$ cream. However, cutaneous reactions and psoriatic like condition following halt its use [133]. IMQ-loaded SLNs were evaluated for their toxicity using MTT assay. In MTT assay, human epithelial cells; $\mathrm{HaCaT}$ cells, were used. The results of the MTT assay showed the A (Absorbance value) as 0.555 of IMQ-SLNs at $490 \mathrm{~nm}$, which was lower than the free 
drug i.e. 0.563. These results were suggesting higher $\mathrm{IC}_{50}$ value and better safety profile of the designed nano-DDS than the plain drug. However, this study has multiple limitations including very few characterization studies, showing A value instead of IC50 values and a lack of antileishmanial assay [134]. As in clinical trials, infection recurrence has been reported owing to IMQ lessen cutaneous permeation [56]. Thus, the fabrication of IMQ nano-DDS possibly potentiate its anti-leishmanial efficacy and ameliorate cutaneous toxicity [135]. Several biodegradable polymers are recently used for the synthesis of these nano-DDS including-synthetic polymers i.e. PLGA, PCL, and natural polymers i.e. Chitosan, Albumin, alginate, and the list goes on [136]. Likewise, lipid nano-DDS, polymeric NPs can also be used in the toxicity reduction of the entrapped drugs. They facilitate passive drug targeting and prevent unnecessary exposure of the drug to normal body tissues and organs [137]. Chitosan-chondroitin sulfate NPs loaded with Amp-B (AmpB-CCs-NPs) was found to have valuable surge in activity against laboratory parasite (L. amazonensis and L. chagasi), followed by enhanced intra-macrophage accumulation as compared to the plain drug. Polymer utilized for this nanosystem have also imparted a sustained release pattern of Amp-B. Another valuable characterization has been conducted to estimate the NPs internalization inside macrophages. The researchers have designed fluorescein isothiocyanate (FTIC) labelled chitosan-chondroitin sulfate NPs and quantify their macrophage internalization using CLSM mainly due to optimal particle size of $136 \pm 11 \mathrm{~nm}$. This study was an indicator of higher buildup of Amp-B-Chitosan-chondroitin sulfate NPs in infected macrophages as it is directly related to its improved leishmanicidal activity, in comparison to the plain Amp-B. The uptake was coupled with reduction in Amp-B cellular toxicity $\left(C_{50}=9 \pm 0 \mu \mathrm{g} / \mathrm{ml}\right)$, hemolysis $\left(\mathrm{RBC}_{50}=240 \pm 33 \mu \mathrm{g} / \mathrm{ml}\right)$ along with efficacy improvement $-\mathrm{IC}_{50}=1 \pm 0 \mu \mathrm{g} / \mathrm{ml}$ and $0.1 \pm 0.1 \mu \mathrm{g} / \mathrm{ml}$ against $L$. amazonensis and L. chagasi, respectively. However, this research also lacks an in vivo anti-leishmanial assay, which is crucial to confirm its utilization as an anti-leishmanial nano-DDS [138]. With a similar aspect, alginate NPs enclosing MFS was designed for the purpose to reduce MFS-associated hemolytic anemia. In this study, the cytotoxicity of designed nanomedicine was evaluated against RBCs. The G. mellonella larvae were also employed for toxicity detection. Having MFS concentration of $35 \mu \mathrm{g} / \mathrm{ml}$, the drug solution caused $50 \%$ hemolysis in contrast to the MFS-alginate-NPs, which had no impact on RBCs morphology and destruction rate. In addition, the plain drug showed 33\% mortality of larvae at $50 \mathrm{mg} / \mathrm{kg}$ for 5 days. Luckily, only $5 \%$ larval mortality was observed with nanosystem delivering $200 \mathrm{mg} / \mathrm{kg}$ of
MFS. The results of the study were highly supportive of the fact that MFS hemolysis and cytotoxicity showed considerable reduction due to MFS incorporation in the nanosystem. These nano-DDS were evaluated only for their anti-fungal potential against clinical strains of $C$. albicans. It is suggestive to conduct anti-leishmanial assay both in vitro and in vivo Leishmania-infected $\mathrm{BALB} / \mathrm{c}$ mice for the purpose to assess leishmanicidal potential of MFS-alginate NPs. [139]. Several polymeric nanocarriers being employed for Leishmaniasis are stated in Table 2. Possibly, these nanocarriers prevent API from harsh environment. Polymeric coat imparts drug release pattern at control rate and gratuitous interaction of drug with healthy tissues mitigates. After all this discussion, we can conclude that polymeric NPs are promising instruments for anti-leishmanial delivery, ensuring significant reduction in their toxicity profile. Albumin NPs also have potential to improve safety and efficacy of entrapped agents. Recently, MA-albumin NPs were designed and evaluated for their cytotoxicity and efficacy parameters. The engineered nanosystem was found to greatly reduce $\mathrm{IC}_{50}$ values against $L$. major promastigotes along with valuable increment of $\mathrm{CC}_{50}$ value against $\mathrm{J774}$ macrophages, using MTT assay. The $\mathrm{IC}_{50}$ and $\mathrm{CC}_{50}$ values of MA-Albumin NPs were $8.35 \pm 0.92 \mu \mathrm{g} / \mathrm{ml}$ and $309.7 \pm 2.49 \mu \mathrm{g} / \mathrm{ml}$, correspondingly. However, plain MA possessed $\mathrm{IC}_{50}$ and $\mathrm{CC}_{50}$ values of $26.67 \pm 1.42 \mu \mathrm{g} / \mathrm{ml}$ and $112.5 \pm 2.05 \mu \mathrm{g} / \mathrm{ml}$, which were significantly different i.e. less effective and more toxic, from erstwhile mentioned values of the designed MA-Albumin NPs [140]. Another research reported by Casa et al. [141] has claimed the reduction in Amp-B toxicity by designing Amp-B loaded bovine serum albumin NPs (Amp-B-BSA-NPs). However, this study had multiple limitations, as they assessed toxicity only in laboratory J774.A1 macrophages and evaluated in vivo anti-leishmanial response only by estimating lesion size reduction. These results could be much better if parasitic eradication would be determined by estimating parasite load in the lesion as well as in the spleen and liver. However, due to supporting results of macrophage cytotoxicity assay, with 70-fold increased $\mathrm{CC}_{50}$ in comparison to plain Amp-B, and in vitro anti-leishmanial activity against L. amazonensis infected $\mathrm{BALB} / \mathrm{c}$ mice, this candidate could be of interest for advance in vivo assessment for its claimed enhanced efficacy and reduced toxicity [141]. These properties are, however, not only limited to lipid or polymeric based nanocarriers. Several other nano-DDS have been synthesized to curtail antileishmanial unwanted and toxic outcomes. For instance, fabrication of Amp-B-loaded functionalized-CNTs ( $\mathrm{f}-\mathrm{CNTs}$ ) were fruitful in downgrading the Amp-B associated hepatic and renal damage [142]. Toxicity studies were conducted in vitro and in vivo, using MTT assay 


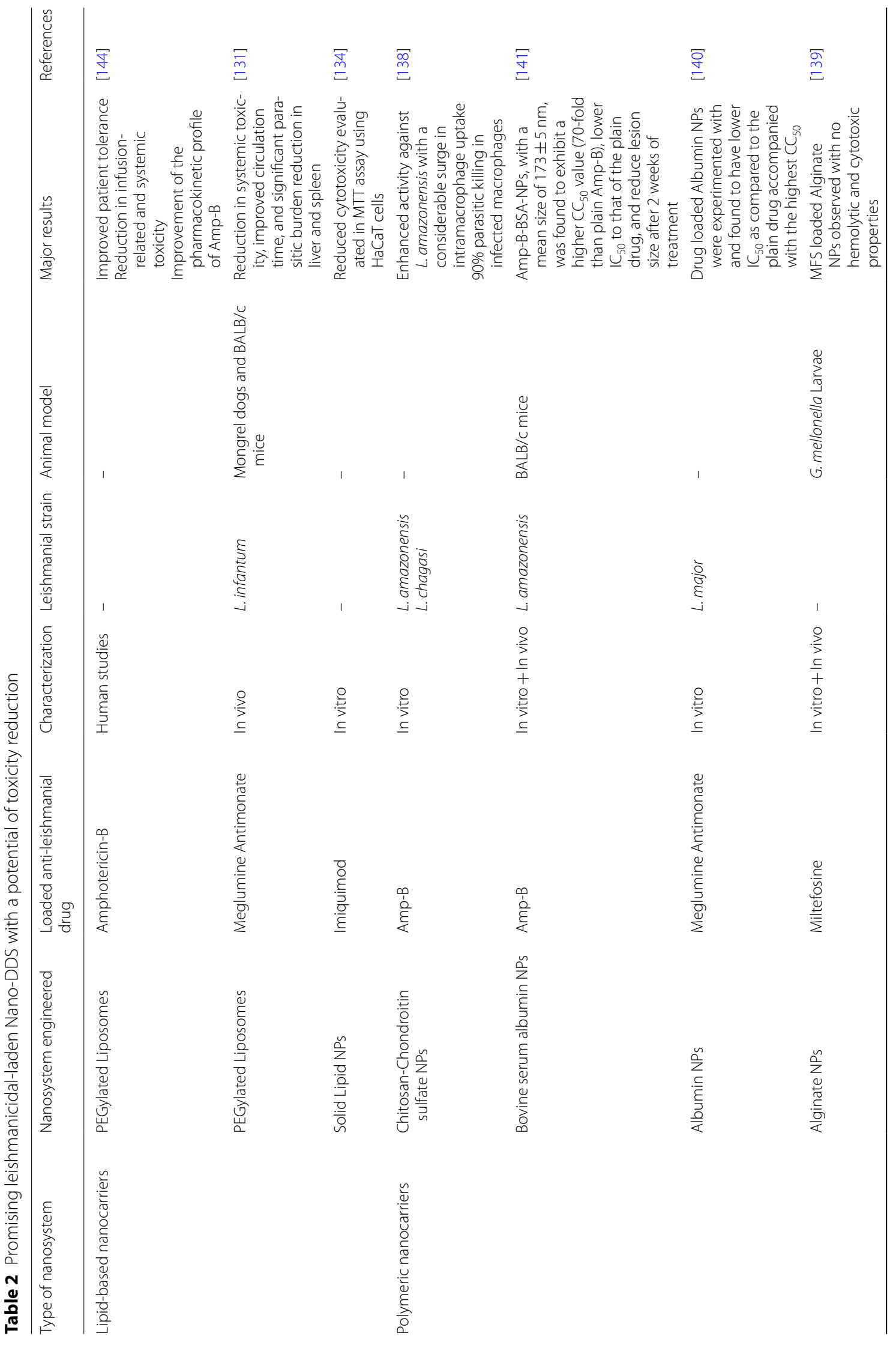




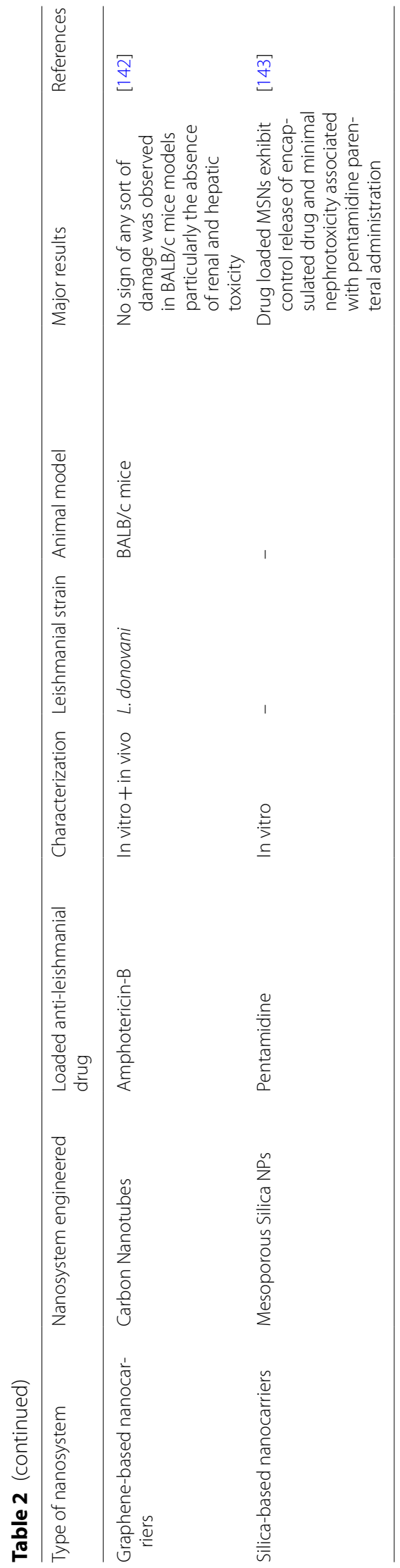


and $\mathrm{BALB} / \mathrm{c}$ mice models, respectively. Briefly, MTT assay compared the $\mathrm{CC}_{50}$ of plain Amp-B, $\mathrm{f}-\mathrm{CNTs}$, and Amp-B-f-CNTs. Amp-B-f-CNTs was found to be less toxic than plain Amp-B. Moreover, the designed Amp-B loaded $\mathrm{f}-\mathrm{CNTs}$ were also non-toxic to the liver and kidneys as none of the liver or kidney destructive biological markers were elevated followed 5 days intra-peritoneal administration. Treatment with Amp-B-f-CNTs in $L$. donovani infected Syrian golden hamsters has exhibited better efficacy with plain Amp-B in terms of spleen weight reduction, parasitemia reduction, and inhibition of parasite replication. In order to advance this candidate towards clinical trials, its efficacy and safety should be compared pre-clinically with L-Amp-B, as Amp-B-f$\mathrm{CNTs}$ are superior due to low production cost and stable nature [142]. Likewise, MSNs are also capable of a safer supply of drugs with minimal exposure to normal body tissues and organs. Findings have claimed that loading PTM-MSNs have significantly minimized its major doselimiting adverse event-the nephrotoxicity, mainly due to incorporation of drug release at control rate. Inadequate loading of PTM isethionate inside NPs was resolved by simply de-salting it [143].

\section{Promising nano-DDS - capable for oral delivery of injectable anti-leishmanials}

Polymeric nano-DDS is accompanied by numerous beneficial aspects in oral drug delivery. For instance, they are used to modify the pharmacokinetics and bioavailability of orally un-absorbable drugs. Furthermore, controlled rate and targeted drug delivery can be achieved by these nano-DDS $[136,145]$. Thus, for effective oral delivery of conventional injectable anti-leishmanials, several polymeric nano-DDS have been designed. A recent study aimed to develop PEG-PLGA oral Amp-B NPs with prominent spleen, liver, and bone marrow parasite load reduction as compared to the injectable liposomal Amp-B. In this valuable experimental study, the pharmacokinetics of the designed oral nanosystem was compared with oral Fungizone ${ }^{\circledR}$. AUC and $C_{\max }$ of PEGPLGA NPs loaded with Amp-B was highly improved i.e., $12,325.1 \mu \mathrm{g} . \mathrm{h} / \mathrm{l}$ and $480.2 \mathrm{ng} / \mathrm{ml}$, as compared to Fungizone $^{\circledR}$ having AUC and $C_{\max }$ of $9832.4 \mu \mathrm{g} . \mathrm{h} / \mathrm{l}$ and $298.2 \mathrm{ng} / \mathrm{ml}$, respectively. The oral bioavailability results of this study are, additionally, illustrated in Fig. 8. Improved oral bioavailability (GIT absorption) of Amp-B using PEG-PLGA nano-DDS is highly valuable because of speculated passive targeting of the hepatic leishmanial parasite. However, it should be evaluated, in vitro as well as in preclinical settings, to demonstrate its utilization against Leishmaniasis [146-148]. For PTM, trading-off between hydrophilic and lipophilic character is deemed to be necessary to compensate for its inadequate GIT absorption. This can be achieved through these, polymeric-based nano-DDS. These points are, however, supported by the research study carried out by Valle et al. [149] as they conducted multiple experiments to assess the release model and efficacy of PTM-PLGA-NPs. Orally administered NPs were found to exhibit a remarkable reduction in organ mass (liver and spleen) and parasitic burden in the murine model induced by L. infantum $[44,149]$. In addition, multiple studies aiming to fabricate oral NPs have been conducted and some potentially important ones are mentioned in Table 3. These studies have, fortunately, proved the aptness of polymeric NPs as an effective nano-DDS with remarkable properties to intensify GIT absorption of anti-leishmanials, pictorially represented in Fig. 5b. Surfactant stabilized nanosized colloidal dispersion-nanosuspensions, can modify the dissolution properties of anti-leishmanialsameliorate oral bioavailability by enhancing their water solubility [150]. Many studies have attempted to boost oral absorption and bioavailability of promising antileishmanial agent, Amp-B, by the utilization of nanosuspension. However, no such study has evaluated the Amp-B-nanosuspension activity against Leishmaniasis, neither in vitro nor in vivo [151, 152]. In 2016, Amp-BSLNs has also been designed to promote its GI absorption and to escalate its oral bioavailability. Unfortunately, the results of the study were not much promising as AUC was $6063.11 \mu \mathrm{g} . \mathrm{h} / \mathrm{l}$ which is lower than Amp-B loaded PEG-PLGA oral system as discussed earlier [148, 153]. Following the principle of cyclodextrin conjugation, surface modified SLNs have been fabricated facilitating the oral delivery of poorly absorbed anti-leishmanial agents-Amp-B and PMC. The SLNs (Amp-B-PMCHPBC-SLNs) were modified using a 2-hydroxypropyl$\beta$-cyclodextrin to enhance their intestinal permeability and absorption owing to its ability to impart hydrophilic character. Ample macrophage internalization has taken place, evaluated through confocal scanning microscopic technique. The cytotoxicity was also found to be $20 \%$ less than plain SLNs. Leishmanial $\mathrm{IC}_{50}$ has shown 10.07 times more efficacy than unmodified Amp-B-SLNs. These modified SLNs (abbreviated as n-DDSLNs in Fig. 9) were also presented with $95 \% \mathrm{~L}$. donovani amastigotes internalized in J774A.1 macrophage, which was highest in comparison to Amp-B-SLNs, AmBisome ${ }^{\circledR}$, and PMC. Moreover, kidney damage markers (creatinine and BUN) and hepatic damage markers (ALT and APT) were not elevated, demonstrating the safety of designed nanocarrier (Amp-B-PMC-HPBC-SLNs) post oral administration. This insightful study has also performed an in vivo anti-leishmanial assay against $L$. donovani in BALB/c mice model and compared the efficacy of oral Amp-BPMC-HPBC-SLNs (20 mg/kg for 5 days) and compared 


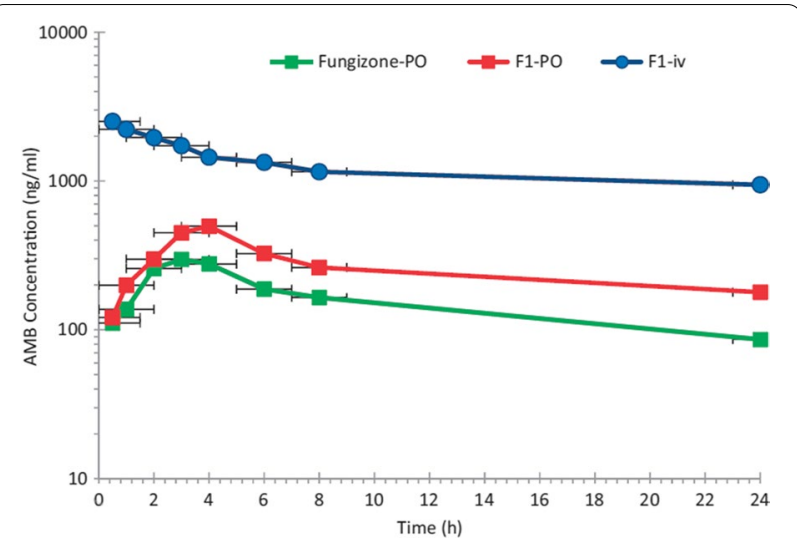

Fig. 8 Graph plotted against mean plasma concentration (ng/ $\mathrm{ml}$ ) of Amp-B and time (h) clearly demonstrating improved intestinal absorption and bioavailability of Amp-B followed by oral administration (Dose $=10 \mathrm{mg} / \mathrm{kg}$ ) of Amp-B-PLGA NPs (F1-PO) in comparison to Fungizone ${ }^{\circledR}-\mathrm{PO}$ in healthy rats [147]

with oral MFS ( $3 \mathrm{mg} / \mathrm{kg}$ for 5 days) and the liver parasitic percent inhibition was found to be $91.12 \%$ and $49.30 \%$, respectively. Results of this study are represented pictorially in Fig. 9. Due to extensive characterization and anti-leishmanial activity comparison of this nano-DDS with currently employed treatment modalities (Amp-B, MFS, and PMC), this candidate could be selected for testing against a small human population [154]. This meaningful study has paved the way for modified nano-DDS and with more intense animal testing, this candidate can be enrolled in human clinical trials. An oral nano-DDS of PMC was designed, comprising of PLGA NPs modified with mannosylated thiolated chitosan, for imparting parasite selectivity [155]. Critical attention of researchers, however, is necessary to design more effective orally delivered anti-leishmanial nano-DDS towards achieving passive targeting and potential eradication of splenic and hepatic parasites.

\section{Targeted delivery of anti-leishmanials-unfettered access to intramacrophage parasite}

\section{Active targeting-NPs surface tuning approach}

Active drug targeting is a valuable phenomenon opted for the purpose to achieve selective drug accumulation inside the organs, tissues, or cells of interest. Lower systemic toxicity has also been observed with actively targeted formulations. Also, the targeted formulations undergo a significant uptick in drug accumulation, as compared to untargeted moieties, inside desired targeted tissue [158, 159]. Nano-DDS with appropriate surface modification is an efficient system for active targeting of entrapped drug [160]. To concise our discussion towards Leishmaniasis, myriad surface labeling ligands have been used to target amastigote- $\mathrm{a}$ resident of tissue macrophage. These include D-Mannose, Phosphatidylserine, Lactoferrin, Chondroitin sulfate, and $p$-aminophenyl$\alpha$-D-Mannopyranoside. These ligand moieties are decorated at the NPs surface. This, in return, provide capability-the NPs are attracted towards their corresponding receptors (Mannose and Scavenger receptors). In detail, mannose-receptors (MR or CD206) are the glycoproteins, C-type lecithin, born by the membrane of tissue macrophages, RES macrophages, and dendritic cells. The outer (extracellular) portion of the mannose receptor comprises the cysteine-rich domain and carbohydrate recognition domain, which have a high affinity for sugars i.e. mannose, fructose, etc. [161]. Mannose attachment exteriorly to the NPs enhances its macrophage recognition and internalization. All these series of events, illustrated in Fig. 10, steer towards the intramacrophage accumulation of anti-leishmanial moiety. By now, several ligand-decorated NPs have been devised using the aforementioned surface modifying entities and shown to have compelling results in contrast to the sresults of previously engineered unlabeled nano-DDS.

\section{Surface modified nano-DDS for active intramacrophage parasitic targeting}

The most usual approach opted for active targeting of anti-leishmanial agents is entrapping the conventional agent inside the lipid-based, polymeric-based, or other nano-DDS, followed by surface re-modeling through an attachment of D-Mannose-a ligand for Mannose receptor expressed by tissue macrophages [77]. In the previous decade, multiple attempts have been made to design surface tuned drug-loaded NPs as given in Table 4. Shahnaz et al. [162] designed Mannosylated thiolated chitosan (MTC) nanosystem loaded with Amp-B (Amp-B-MTC) having rod-shape, $362 \mathrm{~nm}$ particle size and $90 \%$ macrophage viability. Another worth mention finding was the retention of Amp-B-MTC inside reticuloendothelial system (RES) macrophage up to 10 days, confirming the effectiveness of thiolation. In addition, $1 \mu \mathrm{g} / \mathrm{ml}$ of AmBisome ${ }^{\circledR}$ and Amp-B-MTC respectively showed amastigote percent inhibition of $60 \%$ and $95 \%$. The Amp-B-MTC fabrication was found to be a meaningful study showing $\mathrm{IC}_{50}$ values of $0.02 \mu \mathrm{g} / \mathrm{ml}$ as compared to Amp-B- $0.26 \mu \mathrm{g} / \mathrm{ml}$. In the $B A L B / c$ mice model, Amp-B-MTC was also found to be superior with $90 \%$ parasitic inhibition. Higher vesicular size of Amp-B-MTC was however of concernas vesicles having a size from $100-300 \mathrm{~nm}$ [163] would experience optimum penetration macrophage internalization. These valuable results were highly suggestive for additional safety and efficacy assessment, to pursue its recruitment towards clinical trials. The inclusion of macrophage internalization assay would, however, effectively 


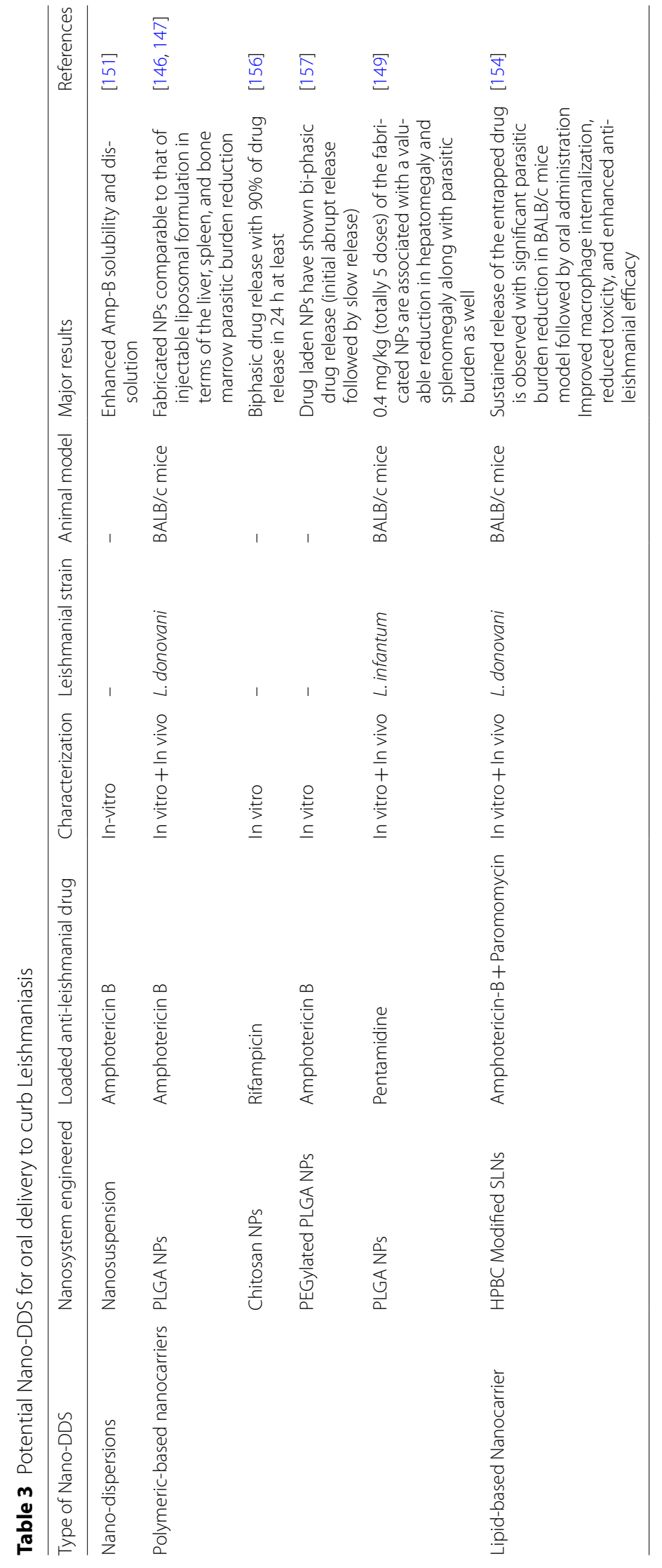




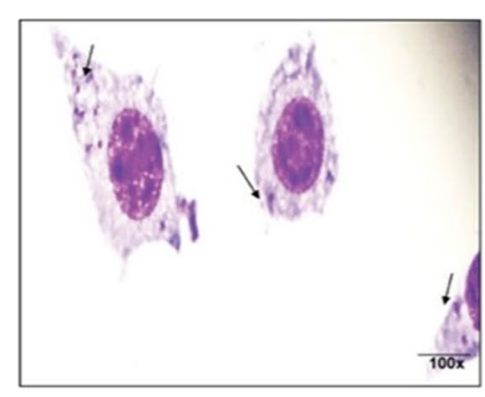

Infected control

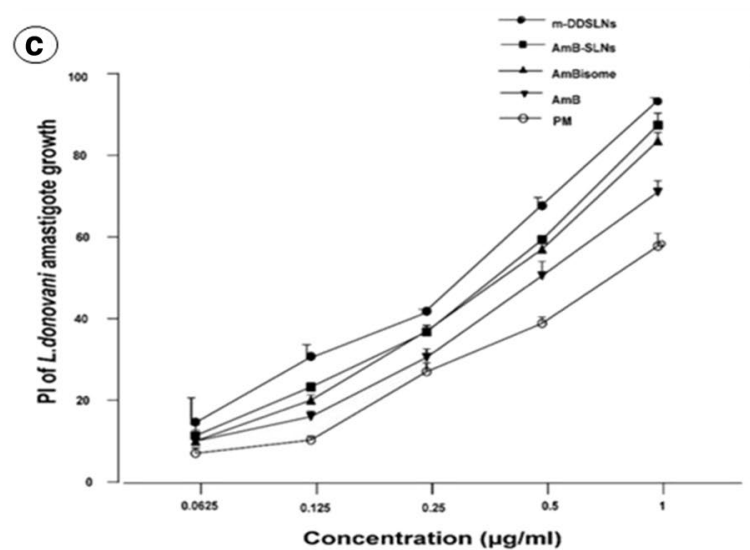

(a)

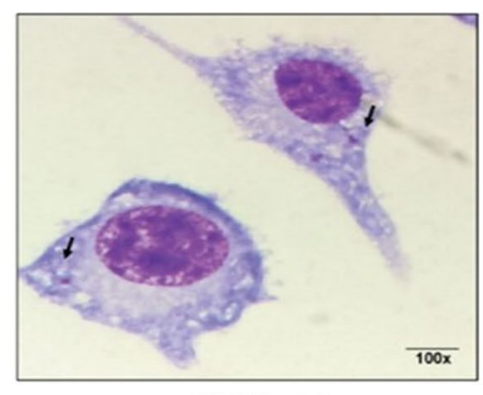

$100 x$

d 350 (b)

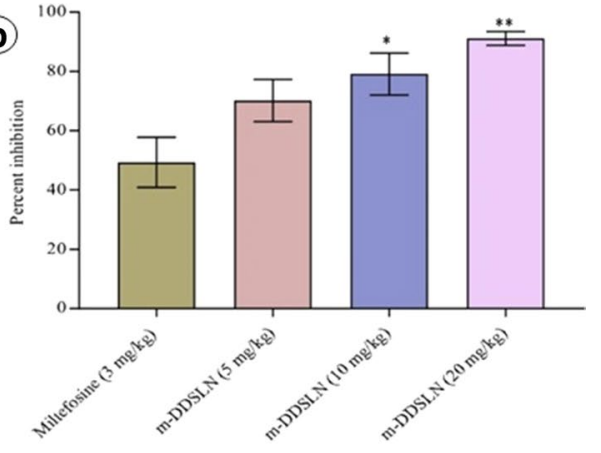

घControl aPM $\triangle A m B \quad$ am-DDSLNs

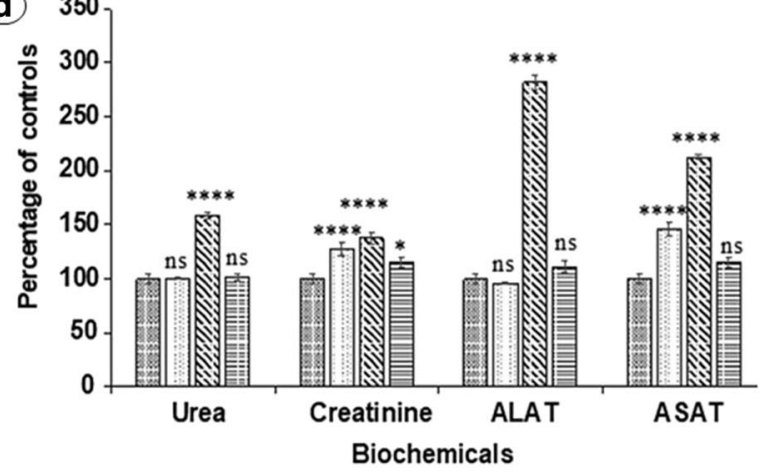

Fig. 9 a Microphotographs of pre-treatment infected macrophage (left) and reduce intra-macrophagial parasitic burden post treatment with the surface modified drug loaded SLNs (m-DDSLNs) [154]. b Comparative liver parasite percent inhibition with m-DDSLNs in various doses and MFS (3 mg/kg) observed in L. donovani infected BALB/C mice model [154]. c Comparative in vitro percent inhibition of L. donovani amastigotes with paromomycin (PM), Amphotericin B (AmB), AmBisome ${ }^{\circledR}, A m B-S L N s$ and the surface modified drug loaded SLNs (m-DDSLNs) [154]. d Level of biochemical markers for renal toxicity (Urea \& Creatinine) and for hepatotoxicity (ALAT \& ASAT) followed by 14 days treatment with different modalities i.e., paromomycin (PM), Amphotericin B (AmB), AmB-SLNs and the surface modified drug loaded SLNs (m-DDSLNs) [154]

address this raised concern [162]. Moreover, the thiolation was speculated to reduce drug efflux via P-gp and TR-system inhibition. To improve macrophage internalization of Amp-B, another research study was carried out. They labeled CD-14 on the surface of formulated PLGAPEG NPs [164]. Surface decorated PLGA NPs were also been engaged to enhance RES targeting of PMC by designing MTC-PLGA-PMC. In detail, the flow cytometric evaluation has shown the surged internalization of PMC in L. donovani infected J774A.1 macrophage. With MTC-PLGA-PMC, the concentration of PMC in $10^{6}$-macrophages was found to be $43.110 \mu \mathrm{g}$ which was significantly higher than PLGA-PMC and plain drug i.e., $4.45 \mu \mathrm{g}$ and $4.28 \mu \mathrm{g}$, respectively. The in vivo pharmacological assay was also supportive with a 3.6-fold increase in efficacy in terms of liver parasitic burden reduction. Additionally, in this study cytokine and $\mathrm{NO}$ evaluation was also carried out and displayed the highest IL-12 $(600 \mathrm{pg})$ and INF- $\gamma(550 \mathrm{pg})$ values in comparison to simple PLGA-PMC and plain PMC. Evaluation of NO level with a value of $85 \mu \mathrm{M}$ has also exhibited the superiority of MTC-PLGA-PMC. Thus, the mannosylated system possesses more efficacy and anti-leishmanial response in contrast to the simple nano-formulation, as can be seen in case of the PLGA-PMC NPs [155]. As discussed earlier, the reduced efficacy of MA was due to the trypanosomatid TR-system mediated efflux. MA laden mannosylated thiolated polyethylenimine NPs have been investigated thoroughly and experimentally proved to have superiority over the plain drug owing to higher host RES uptake and inhibition of amastigote P-gp and other efflux pumps [165]. Lipid-based nano-DDS can also be tuned (surface modification) for active drug targeting and surged intra macrophage internalization [166]. Results of several recent studies stated erstwhile are elaborated in Table 4. However, the graphical results are visualized in Fig. 6. Additional ligands for APCs mannose receptors include lactoferrin, chondroitin sulfate, and $p$-Aminophenyl$\alpha$-D-mannopyranoside. Lactoferrin, an iron-binding glycoprotein, having a binding affinity with C-type lecithin receptors hold by macrophages and rest of APCs, due to the presence of $\mathrm{N}$-glycosylation binding sites on lactoferrin. To enhance Amp-B RES intake, lactoferrin anchored PLGA NPs (LcPLGA-Amp-B) were designed. 


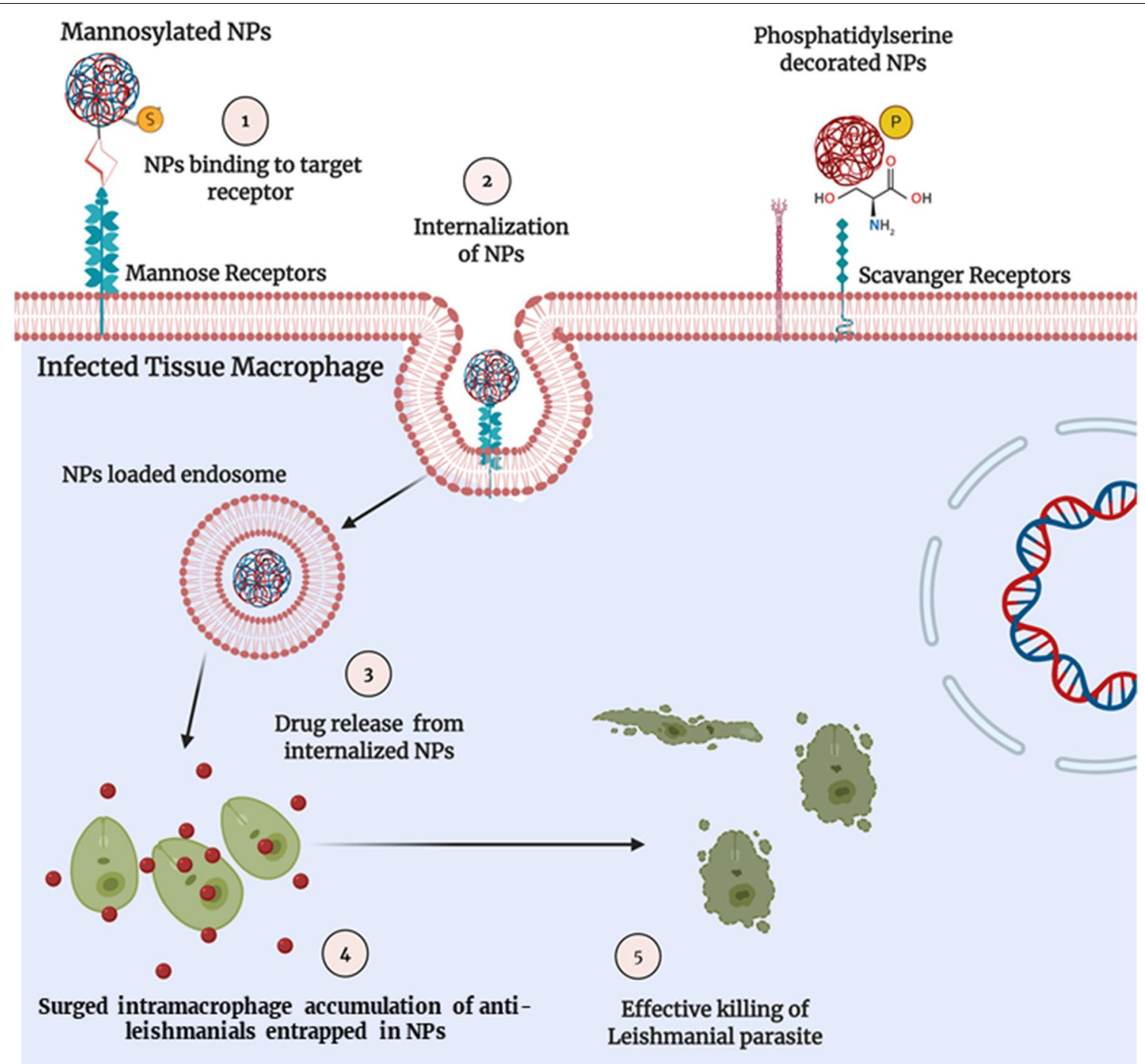

Fig. 10 Surface-modified/antigen labelled NPs for enhanced drug accumulation and target killing of intra-macrophagial amastigotes; [1] Attachment of Mannose labeled anti-leishmanial nano-DDS with Mannose-receptors on macrophage membrane, [2] Receptor mediated endocytosis of Mannosylated anti-leishmanial nano-DDS, [3] Release of entrapped drug, [4, 5] Effective intramacrophage parasitic killing by Mannosylated nano-DDS

The designed formulation, interestingly, possessed promising results in terms of cure rates in L. donovani infected hamsters. LcPLGA-Amp-B have shown 2.15-fold intense internalization in $L$. donovani infected macrophages as compared to lactoferrin-free PLGA-Amp-B, evaluation was done through flow cytometry and confocal laser scanning microscopy. In vitro anti-parasitic study exhibited $\mathrm{IC}_{50}$ values of LcPLGA-Amp-B 3.20, 2.13, and 2.50 times higher than Fungizone ${ }^{\circledR}$, AmBisome $^{\circledR}$, and PLGAAmp-B, respectively. Fortunately, the levels of protective cytokines-IL-12, TNF- $\alpha$, and INF- $\gamma$ increased 2-times with LcPLGA-Amp-B. The safety parameter was assessed using acute toxicity demonstrated $12.5 \%$ mice killing as compared to Fungizone ${ }^{\circledR}(100 \%)$ and AmBisome ${ }^{\circledR}$ (37.5\%) [167]. Designed rifampicin-loaded mannosylated chitosan NPs (R-mCNPs) also illustrated 2.31 and 16.2 times more macrophage internalization than the chitosan free NPs (CNPs) and conventional drug, respectively, and results of confocal scanning microscopy visualizing macrophage endocytosis are represented in Fig. 11 [168]. Another class of receptors responsible for the internalization of multiple entities; proteins and intruding pathogens, into APCs are the scavenger receptors (SR). A group of scientists has recently developed phosphatidylserine labeled MA-LPS (PS-MA-LPS). The anti-leishmanial assay was assessed against $L$. major amastigotes, 


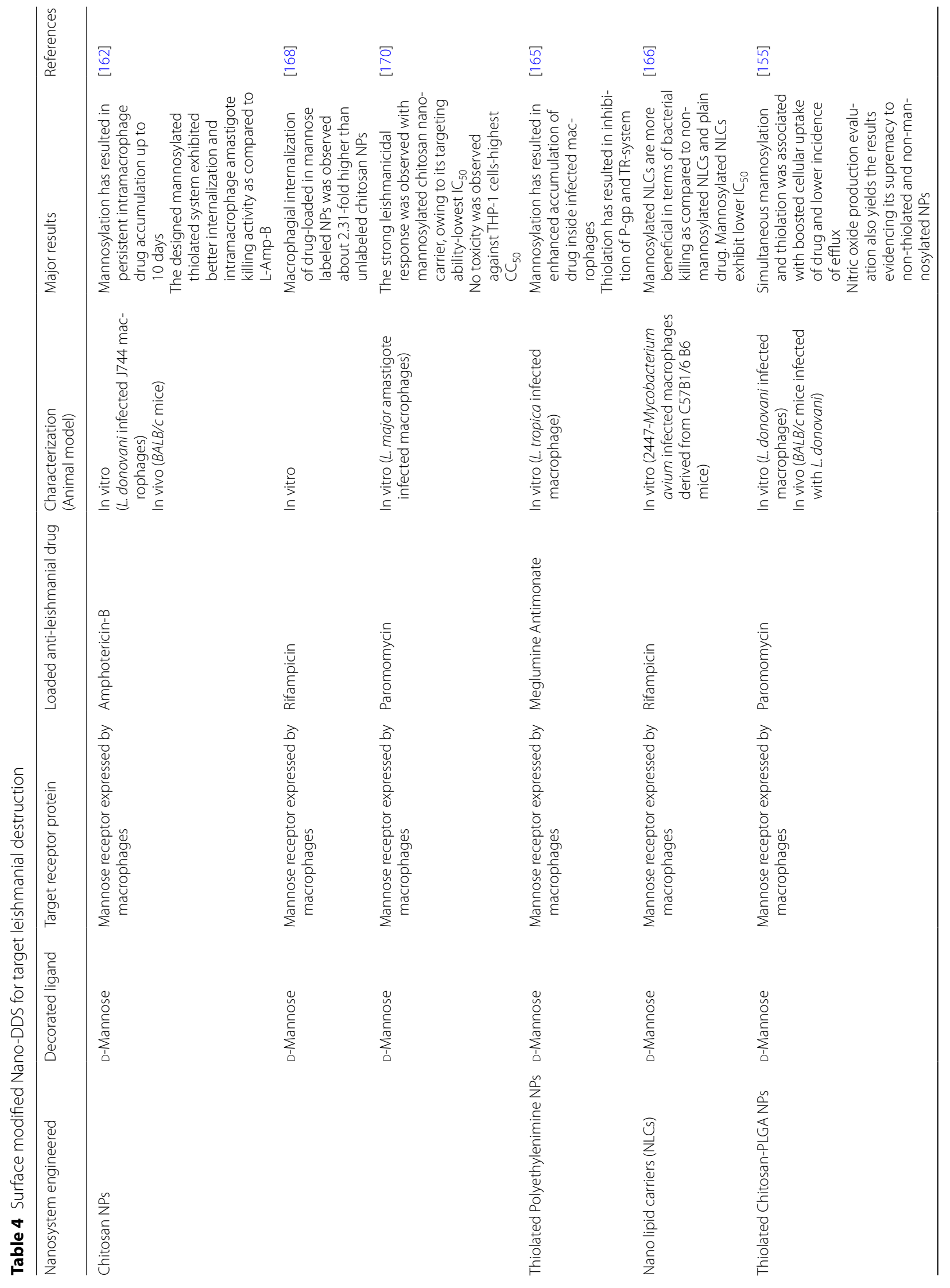




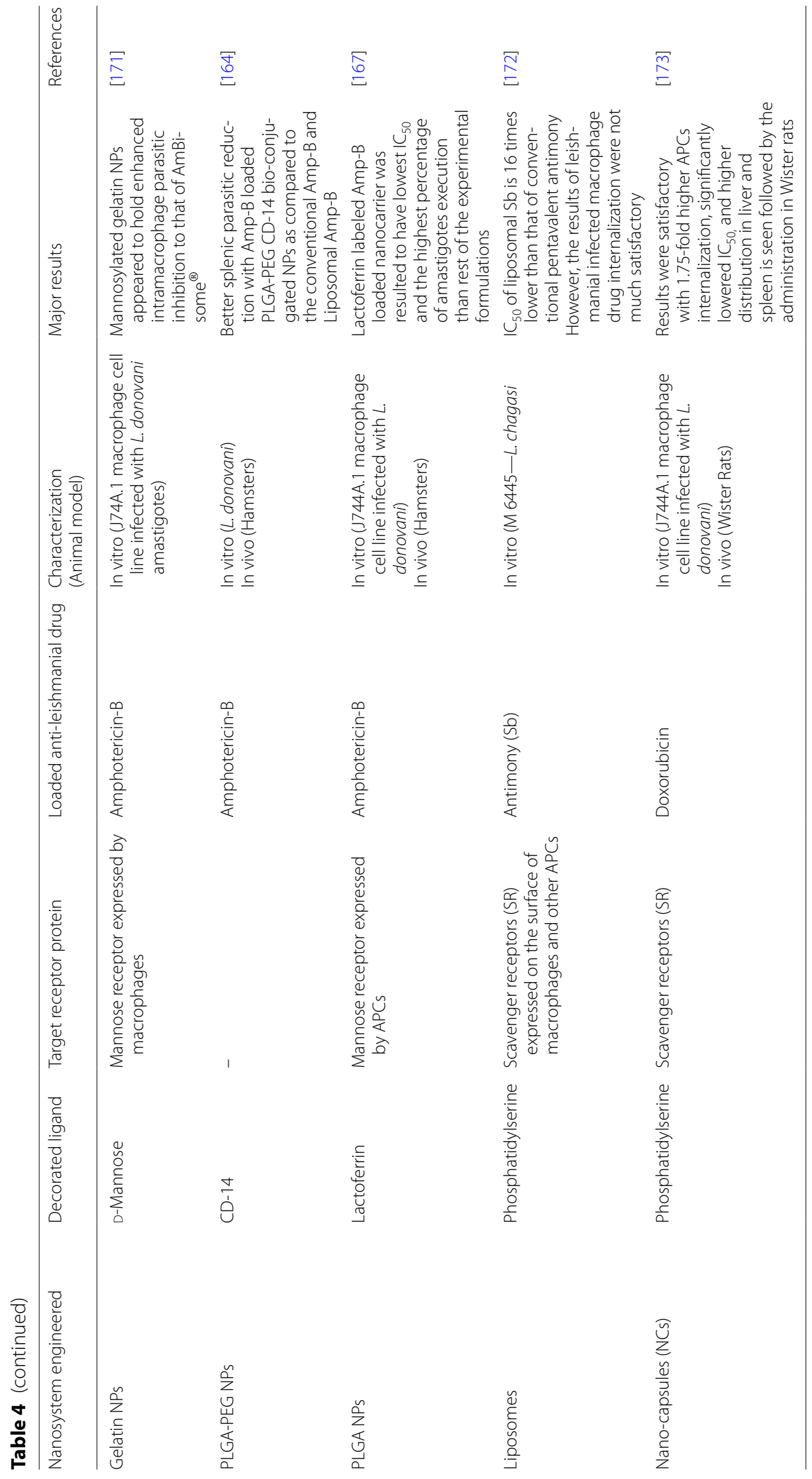



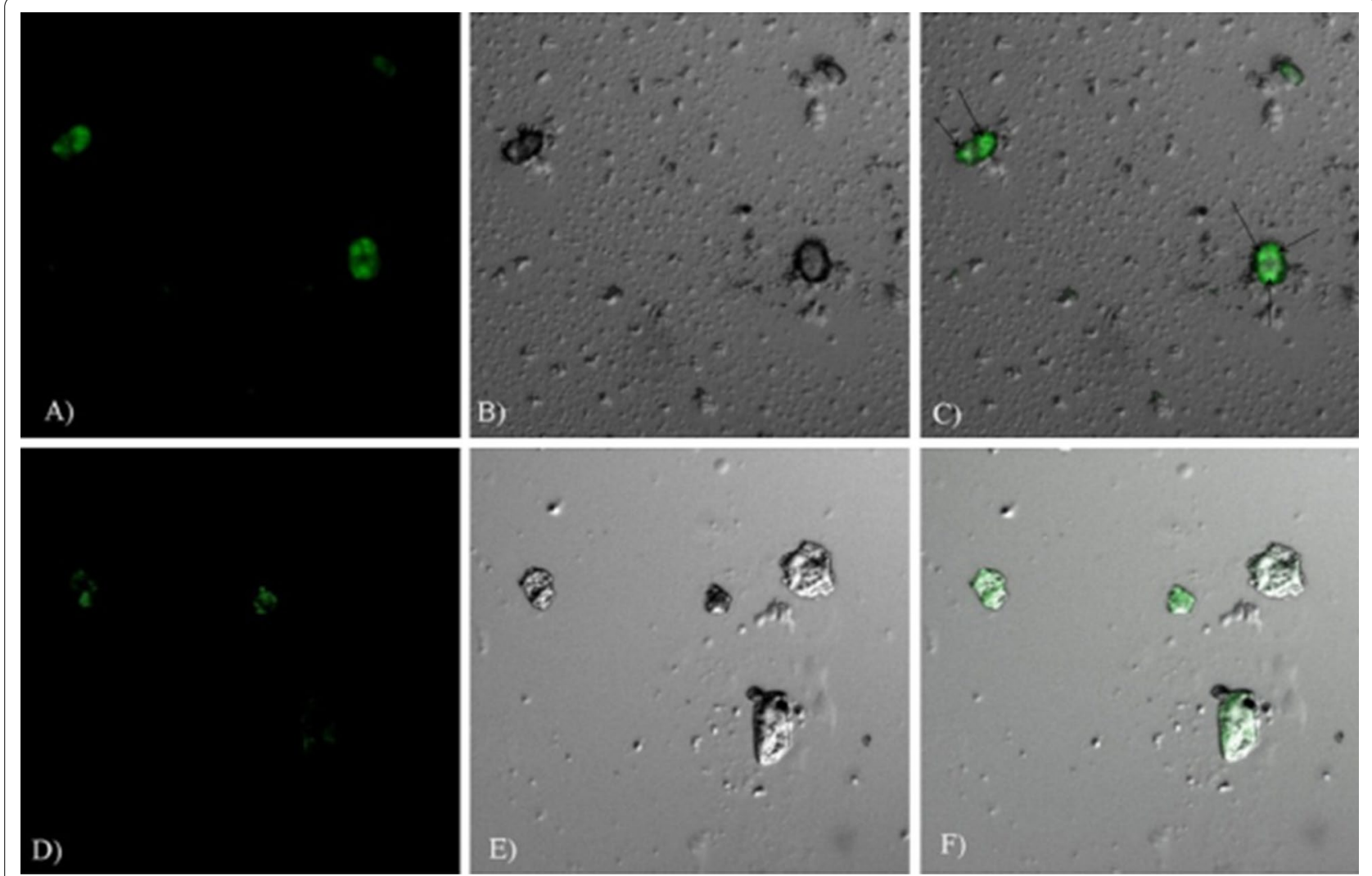

Fig. 11 Confocal laser scanning microscope (CLSM) micrographs; a-c demonstrating significant macrophage internalization and accumulation of Fluorescein-mCNPs, d, e Indicating reduced macrophage internalization of CNPs [168]

promastigotes, and intracellular amastigotes, which displayed approximately tenfold enhanced anti-leishmanial response of the PS-MA-LPS displayed. Complete killing of intra-cellular amastigotes was experienced at 40-times lower concentration of PS-MA-LPS, in contrast to the free MA. Theoretically, the PS-MA-LPS trade showed enhanced intra-macrophagial accumulation due to SR mediated APC targeting [169]. Phosphatidylserine labeled doxorubicin-loaded nanocapsules (PS-DOX-NPs) exhibited 1.75-fold higher APCs internalization, significantly lowered $\mathrm{IC}_{50}$ (against $L$. donovani) along with elevated distribution in liver and spleen was also seen followed by administration in wister rats [77]. NPs apprehended with ligands of SRs were designed in attempt to promote intra-macrophagial drug accumulation which are mentioned in Table 4. Post critical evaluation of the above-mentioned research trials, it can be construed that surface labeled nanosystems are found to possess enhanced macrophage targeting and accumulation. This approach is, indeed, a value-added towards safety and efficacy as well. Anti-leishmanial nano-DDS, claiming the inhibition of TR-system and P-gp pumps, should also need to be assayed against animal models infected with
MA/SSG resistant leishmanial strains. In this way, their preeminence can be evaluated properly in contrast to conventional anti-leishmanial nano-DDS. However, the designing of thiolated-mannosylated nano-DDS could be an expensive approach, mainly due to costly raw material and process complexity-for production of mannosylated thiolated polymer [155].

\section{Anti-leishmanial nano-DDS—a passive targeting strategy as well}

Contrary to active targeting, passive targeting is just a spontaneous targeting of cells, tissue, or organ, based upon the enhanced permeation of designed NPs. This enhanced permeation would result in enough tissue accumulation sufficient to eradicate the underlying pathological conditions. It is usually attained through alteration in physicochemical and pharmacokinetic properties of the drug [174]. An advanced way to achieve passive targeting is the use of nanomedicine-nanocarrier-based drug delivery system. In Leishmaniasis, a passive targeting technique has been employed for both $\mathrm{CL}$ and VL forms of the infection. The orally designed polymeric NPs undergo intestinal absorption through M-cells in 
the peyer's patch that enables them to internalize in epithelial APCs. Moreover, adequate intestinal absorption of drug-loaded nanosystem would result in appreciable internalization and accumulation of anti-leishmanials in damaged liver and spleen [32]. The orally administered nano-DDS are previously discussed in detail in "Promising nano-DDS-capable for oral delivery of injectable anti-leishmanials" section and Fig. 5b. WHO has recommended the use of topical dosage forms for the treatment of uncomplicated CL. Topical application is beneficial because of better acceptability and less systemic toxicity. However, several limitations still encounter with cutaneous/topical drug delivery. A major challenging factor for topical drug delivery is inadequate permeation of drug through densely packed skin barrier-stratum corneum (SC) [175]. This could be the possible reason for inadequate parasitic eradication in CL patients.

\section{Passively target nano-DDS for $C L$}

In the former decade, the evolution of topically applied nano-DDS has also resolved the permeation challenges. Nano-sized, deformable lipid-based vesicular NPs are the key candidate for topical delivery [176]. Moreover, the topically administered drug target passively the CL parasite, illustrated in Fig. 12, as the absorbed drug internalize and accumulate selectively inside the skin APCs infected with the leishmanial parasite. Lipid-based NPs, particularly the TFS, experience the least hindrance while crossing epithelial skin to reach underneath diseased macrophages [177]. In addition, other types of nano-DDS can also have the potential of permeating through deeper layers of the epidermis. Niosomes, nano-emulgels, and microemulsion have also been evaluated as a topical nanosystem for passive CL targeting [178-180]. Topical nano-DDS are advantageous as a consequence of lower systemic permeation of anti-leishmanials. This would ultimately reduce the incidence of toxicity as well as parasitic resistance. In 2014, the first study was reported which has evaluated the response of topical LPS formulation of MA (MA-LPS). Only $1.5 \%$ of MA-LPS permeate while $65 \%$ retained in the skin, assessed through in vitro skin permeation test. $\mathrm{ED}_{50}$ against amastigotes (L. major) was found to be $46.36 \mu \mathrm{g} / \mathrm{ml}$, significantly higher than the plain drug. The efficacy against $L$. major induced $B A L B / c$ leishmanial model was however surprising. Till 4 weeks of treatment ( $50 \mathrm{mg}$ twice daily), the lesion size gets reduced. The treatment discontinuation, unfortunately, rehabilitates the lesion size. This could be due to resistance development in L. major amastigotes [181]. In another published report, Amp-B-LPS were designed and shown to have skin penetration only of $4 \%$ supplemented with $73.92 \%$ retention. Followed by the treatment with $0.4 \%$ Amp-B-LPS complete skin and splenic parasitic eradication was achieved [182]. In a similar study, MFS-LPS exhibited only $3 \%$ permeation through the skin. Accompanied with dodging the needless drug permeation, lesion size and splenic and skin lesion parasitic minimization were highly significant $(\mathrm{p}<0.001)$, contrary to plain LPS and drug [183].

Owing to the inadequate treatment response, topical LPS were modified into TFS gels, designed extensively in the last 5 years. These nano-deformable systems have better potential to cross SC owing to their elastic nature. Dar et al. [163] designed SSG-TFS and found to have a deformability index of $43 \%$. Macrophage cytotoxic test demonstrated the safety of the designed nanosystem and displayed $\mathrm{CC}_{50}$ values of SSG and SSG-TFS as 1.65 and $1.3 \mathrm{mg} / \mathrm{ml}$, respectively. $\mathrm{IC}_{50}$ value of SSG-TFS was found to be $50.86 \mu \mathrm{g} / \mathrm{ml}$ in comparison to the plain SSG $(184.66 \mu \mathrm{g} / \mathrm{ml})$ representing marked efficacy. Moreover, to support this in vivo characterization was also conducted which exhibited significant lesion size reduction $(1.92 \pm 0.31 \mathrm{~mm})$ as compared to the plain SSG treatment group $(5.03 \pm 0.44 \mathrm{~mm})$ [163]. In another recent report, the rifampicin-TFS gel was designed, having deformability of $93 \%$, and evaluated for its usefulness against CL. In addition to its sustained release behavior, the intramacrophage buildup was also significantly enhanced as compared to the plain drug, Moreover, flow cytometry assay resulted in $0.3 \%$ viable cells only with rifampicin-TFS [177]. Their deformable nature departs anti-leishmanial agents more impressively to intramacrophage cutaneous parasites, as proven by the previously mentioned results. Hence, these elastic nano-DDS have the potential to improve treatment outcomes of $\mathrm{CL}$ and other cutaneous anomalies. Further estimation of safety and efficacy would determine the fate of these promising nano-DDS. For comparative analysis, their in vivo anti-leishmanial activity should be compared with PMC, as a reference standard, because it is the only available drug for topical application in CL patients [40]. Furthermore, the assessment of lesion parasite reduction is not sufficient as Leishmania can be disseminated to the spleen and liver, causing hepato-splenomegaly [184]. Additional details of recently fabricated lipid nano-formulations (SLNs, LPS, and TFS) are discussed systematically in Table 5 along with their results and outcomes.

\section{Nanosystem based modalities to curb parasitic resistance}

Numerous nanosystem based schemes have been employed to tackle leishmanial parasitic resistance against the fundamental treatment approach-the chemotherapy. Active drug targeting, already discussed 


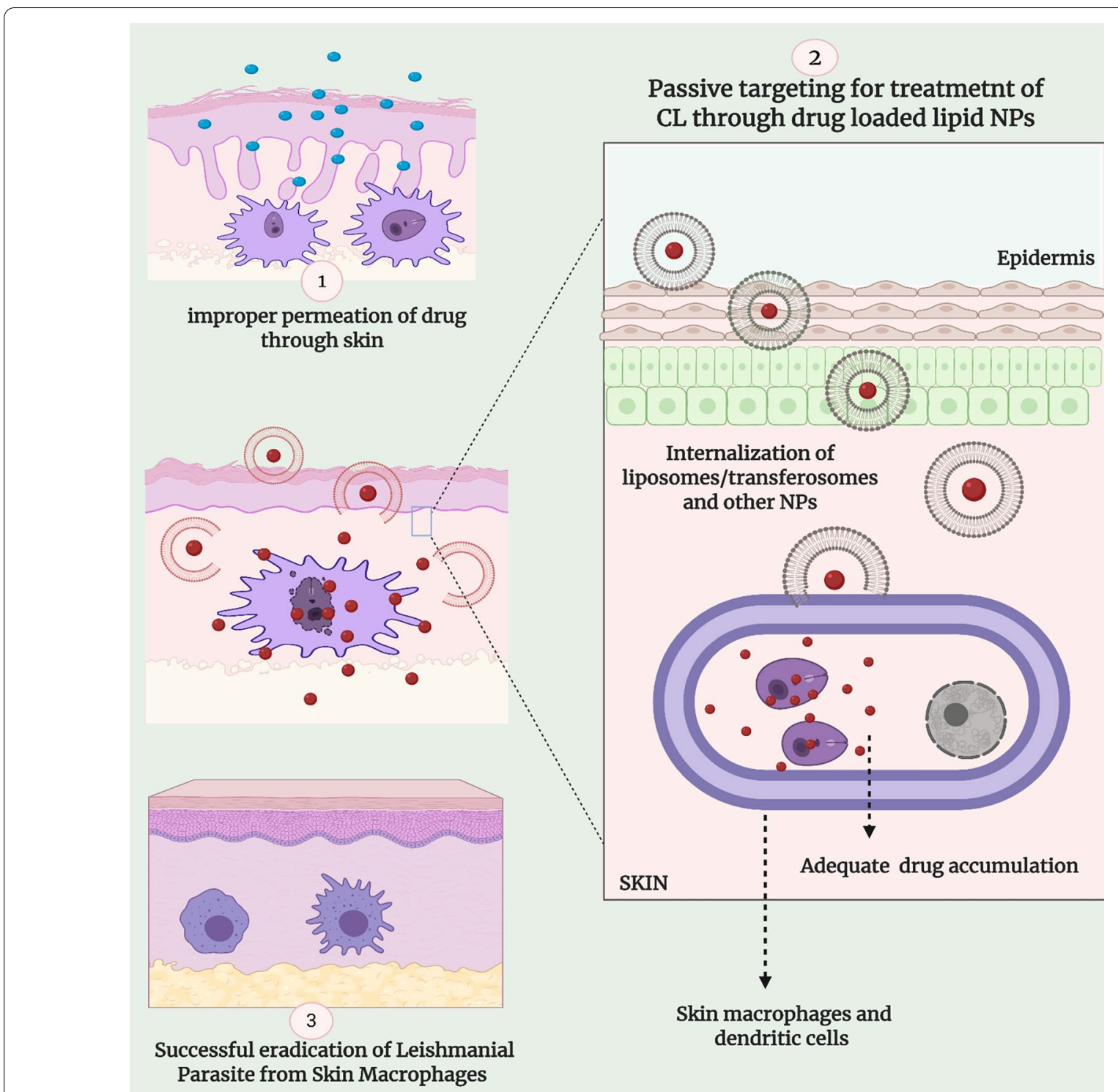

Fig. 12 Aggravated Skin permeation, intra-macrophagial internalization and target execution of leishmanial parasite responsible for $C L$ by topically applied nano-DDS

in detail, has been evaluated as a reasonable approach exhibiting appropriate intra macrophage accumulation of various leishmanicidals. In return, this could prevent the resistance and survival of the parasite. Thiolation is another excellent means to minimize the risk of resistance emergence discussed later. Another practical approach to head towards the formerly stated aim is the entrapment of multiple (more than one) antileishmanial drug inside the nanosystem. The delivery of multiple drugs loaded NPs (co-loaded NPs) not only improves drug efficacy but also prevents the rapid expulsion of drugs because of simultaneous leishmanial apoptosis in numerous ways. The details of these strategies are discussed below along with pictorial representation in Fig. 4b.

\section{Thiolated Nano-DDS—inhibitors of trypanothione (TR) metabolism}

The practical mechanism for parasite protection against numerous toxins, drugs, and oxidative stress-the TRsystem, when suppressed would result in adequate drug internalization and enhancement of nanosystem efficacy. Thiomers-the polymers, have properties to impart sustained release behavior in consort with enzymatic and 
Table 5 Lipid-based drug-loaded Nano-DDS of Passive CL targeting

\begin{tabular}{|c|c|c|c|c|c|c|}
\hline $\begin{array}{l}\text { Nanosystem } \\
\text { engineered }\end{array}$ & $\begin{array}{l}\text { Loaded anti- } \\
\text { leishmanial drug }\end{array}$ & $\begin{array}{l}\text { Core components for } \\
\text { fabrication }\end{array}$ & Characterization & Animal model & Major results & References \\
\hline \multirow[t]{3}{*}{ Liposomes } & $\begin{array}{l}\text { Meglumine Anti- } \\
\text { monate }\end{array}$ & $\begin{array}{l}\text { Sphingosylphos- } \\
\text { phorylcoline } \\
\text { Cholesterol } \\
\text { Propylene glycol }\end{array}$ & In vitro + In vivo & $\begin{array}{l}\text { L. major infected } \\
B A L B / C \text { mice }\end{array}$ & $\begin{array}{l}\text { Designed nano- } \\
\text { formulation was } \\
\text { associated with } \\
\text { significantly lower } \\
\text { lesion size and } \\
\text { splenic parasites } \\
\text { post-treatment }\end{array}$ & [181] \\
\hline & Amphotericin-B & $\begin{array}{l}\text { Phosphatidylcholine } \\
\text { Cholesterol }\end{array}$ & In vitro + In vivo & $\begin{array}{l}\text { L. tropica infected } \\
B A L B / c \text { mice }\end{array}$ & $\begin{array}{l}\text { Topical L-Amp-B 0.4\% } \\
\text { was found with the } \\
\text { capability to com- } \\
\text { plete eradication } \\
\text { of skin lesions and } \\
\text { splenic parasites } \\
\text { as well }\end{array}$ & [182] \\
\hline & Miltefosine & $\begin{array}{l}\text { Phosphatidylcholine } \\
\text { Cholesterol } \\
\text { Propylene glycol }\end{array}$ & In vitro + In vivo & $\begin{array}{l}\text { L. major infected } \\
B A L B / C \text { mice }\end{array}$ & $\begin{array}{l}\text { Lesion size and } \\
\text { parasitic burden } \\
\text { reduction with 2\% } \\
\text { and 4\% MFS loaded } \\
\text { LPS }\end{array}$ & [183] \\
\hline \multirow[t]{2}{*}{ Transfersomes } & $\begin{array}{l}\text { Sodium Stibogluco- } \\
\text { nate }\end{array}$ & $\begin{array}{l}\text { Phospholipon G } \\
\text { Tween } 80\end{array}$ & In vitro + In vivo & $\begin{array}{l}\text { L. tropica infected } \\
B A L B / C \text { mice }\end{array}$ & $\begin{array}{l}\text { Drug loaded TFS } \\
\text { shown to have } \\
\text { tenfold improved } \\
\text { deep epidermal } \\
\text { permeation and } \\
\text { fourfold lower } \mathrm{IC}_{50} \\
\text { as compared to the } \\
\text { plain drug solution }\end{array}$ & [163] \\
\hline & Rifampicin & $\begin{array}{l}\text { Phospholipon G } \\
\text { Span } 60 \& 80 \\
\text { Tween } 20 \& 80 \\
\text { Sodium lauryl sulfate }\end{array}$ & In vitro + In vivo & $\begin{array}{l}\text { L. tropica infected } \\
B A L B / c \text { mice }\end{array}$ & $\begin{array}{l}\text { Lower IC } 50 \text { (for } \\
\text { leishmanial cel- } \\
\text { lular apoptosis) of } \\
\text { rifampicin loaded } \\
\text { TFS was observed }\end{array}$ & [177] \\
\hline $\begin{array}{l}\text { Nano-structured lipid } \\
\text { Carriers }\end{array}$ & Amphotericin-B & $\begin{array}{l}\text { Phospholipon G } \\
\text { Isopropyl myristate } \\
\text { Glyceryl monosterate }\end{array}$ & In vitro + In vivo & $\begin{array}{l}\text { L. major infected } \\
B A L B / C \text { mice }\end{array}$ & $\begin{array}{l}\text { Significant parasitic } \\
\text { burden reduction in } \\
\text { leishmanial lesion }\end{array}$ & [185] \\
\hline
\end{tabular}

efflux pump (P-gp) inhibition abilities. Nano-DDS utilizing these polymers are commonly termed as "thiolated" nano-DDS. To study the effect of thiolated nano-DDS for curtailment of the resistant leishmanial strains, MA loaded mannosylated thiolated polyethylenimine chitosan NPs (MA-MTPC-NPs) were designed and evaluated against MA resistant leishmanial strains. Sarwar et al. [165] reported that MA-MTPC-NPs were indicated with the highest meglumine internalization in uninfected macrophages, resistant-strain infected macrophages, and sensitive-strain infected macrophages, 61.47, 61.61, and $61.76 \mu \mathrm{g} \mathrm{MA} / 10^{6}$ macrophages, respectively, in comparison to the plain drug and non-thiolated NPs. Published results of various thiolated nano-DDS are illustrated in Fig. 13. The superiority of other designed anti-leishmanial thiolated nanosystem is discussed erstwhile in section "Surface modified nano-DDS for active intramacrophage parasitic targeting" and mentioned systemically in Table 4, in the "Major results" column. The expulsion intensity of several $\mathrm{ABC}$ transporters in the leishmanial membrane can also be reduced by employing thiolated nano-DDS [162]. Several studies have been carried out to evaluate the intra macrophage residence of thiolated nano-formulations, mentioned in "Anti-leishmanial nano-DDS - a passive targeting strategy as well" section. Amp-B and PMC thiolated nano-formulation have been designed and evaluated. Results have shown 71 and 12.73-fold higher macrophage internalization of the fabricated nano-formulations as compared to the free drugs solutions, respectively $[155,162]$. Silver (Ag) NPs also retained activity for suppression of parasite protective mechanism-the TR-system. A group of Italian scientists has investigated the inhibition potential of silver on the trypanothione reductase activity of the leishmanial parasite. As an indicative of the leishmanicidal effect of AgNPs, $\mathrm{IC}_{50}$ for amastigotes and promastigotes were 1.76 and $2.18 \mu \mathrm{M}$, respectively. Hence, AgNPs exhibited strong leishmanial-toxic effects $[77,186]$. 


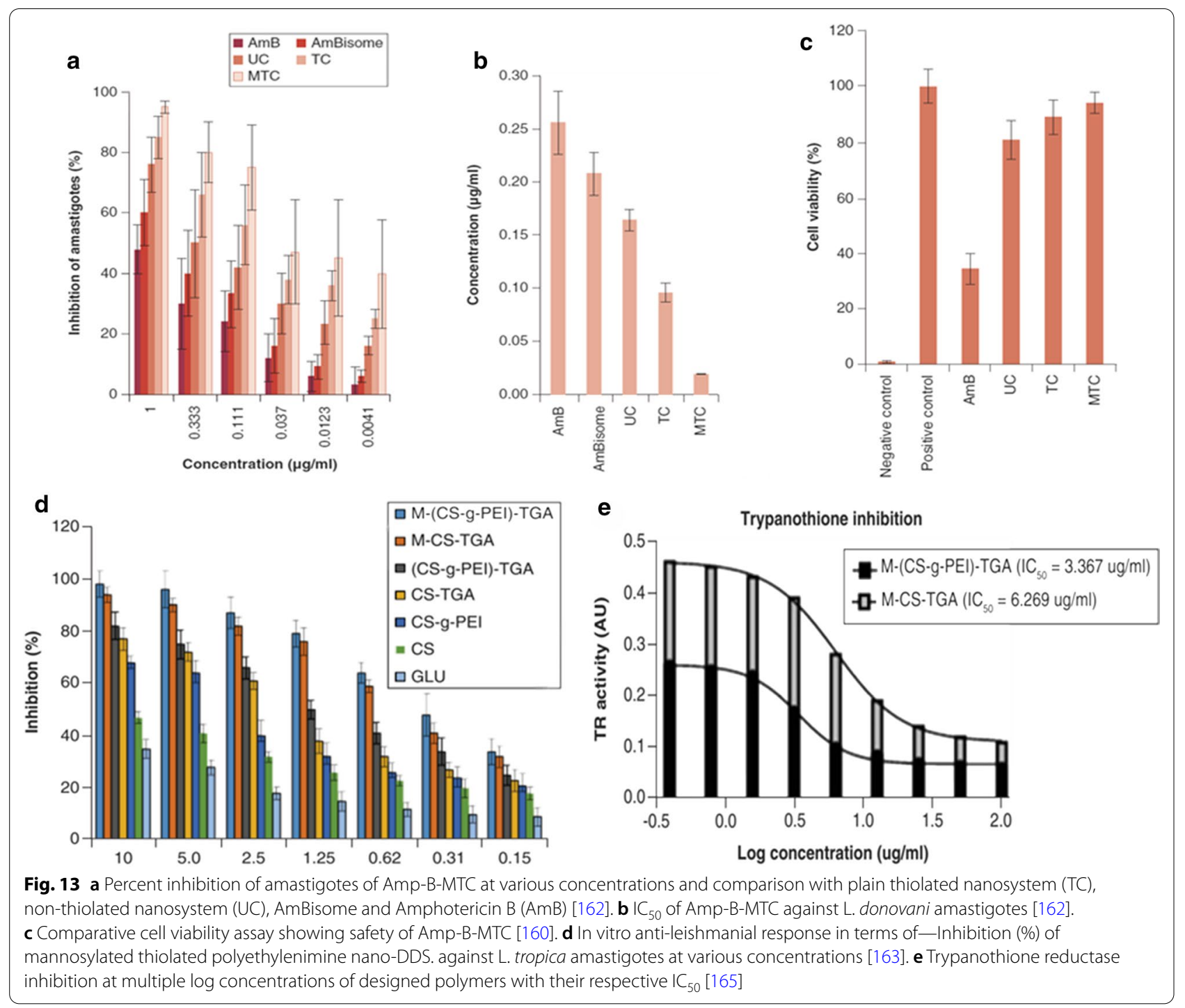

\section{Co-loaded nano-DDS for Leishmaniasis}

Anti-leishmanial monotherapy is considered one of the risk factors for the occurrence of parasitic resistance. Thus, combination therapy with multiple agents is needed not only due to increased anti-parasitic response, but also to prevent the emergence of resistant leishmanial strains in several regions of the world particularly in India and Brazil [187]. Natural immunomodulators, Curcumin (CUR), enclosed in PLGA-NPs had shown to increase MFS in vitro as a well in vivo anti-leishmanial activity when used together orally for VL. Approximately, $90 \%$ parasitic count was reduced with combination use of CUR-PLGA-NPs and MFS on 28th-day post-treatment along with significant elevation of ROS and reactive nitrogen species [188]. MA loaded chitosan- $\mathrm{TiO}_{2}$ $\mathrm{NPs}\left(\mathrm{MA}-\mathrm{CTiO}_{2}-\mathrm{NPs}\right)$ have been designed for synergistic killing of $L$. major promastigotes and intra-macrophage amastigotes. These nano-assemblies were found to be superior over alone MA treatment with respect to enhanced apoptotic potential, 4- and 13-fold, against amastigote and promastigote, respectively [189]. To sum up, the treatment with multiple agents could be beneficial in resistant VL cases. To face-off, the emergence of $\mathrm{CL}$ resistance, duo drug-loaded lipid-based nano-DDS were designed in past few years. These co-loaded topically applied nano-formulations were not only benefited with resistance prevention but also associated with victorious tissue parasite eradication at significantly lower $\mathrm{IC}_{50}$ in $L$. mexicana infected $B A L B / c$ mice model. Dar et al. [190] reported MFS-ketoconazole co-loaded-TFS (MK-TFS) with excessive $L$. mexicana killing assessed through flow cytometry assay. Moreover, in comparison to free SSG, in vitro anti-parasitic experiments have shown 10.67 -fold reduced $\mathrm{IC}_{50}$ of MK-TFS as well 
as 35.33-times more parasitic-density reduction in the skin lesion. In vivo and in vitro results of this study are shown in Fig. 14 [190]. Similarly, MFS-Amp-B-TFS were designed by the researchers to assess the synergistic response against CL. Furthermore, these nano-DDS were evaluated for parasitic reduction through in vitro and in vivo experimentations. The $\mathrm{IC}_{50}$ value of designed MFS-Amp-B-TFS showed 8.62 and 5.22 times reduction contrary to Amp-B and MFS, respectively [191]. Recently, vancomycin and rifampicin were entrapped inside these deformable nanocarriers (RV-TFS) and evaluated for their leishmanial inhibition response. In addition to the sustained release behavior of the enclosed drugs, $\mathrm{IC}_{50}$ values of RV-TFS were found to be 1.41 and $1.52 \mu \mathrm{g} / \mathrm{ml}$ against $L$. tropica promastigotes and amastigotes, respectively. These values were significantly higher than the values of the individual drugs. Hence, due to better release profile and synergistic effect RV-TFS, better provision of parasitic curtailment occurred as presented in Fig. 15a [192]. This strategy could be beneficial as small doses of individual drugs are provided, hence, better results could be achieved with minimal chances of toxicity. The details of these studies, investigations, and explorations are mentioned in Table 6.

\section{Distinctive nano-DDS for Leishmaniasis \\ Photosensitive and inorganic nano-DDS}

Owing to their capability to generate reactive oxygen moieties (ROS), metallic NPs possess clinically significant leishmanial agents killing activities. Although the presence of an anti-oxidative TR-system, that tries to cope with the ROS species, still parasitic damage encounters. Two studies have shown that AgNPs and $\mathrm{TiO}_{2}$-NPs are suitable alternative candidates for Leishmania treatment. The former study reported a 1.5 to 3 times reduction in parasite metabolic and proliferating ability in the dark and 2-6.5 times lowering in presence of UV-light [197]. Moreover, the parasitic external and internal morphology was also damaged, followed by the treatment with AgNPs. In fact, it possessed the strongest leishmanicidal activity among all metallic NPs. $\mathrm{Cu}$-doped $\mathrm{ZnO}$-NPs are also shown with surge $\mathrm{ROS}$ level, intra-parasitically, after exposure to visible light [198]. On the similar proof-of-concept, $\mathrm{Zn}$-doped- $\mathrm{TiO}_{2}$ hypericin photosensitive nano-DDS formulated by

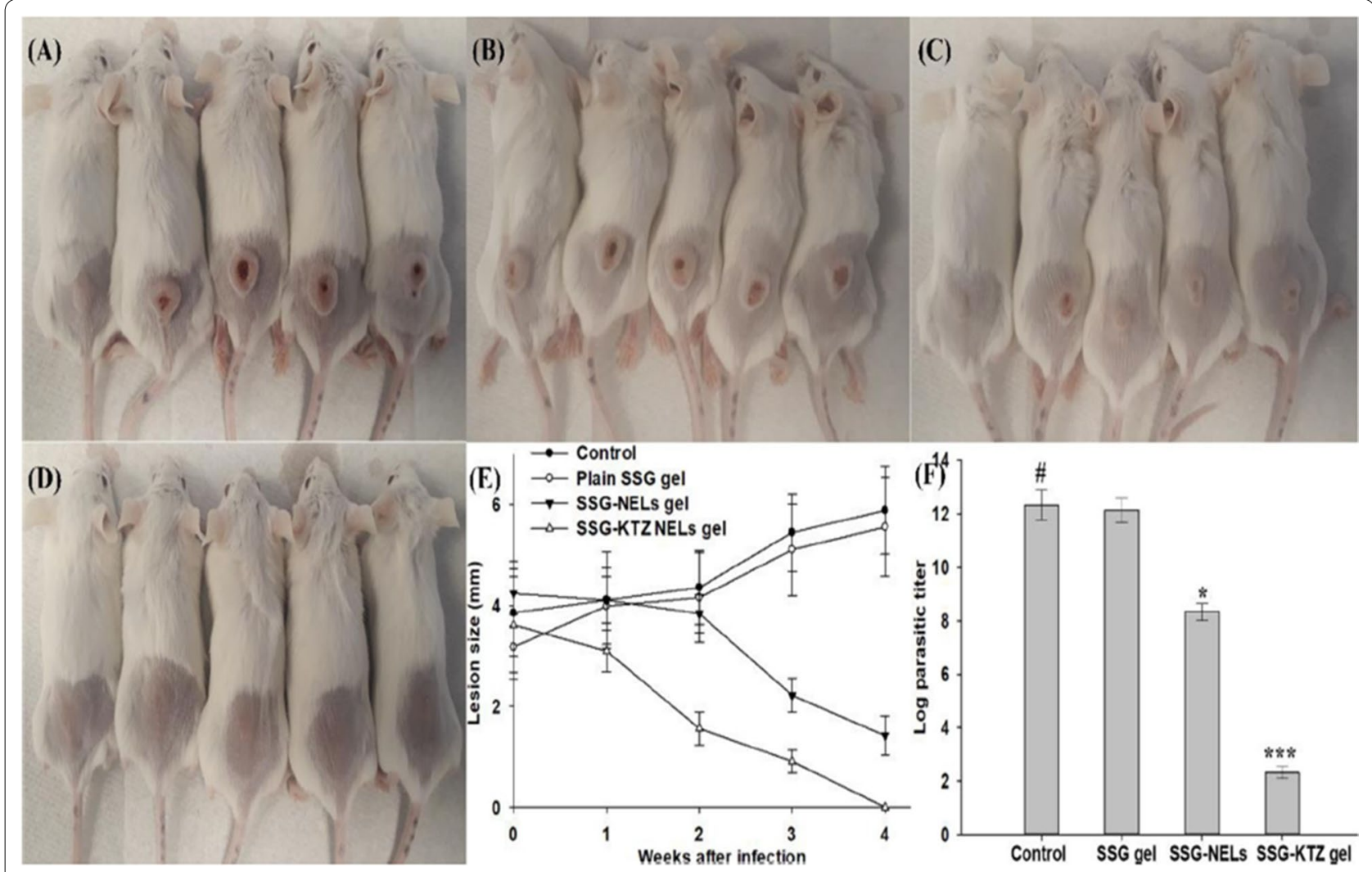

Fig. 14 Back rump CL lesion of various groups of infected BALB/C mice model a Control, b Plain SSG gel, c SSG-TFS gel, d SSG-ketoconazole-TFS gel. e CL lesion size evaluation post treatment with various formulation with highest response with SSG-ketoconazole-TFS gel (SSG-KTZ gel). $\mathbf{f}$ Significant lesion parasite minimization with SSG-ketoconazole-TFS gel (SSG-KTZ gel) [190] 

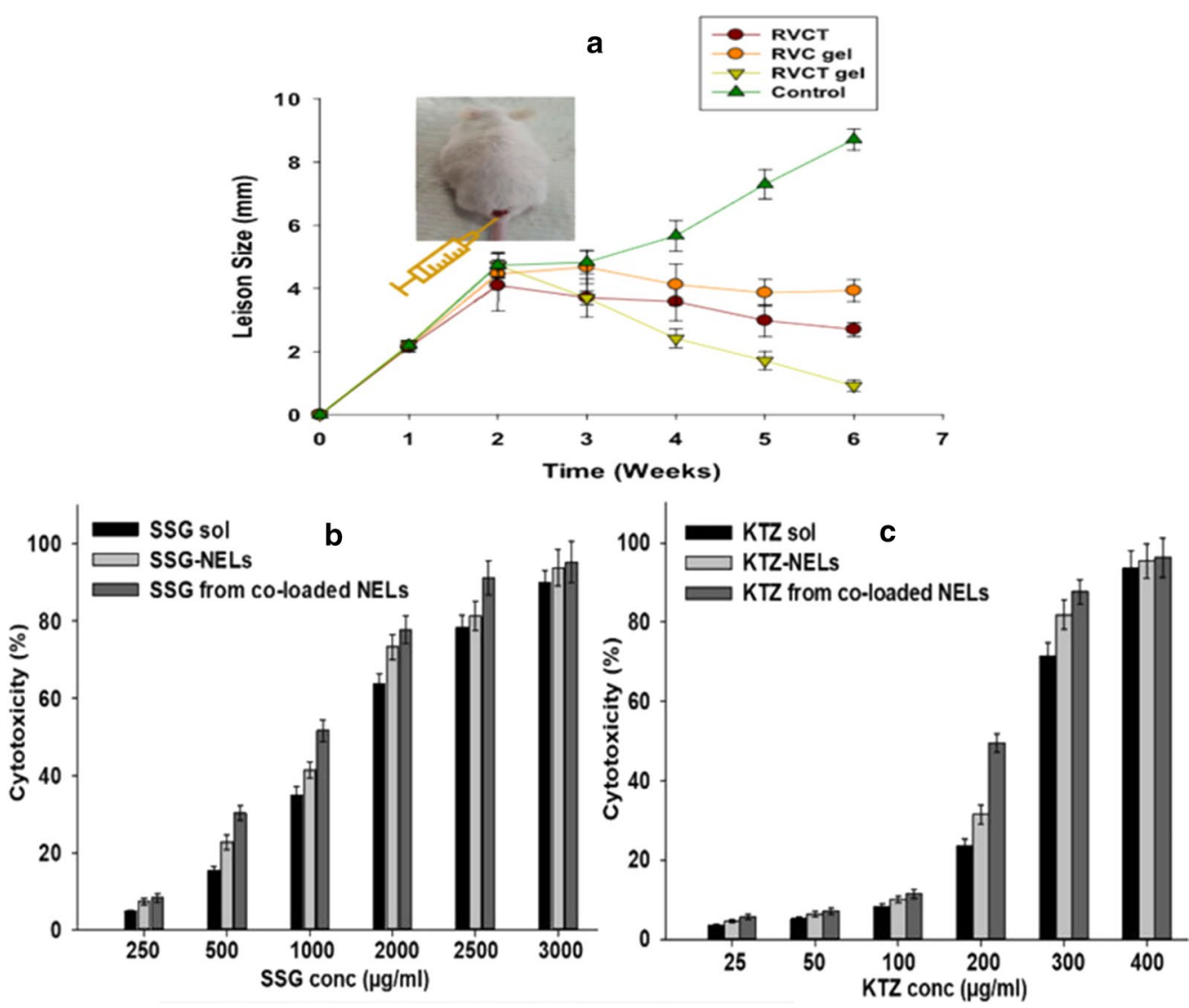

Fig. 15 a CL lesion size reduction in infected BALB/c mice model followed by treatment with RV-TFS (RVCT) [192]. b Cytotoxicity comparison of SSG solution (SSG sol), SSG-TFS (SSG-NELS) and SSG-Ketoconazole TFS (SSG-KTZ-NELs) [190]. c Cytotoxicity comparison of KTZ solution (KTZ sol), KTZ -TFS (KTZ -NELS) and SSG-Ketoconazole TFS (SSG-KTZ-NELs) [190]

Sepúlveda et al. [199] demonstrated that the mixture of red and blue light posing an intensity of $22 \mathrm{~mW} /$ $\mathrm{cm}^{2}$ caused $43-58 \%$ reduction in lesion parasitic burden in $L$. amazonensis infected $B A L B / c$ mice CL model. Moreover, its effectiveness as an antileishmanial nanoDDS candidate was found to be comparable with Amp-B. Photodynamic nano-DDS can be a suitable alternative to conventional anti-leishmanials. However, more advanced in vitro and preclinical assessment is required to promote their utilization in Leishmaniasis [199]. Another innovative approach, Amp-B-Ag NPs, were designed and investigated for in vitro anti-leishmanial activity. The results were declared satisfactory with significant potency and uptick in ROS. Moreover, the activity was significantly enhanced following exposure to visible light [200]. The combined application of Nigella sativa oil and $\mathrm{TiO}_{2}$-Ag-NPs showed enhanced anti-leishmanial response against both forms of the parasite [201]. A drug with anti-viral, anti-inflammatory and anti-tumor potential, betulinic acid, has been entrapped inside chitosan NPs for evaluation regarding its safety and efficacy in $L$. major (resistant strain) infected $B A L B / c$ mice. The results of the study were found to be very satisfactory in terms of parasitic burden reduction and nitric oxide (NO) production. Approximately, $86 \%$ killing of promastigotes, $81 \%$ lowering in the intracellular parasite, and highest NO production was observed with this fabricated nanosystem [202]. Recently, manganese oxide NPs have been formulated for the purpose to search for alternative treatment modalities against Leishmaniasis. This metallic nano-DDS was associated with $57 \%$ promastigotes apoptosis, estimated using flow cytometry, at $\mathrm{IC}_{50}$ of $15 \mu \mathrm{g} / \mathrm{ml}$. Metallic nano-DDS was believed to be cytotoxic in nature, thus, to assess its safety MTT assay was conducted and it was found to be toxic to macrophages

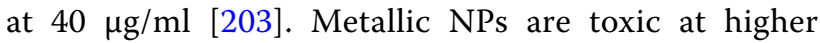
doses, thus, the use of anti-leishmanial loaded metallic nano-DDS could be effective even at non-toxic lower concentrations. 
Table 6 Promising Nanosystem candidates, with eminent in vivo results, to curb leishmanial resistance

\begin{tabular}{|c|c|c|c|c|c|c|c|}
\hline $\begin{array}{l}\text { Nanosystem } \\
\text { engineered }\end{array}$ & $\begin{array}{l}\text { Loaded anti- } \\
\text { leishmanials drug }\end{array}$ & Year & $\begin{array}{l}\text { Route of } \\
\text { administration }\end{array}$ & Leishmanial strain & Animal model & Major results & References \\
\hline \multirow[t]{3}{*}{$\begin{array}{l}\text { Stearylamine bearing } \\
\text { Liposomes }\end{array}$} & Amphotericin-B & 2008 & Parenteral & L.donovani & $\begin{array}{l}V L \text { induction in } B A L B / C \\
\text { mice }\end{array}$ & $\begin{array}{l}\text { SA bearing Amp-B } \\
\text { LPS are superior } \\
\text { to AmBisome in } \\
\text { parasitic burden } \\
\text { reduction, IL-10, and } \\
\text { TNF-a downregula- } \\
\text { tion }\end{array}$ & [193] \\
\hline & Paromomycin & 2011 & Parenteral & L. donovani & $\begin{array}{l}V L \text { induction in } B A L B / C \\
\text { mice }\end{array}$ & $\begin{array}{l}\text { The prominent } \\
\text { synergistic response } \\
\text { was observed } \\
\text { evidenced by eleva- } \\
\text { tion of INF-a levels } \\
\text { and reduction in } \\
\text { IL-10 levels }\end{array}$ & [194] \\
\hline & $\begin{array}{l}\text { Sodium Stibogluco- } \\
\text { nate }\end{array}$ & 2011 & Parenteral & $\begin{array}{l}\text { SSG-resistant } \\
\text { strains of } L \text {. } \\
\text { donovani }\end{array}$ & $\begin{array}{l}V L \text { induction in } B A L B / C \\
\text { mice }\end{array}$ & $\begin{array}{l}\text { Successful destruc- } \\
\text { tion of SSG-resistant } \\
\text { strain of L. donovani } \\
\text { with the significant } \\
\text { rise in NO levels }\end{array}$ & [195] \\
\hline \multirow[t]{3}{*}{ Transferosomes } & $\begin{array}{l}\text { Miltefosine + Api- } \\
\text { genin }\end{array}$ & 2019 & Topical & L. Mexicana & $\begin{array}{l}C L \text { induction in } \\
B A L B / C \text { mice }\end{array}$ & $\begin{array}{l}\text { With co-loaded nano- } \\
\text { formulation, } 8.0 \text {-fold } \\
\text { lower IC } \mathrm{C}_{50} \text { and } \\
9.5 \text {-fold eradication } \\
\text { of lesional parasite } \\
\text { than plain MFS } \\
\text { solution }\end{array}$ & [196] \\
\hline & $\begin{array}{l}\text { Amphotericin- } \\
\text { B+ Miltefosine }\end{array}$ & 2020 & Topical & L. Mexicana & $\begin{array}{l}C L \text { induction in } \\
B A L B / C \text { mice }\end{array}$ & $\begin{array}{l}\text { Significant reduction } \\
\text { (8.6 \& 5.22-times) in } \\
\text { IC } C_{50} \text { as compared to } \\
\text { the plain drug solu- } \\
\text { tion of Amp-B and } \\
\text { MFS respectively }\end{array}$ & [191] \\
\hline & $\begin{array}{l}\text { Sodium Stibogluco- } \\
\text { nate + Ketocona- } \\
\text { zole }\end{array}$ & 2020 & Topical & L. Mexicana & $\begin{array}{l}C L \text { induction in } \\
B A L B / C \text { mice }\end{array}$ & $\begin{array}{l}10.67 \text { times lower } I_{50} \\
\text { was observed with } \\
\text { fabricated nano- } \\
\text { formulation and } \\
\text { 35.33-times lesional } \\
\text { parasitic load reduc- } \\
\text { tion was observed } \\
\text { in comparison to } \\
\text { plain SSG }\end{array}$ & [190] \\
\hline
\end{tabular}

\section{Phytonanotechnology against leishmaniasis-a bio-friendly and cost-effective approach}

Synthetically fabricated NPs are accompanied by multiple drawbacks as discussed in "Loopholes in designed nano-DDS" section. Nevertheless, these "nature's nanoDDS" have enumerated myriad dilemmas associated with "synthetic nano-DDS". This statement is supported by the experimental data stating "plant-derived nano-DDS" are eco-friendly, bio-friendly (non-toxic), and cost-effective [204]. Botanically-obtained isolates are currently being used for no-toxic and eco-friendly synthesis of various metallic NPs. This newly emerging arena is referred to as "Phyto-nanotechnology" [205]. The use of phytonano-DDS to curtail anti-leishmanial chemotherapy challenges is another appropriate way out. Saponins are the triterpene glycosides having intrinsic anti-biological, anti-infective, anti-leishmanial, and anti-inflammatory activity [206, 207]. An attempt was made to engineer Aescin-entrapped PLGA NPs. After accomplishment of the study, the results were clearly pointing towards improvement of intra-macrophage trafficking of designed phyto-nanosystem along with twice reduction in $\mathrm{IC}_{50}$ value as compared to blank aescin [208]. Anti-biological activities of propolis, a biotechnological product attained from bees (Apis mellifera), advocated the group of Brazilian and English scientists to design propolis loaded nanosystem. Brazilian red propolis extract was encapsulated 
inside the polymeric NPs constructed using poly-caprolactone and pluronic. This polymeric formulation had particle size in 200-300 nm range, inhibited L. braziliensis parasite at significantly lower $\mathrm{IC}_{50}$ values along with improved anti-oxidant properties contrary to the ethanolic extract [209]. Experiments conducted by Monzote et al. [210] revealed the anti-leishmanial activity of essential oil derived from Artemisia absinthium. Later, nanochelates (74 $\mathrm{nm}$ in diameter) of $A$. absinthium extracted essential oil was designed to gauge their anti-leishmanial response via duo in vitro and in vitro experiments. Results of both studies were conflicting; adequate lesion size reduction was achieved, but in vitro anti-leishmanial activity was limited with higher $\mathrm{IC}_{50}$ values [211]. By critical analysis of the results, the designed nanochelates were found appropriate channel for safer delivery of the plant extracts. Ocotea duckei vattimo, a Brazilian plant extract laden SLNs have also been extensively evaluated and found to be significantly parasiticidal to Leishmania [212]. CUR, a polyphenol enriched inside curcuma longa rhizomes had also displayed anti-leishmanial activity, as reported by a group of researchers from Pakistan [213]. They loaded CUR in NLCs for topical application against CL. In vitro anti-promastigote experiments yielded reduced $\mathrm{IC}_{50}$ readings of CUR-NLC gel as compared to the plain CUR-solution i.e. $105 \mu \mathrm{g} / \mathrm{ml}$ and $165 \mu \mathrm{g} / \mathrm{ml}$, respectively [214]. Similarly, due to leishmanicidal activity of Cupressus semipervirens isolates containing cedrol, its NLCs have been engineered. Myriad in vitro and in vivo characterization have shown the superiority of cedrolcomplexed-NLCs over plain cedrol extract and MTF. Moreover, its anti-leishmanial activity was also evaluated against SSG and PMC AG83-R and GE-1 amastigotes, in addition to the in vivo assay [215]. Another triterpeneursolic acid, has been entrapped chitosan shielded NLCs, because of its ability to exhibit apoptotic changes in the leishmanial parasite [216]. Evaluation of leishmanicidal response was assessed by both in vitro and in vivo assays. In contrast to the free ursolic acid, the anti-leishmanial activity was increased by 12 -fold against wild stains and fourfold against SSG and PMR resistant strains. Moreover, these in vitro results are supported by outcomes of in vivo assay-approximately $99 \%$ reduction in parasitic burden post oral administration of ursolic acid-loaded NLCs [217]. The instability of lipid nano-formulations was tackled using Aloe Vera leaf extract nano-assemblies. This novel methodology was presented with reduced nephrotoxicity and hemolysis as well as the nanosystem stability also improved to a greater extent. Its therapeutic efficacy was evaluated against fungal infection (caused by candida spp.), however, its anti-leishmanial response needs to be evaluated [218]. In literature, the extensive parasiticidal activity of metallic NPs has been reported.
Unfortunately, they were synthesized usually either by physical or chemical method. These methods have incorporated multiple drawbacks in the use of metallic nanoDDS [219]. Phytonanotechnology, as described earlier, has resolved multiple drawbacks, through the employment of biogenesis of nano-DDS. In the current decade, silver and gold nanoparticles have been synthesized through an eco-friendly method-green synthesis and evaluated for their anti-leishmanial response [205]. Isatis tinctoria extract was loaded inside AgNPs and the $\mathrm{IC}_{50}$ value was determined against $L$. tropica promastigotes. Solo use of AgNPs presents $\mathrm{IC}_{50}$ values of $4.2 \mu \mathrm{g} / \mathrm{ml}$ and with the combined use of Amp-B, the $\mathrm{IC}_{50}$ was reduced to $2.43 \mu \mathrm{g} / \mathrm{ml}$ [200, 220]. In another recent report, AgNPs were designed with Euphorbia prostrata leaves extract. The in vitro leishmanicidal assay generates the $\mathrm{IC}_{50}$ values of 3.89 and $14.94 \mu \mathrm{g} / \mathrm{ml}$ against $L$. donovani amastigotes and promastigotes, respectively [221]. Similarly, Kalangi et al. (2016) [222] have found that AgNPs encapsulated Anethum greveolens leaves extract ( $35 \mathrm{~nm}$ in size) was less effective, when used alone. However, its antileishmanial response increased twice when employed in MFS doped form (combination use). Ag-Au hybrid NPs were also designed using Dioscorea bulbifera with a particle size of $15 \mathrm{~nm}$. This hybrid approach was found to exhibit a significant anti-leishmanial response i.e. MIC was $32 \mu \mathrm{g} / \mathrm{ml}$ [223]. Extract of Maytenus royleanus and Sargentodoxa cuneata was also exercised to design AuNPs. Promastigote growth inhibition of $75 \%$ and $\mathrm{IC}_{50}$ of $5.29 \mu \mathrm{g} / \mathrm{ml}$ were observed, respectively [224]. In a recently published report, Bagirova et al. [225] have synthesized and compared the leishmanicidal response of AgNPs with green synthesized AgNPs using Cuminum cyminum seed extract. The biosynthesized AgNPs were superior for safety (with $12 \%$ of cell viability) as well as efficacy against L. tropica in comparison to plain AgNPs (with $2 \%$ cell viability). Unfortunately, in vivo leishmanicidal assay was missed in this published research report. To shorten the discussion, the nano-DDS utilizing substances of natural origin are quite beneficial as they provide an opportunity to recuperate the Leishmaniasis management. However, there alone use would not be recommended because of their limited anti-leishmanial activity. Designing co-loaded nanosystem enclosing plant extract and anti-leishmanials in small doses would be appropriate for successful killing of parasite.

\section{Innovative nano-DDS for Leishmaniasis}

Tocopheryl polyethylene glycol 1000 succinate, also termed TPGS, was a P-gp inhibitor and prevent the drug efflux from parasite [226, 227]. In 2018, a novel nanoDDS consisting of Oleanolic acid-loaded PLGA-Vitamin 
E-TPGS NPs (OA-PLGA-TPGS-NPs) was designed, evaluated, and compared for its value-added anti-leishmanial activity in comparison to SSG, PMC, and Amp-B against wild and resistant strains of $L$. donovani. The $\mathrm{IC}_{50}$ values of OA-PLGA-TPGS-NPs, $0.70 \pm 0.10 \mu \mathrm{M}$ and $6.80 \pm 2.20 \mu \mathrm{M}$ against $L$. donovani wild and SSG resistant strains, respectively, have clearly reflected enhanced leishmanial killing contrary to SSG and PMC. However, it also possesses slightly higher $\mathrm{IC}_{50}$ value than Amp-B against wild and resistant strains, which were $0.22 \pm 0.07 \mu \mathrm{M}$ and $0.26 \pm 0.08 \mu \mathrm{M}$, respectively. Furthermore, these NPs possess valuable anti-leishmanial activity in $L$. donovani infected $B A L B / c$ mice with the reduction in spleen mass and splenic parasitic burden coupled with minimal nephrotoxicity (assessed using serum BUN and creatinine levels) [227]. Due to 19-times reduced $\mathrm{IC}_{50}$ than that of SSG, this nano-DDS could be of potential interest for detailed assessment in an in vivo setting. Nitric oxide possesses significant anti-leishmanial activity, however, its short half-life restricts its utilization. Incorporation of $S$-nitroso-mercaptosuccinic acid, a potent NO donor, inside chitosan NPs (NO-CNPs) has provided 99\% release within $10 \mathrm{~h}$. Moreover, 98\% killing of L. amazonensis promastigotes was observed at $200 \mu \mathrm{M}$ concentration, along with $\mathrm{IC}_{50}$ and $\mathrm{IC}_{90}$ were found to be 31.5 and $102.4 \mu \mathrm{M}$, respectively. MTT assay was also conducted to determine the safety of NO-CNPs and results indicated the unaltered mitochondrial activity of macrophages. Interestingly, immunofluorescence was also conducted and displayed with meaningful reduction of parasitophorous vacuoles, the residence of the parasite inside infected macrophages [228]. This study was highly valuable because it has utilized an un-conventional antileishmanial moiety, however, the researchers have not compared NO-CNPs anti-leishmanial activity with other drugs, which otherwise would have been more appropriate. The comparison of NO-CNPs with other nano-DDS, L-Amp-B, and conventional drugs (Amp-B, MA, etc.) could be conducted against Leishmania infected animal model to determine its utilization for further research.

\section{Leishmanial nano-vaccines-an innovative approach towards immunization}

Leishmanial recombinant proteinaceous vaccines are, in fact, associated with poor activation of the MHC-I pathway and cell-mediated immunity. Virtues of nanoDDS and nanocarriers are not only limited to drug delivery. They can also be advantageous for vaccine delivery as well in order to induce an efficient immune response in the recipients. Utilization of peptide antigen-loaded nano-DDS is beneficial owing to shielded, safe, and adequate delivery of immunogenic molecule along with the capability of APCs internalization and innervation of T-helper cells-1 (Th-1) immune mechanism [229]. In other words, nanoparticle adjuvant-NPs capable of effectivelantigen delivery to the APCs, is the very efficient approach towards potential immunization against this parasitic infection as illustrated in Fig. 16. Currently, none of the immunization is approved or marketed against Leishmaniasis. However, a promising immunization nominee (Heterogenous prime-boost) for Leishmaniasis, cysteine proteinase type-I, has been delivered to leishmanial infected mice using SLNs. This nano-DDSbased delivery of vaccine was found to be beneficial with the surge in immunomodulators along with parasitic burden reduction in C57BL/6 mice [230]. Another 2nd generation leishmanial vaccine has been evaluated for its in vivo response, followed by the administration in the form of P8-labelled soluble leishmanial antigen (SLA) loaded PLGA NPs. The PLGA nanocarriers were superficially modified using the sequence of 8 amino acids (P8) for active APCs targeting. The SLA was the active immunogenic moiety, hence considerable immune boost up was achieved in the $B A L B / c$ mice model [231]. At present, some vaccine candidates against Leishmaniasis are under pre-clinical and clinical trials [232]. Some of the limitations, with these under-trial vaccine nominees, can be resolved through the employment of these nano adjuvants or delivery systems.

\section{Liposomal adjuvant system for antigen delivery}

LPS, as discussed erstwhile, are the promising nanoadjuvant for leishmanial antigen delivery to APCs. Antigen-loaded LPS are initially phagocytosed by the macrophages. These phagocytosed NPs are broken down inside lysosomes and antigen protein gets released in the cytoplasm. Which in turn, activates the endoplasmic reticulum or golgi apparatus major histocompatibility class-I and II (MHC-I and MHC-II) pathways. These events, however, activates cytotoxic T-cells response which numerous protein and non-replicating antigenbased vaccines lack [233]. Most of these nano-vaccines have proved their usefulness through the formation of IgG2a antibodies. Numerous factors should be considered while designing a liposomal adjuvant antigen delivery system because its immunogenicity has greatly been impacted by its nature and composition. Among them, the type of phospholipid used for LPS construction, the transition temperature of a phospholipid, liposomal surface charge, its size, and surface modification are the major ones. In general, antigen-loaded LPS having nonphosphatidylcholine phospholipids, phospholipids with higher transition temperature, larger size (above $100 \mathrm{~nm}$ ), and positively charged surface can attain surged APCs uptake and internalization [234]. Most recently, LPS enclosing SLA and imiquimod has been assessed for its 


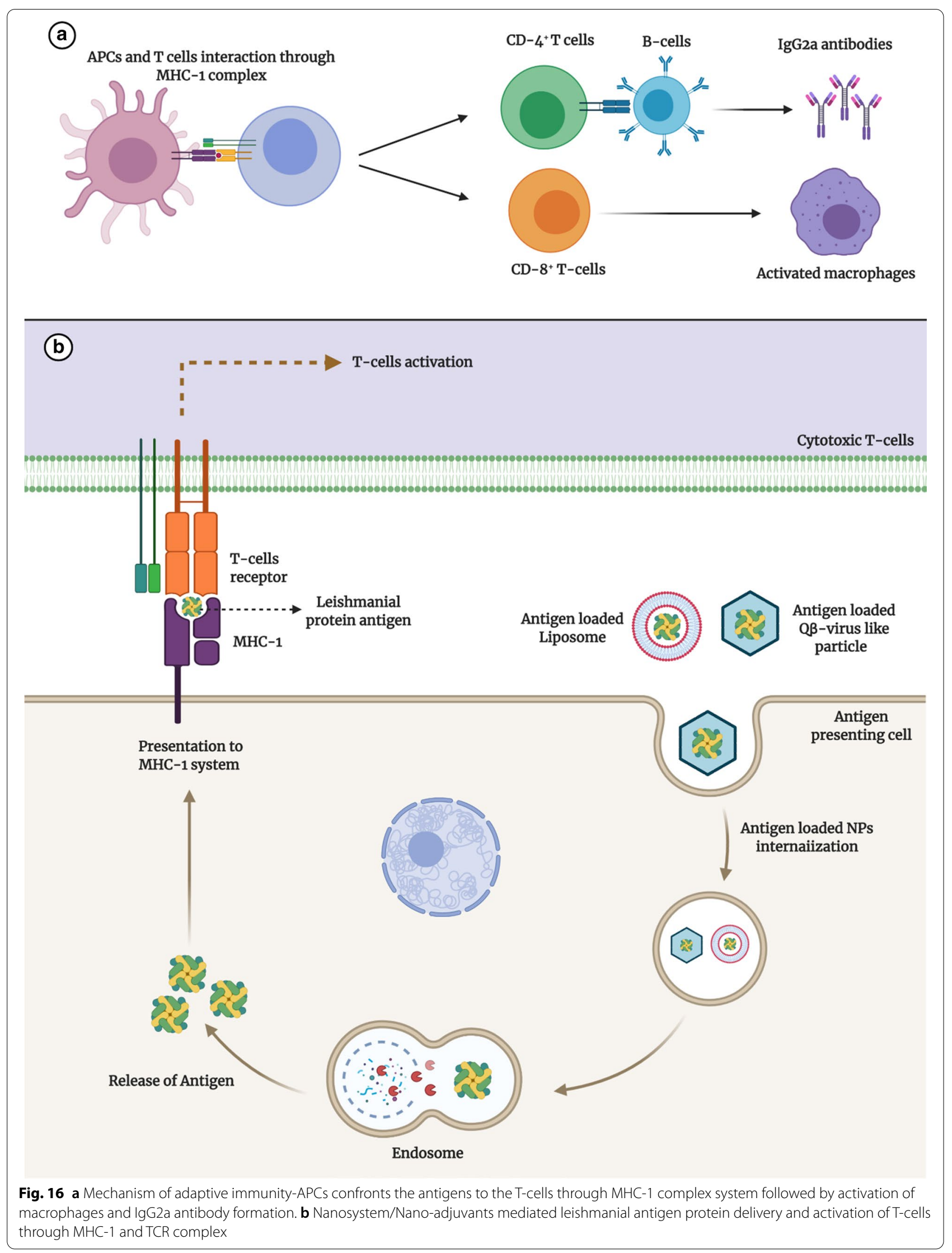


leishmanial immunization response in the $B A L B / c$ mice model. Mice experience reduces lesion size and footpad inflammation along with elevated blood levels of IgG2a and INF- $\gamma$, showing elevated T-helper cells-1 mediated immune response [235]. Other recently designed (in the past 6 years) liposomal based vaccine candidates are enlisted in Table 7.

\section{Polymeric NPs and virosomes for antigen delivery}

Oral delivery of polymeric NPs is associated with M-cells interaction. M-cells traverse these NPs from the intestinal lumen to the APCs resident across the epithelium. Thus, polymeric NPs can be used as an antigenic carrier for mucosal immunization [90, 234]. Katebi et al. [236] loaded PLGA NPs with SLA and TLR receptor agonistsPAM3CSK4 and R848, to trigger macrophage-mediated phagocytosis against L. major parasites. Interestingly, results have shown a marked increment in macrophages phagocytotic potential accompanied by a significant reduction in pro-inflammatory cytokines. This immunogenic candidate should be tested against Leishmania infected animal model to determine in vivo parasitic and disease reduction potential [236]. Another innovative immunization technique is the use of viral-like particles or virosomes as a conveyance for antigen delivery. In contrast to conventional LPS, these are composed of pure glycoprotein viral coat embedded in the lipid bilayer membrane. This strategy not only improved the stability of the lipid bilayer but also promoted the significant improvement of immunogenicity. Influenza virus hemagglutinin and neuraminidase are usually intercalated inside phospholipid layers of virosomes [237]. Some of the recently designed virosomal and polymeric-based peptide nano-vaccines are mentioned and discussed in detail in Table 7. Numerous other nanosystems have also been utilized to evaluate their suitability for antigen/vaccine delivery against Leishmaniasis which includes SLNs, niosomes, micelles, and nanoemulsions.

\section{Nano-repellants and other nano-based strategies for vector control}

For vector-borne infections, the transmission of the parasite can be contained by restricting the vector either by preventing its access to the healthy host or by killing it. Similarly, to control the spread of Leishmaniasis, different strategies may be employed including the use of repellents, insecticides treated nets, and anti-parasitic infestation drug utilization by host organism [252]. The use of chemically derived repellants is a practical approach for Leishmaniasis prevention owing to the unavailability of effective vaccination, but they have the potential to cause toxicity with protracted use. Diethyltoluamide (DEET), diethyl phthalate, and diethyl-phenyl acetamide (DEPA) possess considerable repellant properties for phlebotomine sandflies [253]. Here, nanotechnology was employed to provide longevity of repellant action, impeding its evaporation rate and reduction in its toxicity. Among currently marketed repellants, DEET is the most effective one and considered as a standard for comparison purposes as well. Due to excessive use, unfortunately, its efficacy is declining considerably [78]. A group of scientists has loaded DEET inside polymerically-poly-methacrylate (PMMA), constructed nanospheres and interestingly, this nano-repellant appear to attain the sustained release properties with prolonging the duration of action up to $9 \mathrm{~h}$, significantly enhanced as compared to plain DEET. Thus, its excessive use can be tackled by employing nano-DEET [254]. Permethrin (PMT) has also been loaded inside lipid-based nanosized carriers and applied on clothes as a repellant. This technique was found to be advantageous over free PMT because nanoparticles stuck to the polyester fibers even after washing. Thus, the utilization of PMT-NPs, exhibiting improved repellant effect, can prevent insect bite and parasitic transmission from diseased to healthy host [255]. In another study, DEPA entrapped PEG NPs were prepared by Balaji et al. [256]. This nano-repellant has been found to exhibit 5-times depression in $\mathrm{LC}_{50}$ value as compared to conventional DEPA repellants. Moreover, their impregnation in cotton clothes also appeared with long-lasting repellant nature. To sum up, myriad attempts have been made to fabricate nano-repellants. However, with context to Leishmaniasis, none of them have been evaluated against phlebotomine species for their improved repellant actions. This is a critical point that needs to be addressed by scientists and nano-engineers on an immediate basis. Indoor pesticide sprays of dichloro-diphenyl-trichloroethane (DDT) were, initially, found to be adequately effective in controlling the Leishmaniasis vector, the phlebotomine sand-fly. A study carried out in 2016, to assess the resistance incidence among $P$. argentipes and $P$. papatasi, has found that DDT has become less effective in several areas of India, Sri lanka, and Bangladesh [257]. To the best of our knowledge, no study is available yet that has designed the DDT nanoparticles-a possible way to improve DDT efficacy against sand-fly species. Despite their usefulness as a delivery system, metallic NPs (Au-NPs, Ag-NPs, and ZnO-NPs) have also gained interest in their application for vector control. Particularly, the naturally-obtained extractloaded metallic NPs are proved to exhibit ovicidal and larvicidal properties when obtained through the green synthesis process. These NPs are beneficial in terms of biocompatibility and good safety profile [78, 258]. Still, there is a lack of evidence about their usefulness against Phlebotomus flies and tested only for mosquito (A. egypti) 


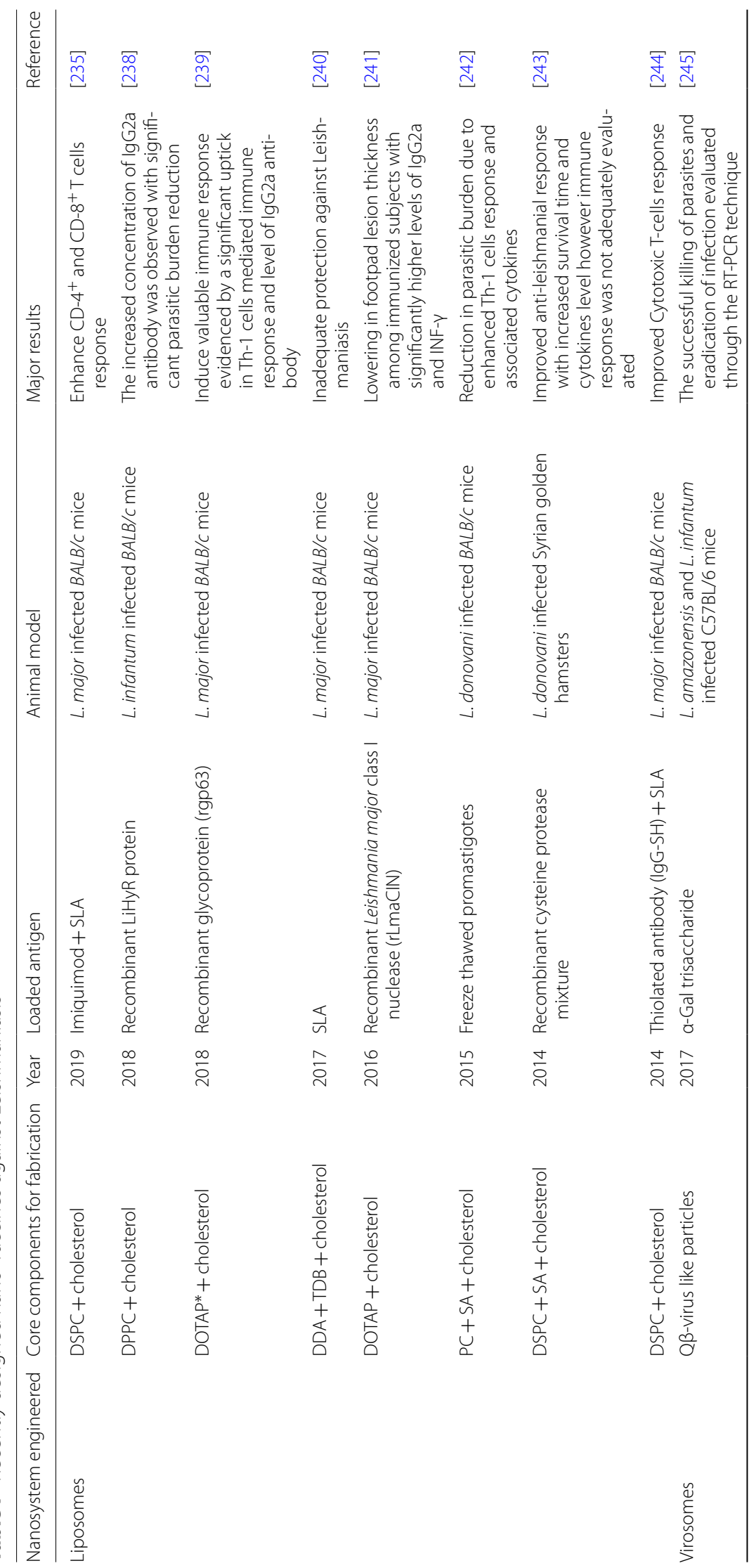




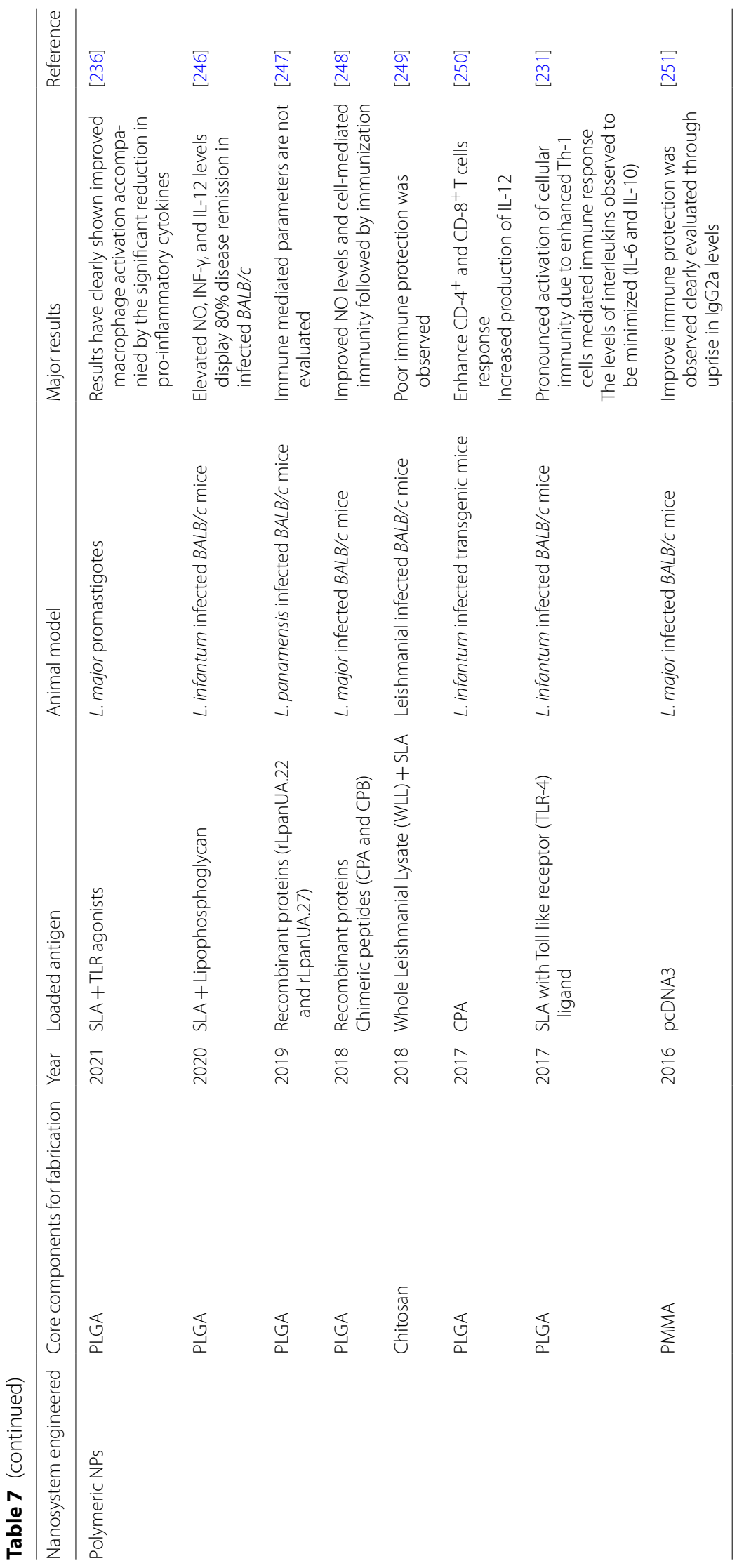


control [259]. These studies should be necessarily conducted in regions where Leishmaniasis is endemic to obtain nanotechnology-based controls against Leishmaniasis vector.

\section{Loopholes in designed nano-DDS}

Nanotoxicity-a critical safety concern, and its assessment Nanomedicine is achieving high milestones and further advancement of this horizon is in progress. Thus, because of their valuable gains, the number of FDA approvals is constantly escalating [260,261]. Due to the rise in their post-market acceptability, there is a crucial requirement to develop accurate methods and tests for the safety or toxicity assessment of nanoparticles. According to our literature survey, the field of nanotoxicity assessment is obscure, and very limited information is available. FDA as a global health authority should require devising the standard testing methods and procedures for nanomaterials toxicity assessment because the conventional safety analysis techniques are not suitable for nano-formulations owing to their distinctive nature, size, and surface properties [262]. It has been evidenced by results variation in a study carried out by Clift et al. [263] showing that nanofibers induced genotoxicity is perceptible through mammalian assay but not with conventional Ames assay. At present, the toxicity of engineered nanomaterials is assessed by several in vitro and in vivo techniques, both of which are associated with certain drawbacks in context to NPs toxicity measurement. As a response, there is a requirement to develop some valuable and accurate QSAR-based in-silico techniques, on an immediate basis [264].

\section{In vitro nanotoxicity assessment}

Inflammation, cytotoxicity, immunotoxicity, genotoxicity, carcinogenicity, and hematotoxicity are the frequently evaluated parameters through in vitro analysis, represented in Table 8 [265]. In vitro assays are mainly employed as they are less time-consuming and low budgeted. Cytotoxicity assessment of NPs is mainly carried out either by determining the presence of apoptotic/ necrotic cells using Annexin- $V$ assay and the proportion of apoptotic/necrotic cells by flow cytometry and cell viability using the most commonly used MTT assay. Moreover, the cell membrane integrity and cell morphology can be examined via lactate dehydrogenase (LDH) assay and phase-contrast microscopic evaluation, respectively $[262,265]$. Unfortunately, nano-DDS have been found to exhibit the interference with aforementioned toxicity assays along with excessive chances of false results [266]. Nanoparticles, specifically, lipid-based nanoDDS when administered via intravenous route face-off the body intrinsic defense system i.e. macrophages, and other components of RES. Certain opsonizing complement proteins mark the NPs which can easily be trapped by phagocytic cells. All these events eventually cause either the destruction of engineered NPs followed by reduced NPs build-up in targeted tissue or the activation of the body's immune response. Type-1 hypersensitivity response is a frequently encountered immune response associated with NPs [266-268]. This would lead to a lifethreatening anaphylactic shock. With all the discussion, it can be concluded that the immunological assessment of designed nano-DDS is a critical requirement. Inflammation can easily be assessed by quantifying the inflammatory markers such as TNF- $\alpha$, IL-6, IL-8, complement proteins, and glycoproteins like granulocyte macrophage-colony stimulating factor (GM-CSF) using the method referred to as Enzyme-linked immunosorbent assay (ELISA) [268, 269]. These pro-inflammatory indicators are also analyzed by their level assessment in human peripheral blood monocytes and lymphocytes [270]. Some nanomaterials are potentially damaging to genetic material as well. This type of toxicity is also concerning and should be routinely examined. Previously Ames assay was utilized, but due to the high incidence of false results mammalian cell, the micronuclear assay has replaced its employment [265, 271]. Furthermore, for NPs associated carcinogenicity detection, the colony transformation assay (CTA) is employing currently [272]. Nanomaterials used for infections and cancer also cause the production of ROS in normal cells. This could possibly lead to cell destruction and toxicity. Apart from erstwhile mention cytotoxic analysis, some other techniques are employed for evaluation of ROS genesis inclusively ferric reduction ability of serum (FRAS) assay, NO evaluation and the use of fluorescent or non-fluorescent markers i.e. dichloroflorescein [262, 273].

\section{In vivo toxicity assessment}

The biological organisms consist of a highly complex system and administered NPs could interact with various biological molecules. The in vivo animal models are the suitable option for NPs toxicity quantification in the biological system. For immunotoxicity, I.V. injection of fabricated nanosystem to the porcine model is most efficient. Thus, NPs with the potential to induce type-1 allergic response, predominantly LPS, are evaluated by this method [265]. In vivo rat's skin irritation test works on the same principle but utilized particularly for topically and transdermally administered nano-formulations [274, 275]. Carcinogenicity of NPs evaluations in laboratory animal models is, in fact, a standard test. However, due to high cost, excessive time consumption, and using plenty of animals, the previously mentioned in vitro experiments are currently being utilized [272]. Imaging 


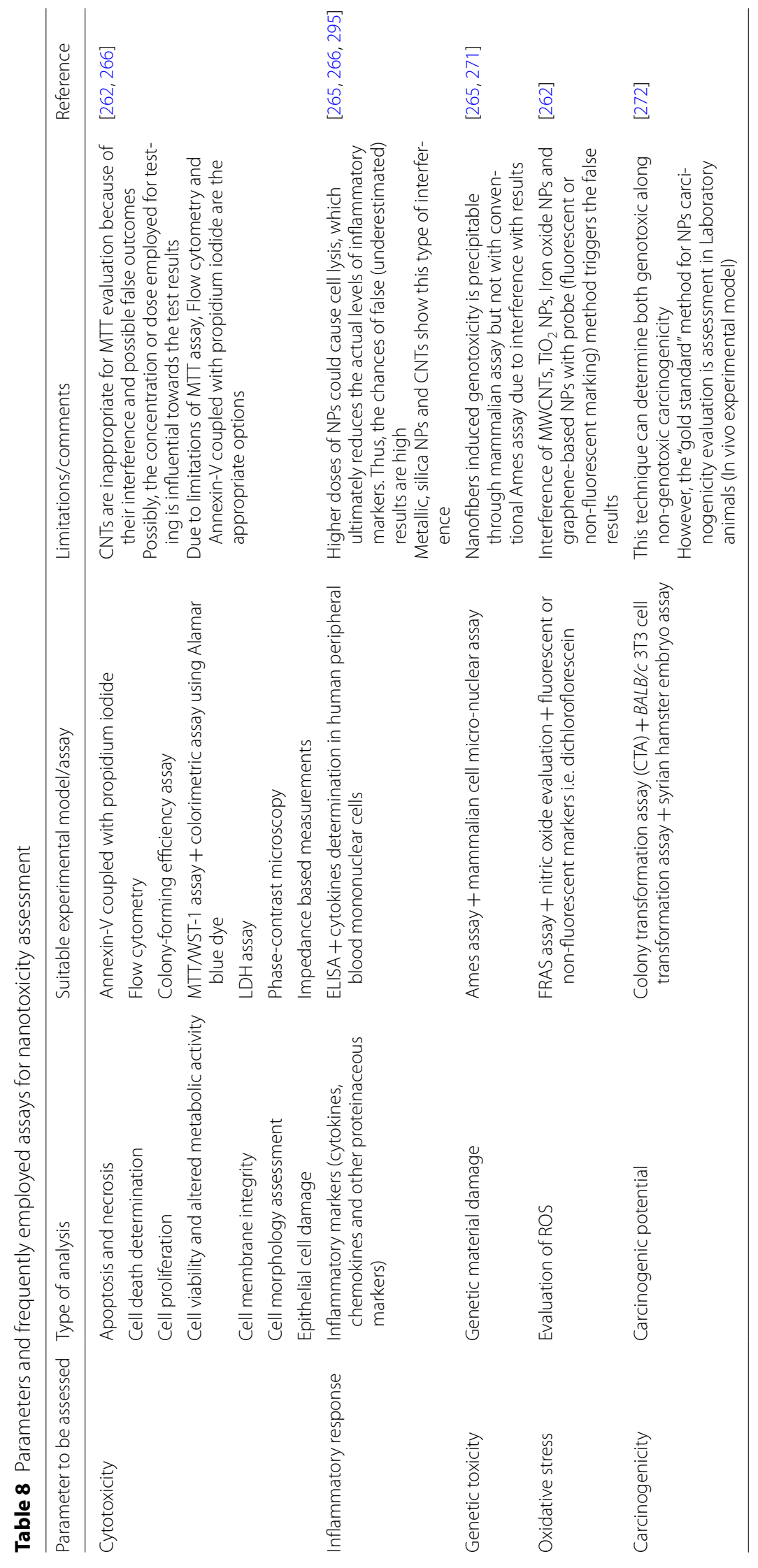


techniques like optical imaging, microscopy MRI [276], CT [277], and PET scanning, are also the suitable options for real-time monitoring of NPs fate and toxicity in vitro as well as in vivo $[278,279]$.

\section{Toxicity coupled with various nano-DDS}

With the expansion of nanomedicine, the knowledge about its harmful effects is also growing at a steady pace. LPS, the most widely used lipid nanomaterial is associated with a serious toxic effect-an anaphylactic shock. This incidence was considerably high with conventional LPS; however, the PEGylated LPS have reduced the chances [280, 281]. The damaging impact of SLNs over the biological system usually depends upon the ingredient i.e. the lipid and the surfactant, employed for their synthesis [282]. Furthermore, other nano-DDS utilizing surfactants are also considered to be toxic in nature [283]. Polymeric NPs, because of using biologically compatible and natural polymers, are considered to be safe, however, toxicity needs to be evaluated properly [284]. Metallic NPs also express some unwanted effects. They are often associated with cytotoxicity, particularly hepatotoxicity [285-288] and neurotoxicity [289, 290], due to the production of ROS, free radicals, mitochondrial damage, and cell death [291, 292]. Generally, the size of nano-DDS is, merely, a critical parameter that assesses the toxicity profile-the smaller the size, the more it will be toxic. Thus, the designed NPs must have a size in the adequate range. Similarly, Carbon nanotubes induced cytotoxicity has also gained attention for further investigations and explorations [293, 294]. The parallel emergence of nano-toxicology with nanotechnology is urging the pharmaceutical scientists and researchers to opt naturally and plant derived nanomaterials, aiming towards minimization of "synthetics" use.

\section{Economic burden - lack of cost-effectiveness}

Unfortunately, nano-formulations (nano-therapeutics, nano-diagnostics, and nano-vaccines) usually hold high research, testing, and manufacturing cost. By 2018, Europeans and American institutes have invested about $€ 430$ million and $\$ 445$ million, respectively for nanomedicine research. These economic constraints have made, the price posing of nano-formulation, a quite challenging task for pharmaceutical companies. Nano-formulations are, indeed, considerably high-priced than traditional dosage forms. There should be adequate cost-effectiveness analysis of nano-formulation, for the purpose to minimize this market hampering factor. Only by this way high selling prices of nano-products could be contained [296].

\section{Marketing and commercialization challenges}

Nanopharmaceuticals are difficult to scale up due to the complexity of ingredients and the manufacturing process. Approval and commercialization of nanopharmaceuticals are hindered by many parameters discussed in this paragraph. Despite the aptness of LPS, some shortcomings are also associated with these lipid-based nanocarriers. Leakage of the entrapped moiety, oxidation, hydrolysis, and inadequate stability are the drawbacks of liposomal nano-DDS [297]. Though SLNs have confronted the erstwhile stated stability enigma, but their employment has also been linked with several setbacks. Inadequate loading efficiency and expulsive release of the entrapped drug, during storage, owing to lipid phase transition are among them. NLCs were thus designed as a solution of SLNs associated negatives [282, 298, 299]. As far as polymeric NPs are concerned, they are inconvenient to scaleup [300]. The hurdles, related to these most commonly employed nano-DDS [260], can be encountered by further investigation and research as these are, perhaps, the hurdles for nanomedicine's market compliance. Generally, the dissimilar in vivo and in vitro behavior of nanoformulations is also a major contributory factor towards their compact market. Proper animal and biomedical testing facilities are required which are not easily achievable and non-cost effective. Some regulatory and ethical problems are also hindering the nanosystem's trackway towards commercialization. FDA and European medicines agency (EMA) have imposed un-necessary (sometimes) and excessive regulatory restrictions, ultimately, restraining the approval process. Globally, pharmaceutical industries are not much interested in this novel medical treatment approach. Research institutes and academia are majorly involved in nanomaterial research. However, due to poor academia-industry collaboration, limited testing facilities, and insufficient funding, very little by the way of nanosystem reach towards successful commercial utilization [301].

\section{Future perspective}

With advancements in nanotechnology and nanoDDS, the associated loopholes and nanotoxicity are demanding more scientific attention and need to be addressed. Mannosylated thiolated nano-formulations, through the evaluation of available literature, are found to be the most promising nano-DDS for Leishmaniasis. However, researchers and scientists should identify some newer metabolic and enzymatic targets-metacaspases, folate biosynthesis, protein kinases, etc., for parasitic curtailment [77]. Leish-111F is having efficacy issues in clinical trials and probably, by the utilization of nano-adjuvants (discussed in "Leishmanial nano-vaccines-an innovative approach 
towards immunization" section), its efficacy would be enhanced. Drug loaded phyto-nano-DDS could also be an appropriate option to tackle Leishmaniasis. After critically evaluating the research work related to antileishmanial nano-DDS, on preclinical grounds, several limitations have been identified. In numerous studies, in vivo anti-leishmanial assay was not performed. In addition, various nano-DDS research reports were not properly compared with standard anti-leishmanial therapies. It is worth mentioning that standard protocols for preclinical evaluation of nano-DDS should be designed in terms of species and strains of the animal to be employed, parasite species and strains, duration of the study, and reference standard by which the antileishmanial activity of nano-DDS can be determined comparatively. By employing these standard protocols uniformity, precision, and robustness of results can be achieved.

Multiple anti-leishmanial nano-DDS with promising results on pre-clinical grounds, must be step up for human clinical studies. According to NIH clinical trial repository, only L-Amp-B has been enrolled against VL, with a trial identifier ID of NCT02025491 and NCT00628719 [302, 303]. However, to improve treatment outcomes of CL, MA-LPS, PMC-LPS, and L-Amp-B have been enrolled in clinical trial (identifier number NCT01050777 and NCT02656797) [304, 305]. Though, there is a fall short of human studies for the evaluation of safety and efficacy of the anti-leishmanial nano-DDS. Probably, with significant academia and pharma industry collaboration, nanotechnologybased drug delivery of anti-leishmanials will eventually be studied in more detail, with a few of the promising candidates will get enrolled in clinical trials for the determination of their efficacy and safety in the human population. Antigenic protein delivery using nano-adjuvants will hopefully emerge some promising immunogenic candidates for immune-based protection against Leishmaniasis. Another important aspect, the cost-effective scaling up of nano-DDS, should require significant attention and improvement. Devising a global policy to provide cost-effective nano-DDS, is the only way to excel towards nanotechnology-based eradication strategies against Leishmaniasis. Nevertheless, approval of cost-effective anti-leishmanial nanoformulations could be speculated to make treatment more effective and shorter in duration. Alongside, total to partial extermination of this disease can be sought, along with associated co-morbidities.

\section{Concluding remarks}

Apart from anti-leishmanials, 28 nano-DDS have attained FDA/EMA approval to date [261, 306]. Extensive nanotechnology based research has carried out to rationalize Leishmaniasis management in all dimensions. Drug loaded nano-DDS have been found to curtail various challenges evidenced by in vitro and preclinical testing. In the last decade, far too many anti-leishmanial nano-DDS have been formulated and tested on animals for the claimed resolution of limiting factors. The most problematic issue encountered during Leishmaniasis treatment, inadequate intracellular accumulation of drug, can effectively improve by employing phosphatidylserine labeled and mannosylated nanoparticles which in turn have a positive impact on treatment prognosis in animal models. Their superiority over plain nanoparticles could clearly be evidenced by multiple studies. Leishmanial resistance, however, can be countered through thiolated nano-DDS, and co-loaded nano-DDS. Remolding conventional routes of administration could also be gained by using a nano-drug delivery-based approach. Similarly, NPs encapsulating the drug, on one hand, improve pharmacokinetics constraints of the drug and on the other hand minimize its exposure to un-infected body cells, thereby reducing drug toxicity. Emerging advancements in LPS and TFS delivery could be an efficient tool in targeting the cutaneous form of Leishmaniasis. With the identification of L-Amp-B resistant case, there is a need of the hour to work more aggressively over co-loaded and targeted nano-formulations for the purpose to prevent further resistance emergence, making the treatment more challenging. Particularly, due to lack of academia and pharmaceutical industry collaboration, very little efforts are so far done to launch the nano-DDS in the market. Phyto-nano-DDS are also gaining attention to curb Leishmaniasis because of their extra-safe nature. Vaccination for Leishmaniasis is under the process of development, and obstacles in the way of effective immunization are being tried to cope with using nanovaccines-using NPs for effective antigen delivery to APCs. In endemic regions, there should be required evaluating the effectiveness of nano-repellants and nano-insecticides in restricting the disease spread via vector control strategy. The discovery of new and more effective agents is deemed to be necessary because of certain reasons but, as mentioned erstwhile, drug discovery is a protracted bid to improve Leishmaniasis treatment and eradication. In addition, chemical and functional group manipulation of existing drugs also appear to possess the same restrictive parameters. Therefore, nanoscale-advancement in drug delivery is the most appropriate approach to attain desired goals. 
In a nutshell, nano-DDS based formulations, are the groundbreaking approach towards the anti-leishmanial therapeutic advancement and success.

\begin{abstract}
Abbreviations
ABC transporter: ATP-binding cassette transporter; AgNPs: Silver nanoparticles; Amp-B: Amphotericin-B; APC: Antigen presenting cells; ATP: Adenosine triphosphate; AUC: Area under curve; AuNPs: Gold nanoparticles; AuNPs: Gold NPs; BCS: Biopharmaceutics classification system; BSA: Bovine serum albumin; $\mathrm{CC}_{50}$ : Concentration to kill $50 \%$ of the cells (cytotoxic concentration); $\mathrm{CL}$ : Cutaneous Leishmaniasis; CLSM: Confocal laser scanning microscopy; $C_{\max }$ : Maximum concentration; CNTS: Carbon nanotubes; CTA: Colony transformation assay; CUR: Curcumin; DDA: Dimethyl-dioctadecyl ammonium; DDT: Dichloro-diphenyl-trichloroethane; DEET: Diethyl-toluamide; DEPA: Diethylphenyl acetamide; DPPC: Dipalmitoyl phosphatidylcholine; DSPC: 1,2-Distearoyl-sn-glycero-3-phosphocholine; $\mathrm{ED}_{50}$ : Median effective dose; ELISA: Enzyme-linked immunosorbent assay; EMA: European medicines agency; f-CNTs: Functionalized carbon nanotubes; FDA: Food and Drug Administration; FRAS: Ferric reduction ability of serum; FTIC: Fluorescein isothiocyanate; GIT: Gastrointestinal tract; GM-CSF: Granulocyte macrophage-colony stimulating factor; $I_{50}$ : Concentration to inhibit micro-organism growth by $50 \%$; IL-12: Interleukin-12; IL-6: Interleukin-6; IL-8: Interleukin-8; IMQ: Imiquimod; L-Amp-B: Liposomal amphotericin $\mathrm{B} ; \mathrm{LC}_{50}$ : Concentration to kill $50 \%$ of organisms; LDH: Lactate dehydrogenase; LDL: Low-density lipoproteins; LPS: Liposomes; MA: Meglumine Antimoniate; M-cells: Microfold cells of the intestine; MCL: Mucocutaneous Leishmaniasis; MFS: Miltefosine; MHC-I: Major histocompatibility complex-I; MHC-II: Major histocompatibility complex-II; MIC-: Minimum inhibitory concentration; MK-TFS: Miltefosine-ketoconazole co-loaded transfersomes; MSN: Mesoporous silica NPs; MTC: Mannosylated thiolated chitosan; MWCNTs: Multi-walled carbon NPs; Nano-DDS: Nano drug delivery system; NLCs: Nanostructured lipid carriers; NPs: Nanoparticles; PC: Phosphatidylcholine; PCL: Poly-caprolactone; PEG: Polyethylene glycol; PET: Positron emission tomography; P-gp: P-glycoprotein; PLGA: Poly-lacto-glycolic acid; PMC: Paromomycin; PMMA: Polymethyl methacrylate; PMQ: Primaquine; PMT: Permethrin; PRP-1: Pentamidine resistant protein-1; PTM: Pentamidine; QSAR: Quantitative structure-activity relationship; RES: Reticuloendothelial system; RMQ: Resiquimod; ROS: Reactive oxygen moieties; SA: Stearylamine; SC: Stratum corneum; SLA: Soluble leishmanial antigen; SR: Scavenger receptor; SSG: Sodium Stibogluconate; TDB: Trehalose-6,6-dibehenate; TFS: Transferosomes; Th-1: T-helper cells $1 ; \mathrm{TiO}_{2}$ : Titanium oxide NPs; TNF-a: Tissue necrosis factor-a; TR-system: Trypanothione reductase system; USD: United States dollar; VL: Visceral Leishmaniasis; WHO: World Health Organization; ZnO-NPs: Zinc oxide NPs.
\end{abstract}

\section{Acknowledgements}

The authors are very thankful to the Higher Education Commission (HEC) Pakistan for their consistent support and encouragement. Some of the figures are designed using BioRender.

\section{Authors' contributions}

FUD and GMK conceive the idea. HJ did the literature review and wrote the first draft of the manuscript. FUD critically reviewed the manuscript. GMK and FUD approved the manuscript for submission. All authors read and approved the final manuscript.

\section{Funding}

This work was partially supported by HEC, Pakistan through a Grant Number 6171/Federal/NRPU/R\&D/HEC/2016.

\section{Availability of data and materials}

Not applicable.

\section{Declarations}

Ethics approval and consent to participate

Not applicable.
Consent for publication

Not applicable.

\section{Competing interests}

The authors declare no competing interests.

\section{Author details}

${ }^{1}$ Nanomedicine Research Group, Department of Pharmacy, Quaid-I-Azam University, Islamabad 45320, Pakistan. ${ }^{2}$ Islamia College University, Peshawar, Khyber Pakhtunkhwa, Pakistan.

Received: 17 December 2020 Accepted: 7 April 2021

Published online: 15 April 2021

\section{References}

1. Pace D. Leishmaniasis. J Infect. 2014;69:S10-8. https://doi.org/10.1016/j. jinf.2014.07.016.

2. Burza S, Croft SL, Boelaert M. Leishmaniasis. Lancet. 2018. https://doi. org/10.1016/S0140-6736(18)31204-2.

3. Organization, WH, Leishmaniasis; 2020. https://www.who.int/newsroom/fact-sheets/detail/leishmaniasis. Accessed 8 Dec 2020.

4. Alvar J, Vélez ID, Bern C, Herrero M, Desjeux P, Cano J, Jannin J, den Boer M, Team WHOLC. Leishmaniasis worldwide and global estimates of its incidence. PLoS ONE. 2012;7:e35671. https://doi.org/10.1371/journal. pone.0035671.

5. Singh OP, Singh B, Chakravarty J, Sundar S. Current challenges in treatment options for visceral leishmaniasis in India: a public health perspective. Infect Dis Poverty. 2016;5:1-15. https://doi.org/10.1186/ s40249-016-0112-2.

6. Inceboz T. Epidemiology and ecology of leishmaniasis, in current topics in neglected tropical diseases. Rijeka: IntechOpen; 2019.

7. Georgiadou SP, Makaritsis KP, Dalekos GN. Leishmaniasis revisited: current aspects on epidemiology, diagnosis and treatment. J Transl Internal Med. 2015;3:43-50. https://doi.org/10.1515/jtim-2015-0002.

8. Gebremichael Tedla D, Bariagabr FH, Abreha HH. Incidence and trends of leishmaniasis and its risk factors in Humera, Western Tigray. J Parasitol Res. 2018. https://doi.org/10.1155/2018/8463097.

9. Alawieh A, Musharrafieh U, Jaber A, Berry A, Ghosn N, Bizri AR. Revisiting leishmaniasis in the time of war: the Syrian conflict and the Lebanese outbreak. Int J Infect Dis. 2014;29:115-9. https://doi.org/10.1016/j.ijid. 2014.04.023.

10. Okwor I, Uzonna J. Social and economic burden of human leishmaniasis. Am J Trop Med Hyg. 2016;94:489-93. https://doi.org/10.4269/ajtmh. 15-0408.

11. Wijerathna T, Gunathilaka N, Gunawardena K. The economic impact of cutaneous leishmaniasis in Sri Lanka. BioMed Res Int. 2018. https://doi. org/10.1155/2018/3025185

12. Zijlstra EE. Visceral leishmaniasis: a forgotten epidemic. Arch Dis Child. 2016;101:561-7. https://doi.org/10.1136/archdischild-2015-309302.

13. de Vries HJC, Reedijk SH, Schallig HDFH. Cutaneous leishmaniasis: recent developments in diagnosis and management. Am J Clin Dermatol. 2015;16:99-109. https://doi.org/10.1007/s40257-015-0114-z.

14. Gálvez R, Descalzo MA, Miró G, Jiménez MI, Martín O, Dos SantosBrandao F, Guerrero I, Cubero E, Molina R. Seasonal trends and spatial relations between environmental/meteorological factors and leishmaniosis sand fly vector abundances in Central Spain. Acta Trop. 2010;115:95-102. https://doi.org/10.1016/j.actatropica.2010.02.009.

15. Yangzom T, Cruz I, Bern C, Argaw D, den Boer M, Vélez ID, Bhattacharya SK, Molina R, Alvar J. Endemic transmission of visceral leishmaniasis in Bhutan. Am J Trop Med Hyg. 2012;87:1028-37.

16. Saha P, Ganguly S, Chatterjee M, Das SB, Kundu PK, Guha SK, Ghosh TK, Bera DK, Basu N, Maji AK. Asymptomatic leishmaniasis in kala-azar endemic areas of Malda district, West Benga, India. PLoS Negl Trop Dis. 2017;11:e0005391. https://doi.org/10.1371/journal.pntd.0005391.

17. Ostyn B, Uranw S, Bhattarai NR, Das ML, Rai K, Tersago K, Pokhrel Y, Durnez L, Marasini B, Van der Auwera G. Transmission of Leishmania donovani in the hills of Eastern Nepal, an outbreak investigation in Okhaldhunga and Bhojpur districts. PLoS Negl Trop Dis. 2015;9:e0003966. https://doi.org/10.1371/journal.pntd.0003966. 
18. Reithinger R, Dujardin J-C, Louzir H, Pirmez C, Alexander B, Brooker S. Cutaneous leishmaniasis. Lancet Infect Dis. 2007;7:581-96. https://doi. org/10.1016/S1473-3099(07)70209-8.

19. Harhay MO, Olliaro PL, Vaillant M, Chappuis F, Lima MA, Ritmeijer K, Costa $\mathrm{CH}$, Costa DL, Rijal S, Sundar S. Who is a typical patient with visceral leishmaniasis? Characterizing the demographic and nutritional profile of patients in Brazil, East Africa, and South Asia. Am J Trop Med Hyg. 2011;84:543-50. https://doi.org/10.4269/ajtmh.2011.10-0321.

20. Elkhair EB. Elevated cortisol level due to visceral leishmaniasis and skin hyper-pigmentation are causally related. Int J Sci Commer Humanit. 2014;2:7.

21. Aoun K, Kalboussi Y, Sghaier IB, Souissi O, Hammami H, Bellali H, Bouratbine A. Assessment of incubation period of cutaneous leishmaniasis due to Leishmania major in Tunisia. Am J Trop Med Hyg. 2020;103:19347. https://doi.org/10.4269/ajtmh.20-0439.

22. Ready PD. Epidemiology of visceral Leishmaniasis. Clin Epidemiol. 2016;2014:147-54. https://doi.org/10.2147/CLEP.S44267.

23. Bennis I, Thys S, Filali H, De Brouwere V, Sahibi H, Boelaert M. Psychosocial impact of scars due to cutaneous leishmaniasis on high school students in Errachidia province. Morocco Infect Dis Poverty. 2017;6:46. https://doi.org/10.1186/s40249-017-0267-5.

24. Espinoza-Morales D, Rodríguez AL, Silva-Caso W, Suarez-Ognio L, Pons MJ, del Valle Mendoza J. An atypical case of disseminated cutaneous leishmaniasis due to Leishmania peruviana in the valleys of AncashPeru. Asian Pac J Trop Med. 2017;10:1101-3. https://doi.org/10.1016/j. apjtm.2017.10.001.

25. Ramot Y, Zlotogorski A. Multilesional cutaneous leishmaniasis. CMAJ. 2016;188:1034-134. https://doi.org/10.1503/cmaj.151115.

26. Fikre H, Mohammed R, Atinafu S, van Griensven J, Diro E. Clinical features and treatment response of cutaneous leishmaniasis in North-West Ethiopia. Trop Med Int Health. 2017;22:1293-301. https://doi.org/10. 1111/tmi.12928.

27. Van Griensven J, Carrillo E, López-Vélez R, Lynen L, Moreno J. Leishmaniasis in immunosuppressed individuals. Clin Microbiol Infect. 2014;20:286-99. https://doi.org/10.1111/1469-0691.12556.

28. Zijlstra EE. PKDL and other dermal lesions in HIV co-infected patients with leishmaniasis: review of clinical presentation in relation to immune responses. PLoS Negl Trop Dis. 2014;8:e3258. https://doi.org/10.1371/ journal.pntd.0003258.

29. David CV, Craft N. Cutaneous and mucocutaneous leishmaniasis. Dermatol Ther. 2009;22:491-502. https://doi.org/10.1111/j.1529-8019.2009. 01272.x.

30. Moafi M, Rezvan H, Sherkat R, Taleban R. Leishmania vaccines entered in clinical trials: a review of literature. Int J Prev Med. 2019. https://doi. org/10.4103/ijpvm.IJPVM_116_18.

31. Yasinzai M, Khan M, Nadhman A, Shahnaz G. Drug resistance in leishmaniasis: current drug-delivery systems and future perspectives. Future Med Chem. 2013;5:1877-88. https://doi.org/10.4155/fmc.13.143.

32. Shahnaz G, Sarwar HS, Yasinzai M. Crossing biological barriers for leishmaniasis therapy: from nanomedicinal targeting perspective. Leishmaniases as Re-emerging Dis. 2018. https://doi.org/10.5772/intec hopen.75911.

33. Srivastava P, Prajapati VK, Rai M, Sundar S. Unusual case of resistance to amphotericin B in visceral leishmaniasis in a region in India where leishmaniasis is not endemic. J Clin Microbiol. 2011;49:3088-91. https:// doi.org/10.1128/JCM.00173-1.

34. Monge-Maillo B, López-Vélez R. Miltefosine for visceral and cutaneous leishmaniasis: drug characteristics and evidence-based treatment recommendations. Clin Infect Dis. 2015;60:1398-404. https://doi.org/10. 1093/cid/civ004.

35. Srivastava S, Mishra J, Gupta AK, Singh A, Shankar P, Singh S. Laboratory confirmed miltefosine resistant cases of visceral leishmaniasis from India. Parasites Vectors. 2017;10:1-11. https://doi.org/10.1186/ s13071-017-1969-z.

36. Manzano Jl, García-Hernández R, Castanys S, Gamarro F. A new ABC half-transporter in Leishmania major is involved in resistance to antimony. Antimicrob Agents Chemother. 2013;57:3719-30. https://doi. org/10.1128/AAC.00211-13.

37. Sundar S, Goyal N. Molecular mechanisms of antimony resistance in Leishmania. J Med Microbiol. 2007;56:143-53. https://doi.org/10.1099/ jmm.0.46841-0.
38. Jhingran A, Chawla B, Saxena S, Barrett MP, Madhubala R. Paromomycin: uptake and resistance in Leishmania donovani. Mol Biochem Parasitol. 2009;164:111-7. https://doi.org/10.1016/j.molbiopara.2008.12.007.

39. Layegh P, Khademi Z, Afzal Aghaee M, Moghiman T. Systemic meglumine antimoniate in cutaneous leishmaniasis of children: clinical and laboratory complications. J Pediatr Infect Dis Soc. 2015;4:356-8. https:// doi.org/10.1093/jpids/piu021.

40. Aronson N, Herwaldt BL, Libman M, Pearson R, Lopez-Velez R, Weina P, Carvalho EM, Ephros M, Jeronimo S, Magill A. Diagnosis and treatment of leishmaniasis: clinical practice guidelines by the Infectious Diseases Society of America (IDSA) and the American Society of Tropical Medicine and Hygiene (ASTMH). Clin Infect Dis. 2016;63:e202-64. https://doi. org/10.1093/cid/ciw742.

41. Nieto J, Alvar J, Mullen AB, Carter KC, Rodríguez C, San Andrés MI, San Andrés MD, Baillie AJ, González F. Pharmacokinetics, toxicities, and efficacies of sodium stibogluconate formulations after intravenous administration in animals. Antimicrob Agents Chemother. 2003;47:2781-7. https://doi.org/10.1128/AAC.47.9.2781-2787.2003.

42. Laniado-Laborín R, Cabrales-Vargas MN. Amphotericin B: side effects and toxicity. Rev Iberoam Micol. 2009;26:223-7. https://doi.org/10. 1016/j.riam.2009.06.003.

43. O'Brien JG, Dong BJ, Coleman RL, Gee L, Balano KB. A 5-year retrospective review of adverse drug reactions and their risk factors in human immunodeficiency virus - infected patients who were receiving intravenous pentamidine therapy for Pneumocystis carinii pneumonia. Clin Infect Dis. 1997;24:854-9. https://doi.org/10.1093/clinids/24.5.854.

44. Omarch G, Kippie Y, Mentor S, Ebrahim N, Fisher D, Murilla G, Swai H, Dube A. Comparative in vitro transportation of pentamidine across the blood-brain barrier using polycaprolactone nanoparticles and phosphatidylcholine liposomes. Artif Cells Nanomed Biotechnol. 2019:47:1428-36. https://doi.org/10.1080/21691401.2019.1596923.

45. Soto J, Toledo J, Gutierrez P, Nicholls RS, Padilla J, Engel J, Fischer C, Voss A, Berman J. Treatment of American cutaneous leishmaniasis with miltefosine, an oral agent. Clin Infect Dis. 2001;33:e57-61. https://doi. org/10.1086/322689.

46. Sundar S, Jha TK, Thakur CP, Bhattacharya SK, Rai M. Oral miltefosine for the treatment of Indian visceral leishmaniasis. Trans R Soc Trop Med Hyg. 2006;100:S26-33. https://doi.org/10.1056/NEJMoa021556.

47. Dorlo TPC, Balasegaram M, Beijnen JH, de Vries PJ. Miltefosine: a review of its pharmacology and therapeutic efficacy in the treatment of leishmaniasis. J Antimicrob Chemother. 2012;67:2576-97. https://doi.org/10. 1093/jac/dks275.

48. Jha TK, Sundar S, Thakur CP, Bachmann P, Karbwang J, Fischer C, Voss A, Berman J. Miltefosine, an oral agent, for the treatment of Indian visceral leishmaniasis. N Engl J Med. 1999;341:1795-800. https://doi.org/10. 1056/NEJM199912093412403.

49. da Gama Bitencourt JJ, Pazin WM, Ito AS, Barioni MB, de Paula Pinto C, dos Santos MA, Guimarães THS, dos Santos MRM, Valduga CJ. Miltefosine-loaded lipid nanoparticles: Improving miltefosine stability and reducing its hemolytic potential toward erythtocytes and its cytotoxic effect on macrophages. Biophys Chem. 2016;217:20-31. https:// doi.org/10.1016/j.bpc.2016.07.005.

50. Italia JL, Yahya MM, Singh D, Kumar MNVR. Biodegradable nanoparticles improve oral bioavailability of amphotericin $B$ and show reduced nephrotoxicity compared to intravenous Fungizone ${ }^{\circledR}$. Pharm Res. 2009;26:1324-31. https://doi.org/10.1007/s11095-009-9841-2.

51. Yang Z, Tan Y, Chen M, Dian L, Shan Z, Peng X, Wu C. Development of amphotericin B-loaded cubosomes through the SolEmuls technology for enhancing the oral bioavailability. AAPS PharmSciTech. 2012;13:1483-91. https://doi.org/10.1208/s12249-012-9876-2.

52. Kip AE, Schellens JHM, Beijnen JH, Dorlo TPC. Clinical pharmacokinetics of systemically administered antileishmanial drugs. Clin Pharmacokinet. 2018;57:151-76. https://doi.org/10.1007/s40262-017-0570-0.

53. Kotthaus J, Kotthaus J, Schade D, Schwering U, Hungeling H, MüllerFielitz H, Raasch W, Clement B. New prodrugs of the antiprotozoal drug pentamidine. ChemMedChem. 2011;6:2233-42. https://doi.org/10. 1002/cmdc.201100422.

54. Wiwanitkit $\mathrm{V}$. Interest in paromomycin for the treatment of visceral leishmaniasis (kala-azar). Ther Clin Risk Manag. 2012;8:323. https://doi. org/10.2147/TCRM.S30139.

55. Tran TNT. Cutaneous drug delivery: an update; 2013. 1. Accessed. 
56. Seeberger J, Daoud S, Pammer J. Transient effect of topical treatment of cutaneous leishmaniasis with imiquimod. Int J Dermatol. 2003;42:5769. https://doi.org/10.1046/j.1365-4362.2003.01955.x.

57. Srivastava S, Shankar P, Mishra J, Singh S. Possibilities and challenges for developing a successful vaccine for leishmaniasis. Parasit Vectors. 2016;9:277.

58. Modabber F. Leishmaniasis vaccines: past, present and future. Int J Antimicrob Agents. 2010;36:S58-61. https://doi.org/10.1016/j.ijantimicag. 2010.06.024.

59. Mohs RC, Greig NH. Drug discovery and development: role of basic biological research. Alzheimer's Dementia Transl Res Clin Intervent. 2017;3:651-7. https://doi.org/10.1016/j.trci.2017.10.005.

60. Varela-M RE, Villa-Pulgarin JA, Yepes E, Müller I, Modolell M, Munoz DL, Robledo SM, Muskus CE, Lopez-Aban J, Muro A. In vitro and in vivo efficacy of ether lipid edelfosine against Leishmania spp. and SbV-resistant parasites. PLoS NegI Trop Dis. 2012;6:e1612. https://doi.org/10.1371/ journal.pntd.0001612.

61. Villa-Pulgarín JA, Gajate C, Botet J, Jimenez A, Justies N, Varela-M RE, Cuesta-Marbán Á, Müller I, Modolell M, Revuelta JL. Mitochondria and lipid raft-located FOF1-ATP synthase as major therapeutic targets in the antileishmanial and anticancer activities of ether lipid edelfosine. PLoS Negl Trop Dis. 2017;11:e0005805. https://doi.org/10.1371/journal.pntd. 0005805.

62. Antwi CA, Amisigo CM, Adjimani JP, Gwira TM. In vitro activity and mode of action of phenolic compounds on Leishmania donovani. PLoS Negl Trop Dis. 2019;13:e0007206. https://doi.org/10.1371/journal.pntd. 0007206.

63. Reimão JQ, Mesquita JT, Ferreira DD, Tempone AG. Investigation of calcium channel blockers as antiprotozoal agents and their interference in the metabolism of Leishmania (L.) infantum. Evid Based Complement Altern Med. 2016. https://doi.org/10.1155/2016/1523691.

64. El Hajj R, Bou Youness H, Lachaud L, Bastien P, Masquefa C, Bonnet P-A, El Hajj H, Khalifeh I. EAPB0503: An Imiquimod analog with potent in vitro activity against cutaneous leishmaniasis caused by Leishmania major and Leishmania tropica. PLoS Negl Trop Dis. 2018;12:e0006854. https://doi.org/10.1371/journal.pntd.0006854.

65. Kramp KL, DeWitt K, Flora JW, Muddiman DC, Slunt KM, Houston TA. Derivatives of pentamidine designed to target the Leishmania lipophosphoglycan. Tetrahedron Lett. 2005;46:695-8. https://doi.org/10.1016/j. tetlet.2004.11.112

66. Kato KC, de Morais-Teixeira E, Islam A, Leite MF, Demicheli C, de Castro WV, Corrêa-Junior JD, Rabello A, Frézard F. Efficacy of meglumine antimoniate in a low polymerization state orally administered in a murine model of visceral leishmaniasis. Antimicrob Agents Chemother. 2018;62:e00539-e618. https://doi.org/10.1128/AAC.00539-18.

67. Vale-Costa S, Vale N, Matos J, Tomás A, Moreira R, Gomes P, Gomes MS. Peptidomimetic and organometallic derivatives of primaquine active against Leishmania infantum. Antimicrob Agents Chemother. 2012;56:5774-81. https://doi.org/10.1128/AAC.00873-12.

68. Caster JM, Patel AN, Zhang T, Wang A. Investigational nanomedicines in 2016: a review of nanotherapeutics currently undergoing clinical trials. Wiley Interdiscip Rev Nanomed Nanobiotechnol. 2017;9:e1416. https:// doi.org/10.1002/wnan 1416

69. Mir M, Ishtiaq S, Rabia S, Khatoon M, Zeb A, Khan GM, Ur Rehman A, Ud Din F. Nanotechnology: from in vivo imaging system to controlled drug delivery. Nanoscale Res Lett. 2017;12:500. https://doi.org/10.1186/ s11671-017-2249-8.

70. ud Din F, Kim DW, Choi JY, Thapa RK, Mustapha O, Kim DS, Oh Y-K, Ku SK, Youn YS, Oh KT. Irinotecan-loaded double-reversible thermogel with improved antitumor efficacy without initial burst effect and toxicity for intramuscular administration. Acta Biomater. 2017;54:239-48. https:// doi.org/10.1016/j.actbio.2017.03.007.

71. Rizvi SZH, Shah FA, Khan N, Muhammad I, Ali KH, Ansari MM, ud Din F, Qureshi OS, Kim K-W, Choe Y-H. Simvastatin-loaded solid lipid nanoparticles for enhanced anti-hyperlipidemic activity in hyperlipidemia animal model. Int J Pharm. 2019;560:136-43. https://doi.org/10.1016/j. ijpharm.2019.02.002.

72. Ud Din F, Aman W, Ullah I, Qureshi OS, Mustapha O, Shafique S, Zeb A. Effective use of nanocarriers as drug delivery systems for the treatment of selected tumors. Int J Nanomed. 2017;12:7291. https://doi.org/10. 2147/IJN.S146315.
73. De Almeida L, Fujimura AT, Cistia MLD, Fonseca-Santos B, Imamura KB, Michels PAM, Chorilli M, Graminha MAS. Nanotechnological strategies for treatment of leishmaniasis - a review. J Biomed Nanotechnol. 2017;13:117-33. https://doi.org/10.1166/jbn.2017.2349.

74. Ventola CL. Progress in nanomedicine: approved and investigational nanodrugs. Pharm Ther. 2017:42:742.

75. Akbari M, Oryan A, Hatam G. Application of nanotechnology in treatment of leishmaniasis: a review. Acta Trop. 2017;172:86-90. https://doi. org/10.1016/j.actatropica.2017.04.029.

76. Gheibi Hayat SM, Darroudi M. Nanovaccine: a novel approach in immunization. J Cell Physiol. 2019;234:12530-6. https://doi.org/10.1002/jcp. 28120.

77. Singh OP, Gedda MR, Mudavath SL, Srivastava ON, Sundar S. Envisioning the innovations in nanomedicine to combat visceral leishmaniasis: for future theranostic application. Nanomedicine. 2019;14:1911-27. https://doi.org/10.2217/nnm-2018-0448.

78. Campos EVR, de Oliveira JL, Abrantes DC, Rogério CB, Bueno C, Miranda VR, Monteiro RA, Fraceto LF. Recent developments in nanotechnology for detection and control of Aedes aegypti-borne diseases. Front Bioeng Biotechnol. 2020;8:102. https://doi.org/10.3389/fbioe.2020.00102.

79. Patra JK, Das G, Fraceto LF, Campos EVR, del Pilar Rodriguez-Torres M, Acosta-Torres LS, Diaz-Torres LA, Grillo R, Swamy MK, Sharma S. Nano based drug delivery systems: recent developments and future prospects. J Nanobiotechnol. 2018;16:71. https://doi.org/10.1186/ s12951-018-0392-8.

80. Akbarzadeh A, Rezaei-Sadabady R, Davaran S, Joo SW, Zarghami N, Hanifehpour Y, Samiei M, Kouhi M, Nejati-Koshki K. Liposome: classification, preparation, and applications. Nanoscale Res Lett. 2013;8:102. https:// doi.org/10.1186/1556-276X-8-102.

81. Qie Y, Yuan H, Von Roemeling CA, Chen Y, Liu X, Shih KD, Knight JA, Tun $H W$, Wharen RE, Jiang W. Surface modification of nanoparticles enables selective evasion of phagocytic clearance by distinct macrophage phenotypes. Sci Rep. 2016;6:1-11. https://doi.org/10.1038/srep26269.

82. Rana I, Khan N, Ansari MM, Shah FA, ud Din F, Sarwar S, Imran M, Qureshi OS, Choi H-I, Lee C-H. Solid lipid nanoparticles-mediated enhanced antidepressant activity of duloxetine in lipopolysaccharide-induced depressive model. Colloids Surf B Biointerfaces. 2020;194:111209. https://doi.org/10.1016/..colsurfb.2020.111209.

83. ud Din F, Zeb A, Shah KU. Development, in-vitro and in-vivo evaluation of ezetimibe-loaded solid lipid nanoparticles and their comparison with marketed produAct. J Drug Deliv Sci Technol. 2019;51:583-90. https://doi.org/10.1016/j.jddst.2019.02.026.

84. ud Din F, Mustapha O, Kim DW, Rashid R, Park JH, Choi JY, Ku SK, Yong CS, Kim JO, Choi H-G. Novel dual-reverse thermosensitive solid lipid nanoparticle-loaded hydrogel for rectal administration of flurbiprofen with improved bioavailability and reduced initial burst effect. Eur J Pharm Biopharm. 2015;94:64-72. https://doi.org/10.1016/j.ejpb.2015.04. 019.

85. Ramalingam P, Ko YT. Enhanced oral delivery of curcumin from N-trimethyl chitosan surface-modified solid lipid nanoparticles: pharmacokinetic and brain distribution evaluations. Pharm Res. 2015;32:389-402. https://doi.org/10.1007/s11095-014-1469-1.

86. Beloqui A, Solinís MA, Rodríguez-Gascón A, Almeida AJ, Préat V. Nanostructured lipid carriers: promising drug delivery systems for future clinics. Nanomed Nanotechnol Biol Med. 2016;12:143-61. https://doi. org/10.1016/j.nano.2015.09.004.

87. Fernández-García R, Lalatsa A, Statts L, Bolás-Fernández F, Ballesteros MP, Serrano DR. Transferosomes as nanocarriers for drugs across the skin: quality by design from lab to industrial scale. Int J Pharm. 2020;573:118817. https://doi.org/10.1016/j.ijpharm.2019.118817.

88. Duangjit S, Obata Y, Sano H, Onuki Y, Opanasopit P, Ngawhirunpat T, Miyoshi T, Kato S, Takayama K. Comparative study of novel ultradeformable liposomes: menthosomes, transfersomes and liposomes for enhancing skin permeation of meloxicam. Biol Pharm Bull. 2014. https://doi.org/10.1248/bpb.b13-00576.

89. Marwah H, Garg T, Rath G, Goyal AK. Development of transferosomal gel for trans-dermal delivery of insulin using iodine complex. Drug Deliv. 2016;23:1636-44. https://doi.org/10.3109/10717544.2016.11552 43.

90. Durán V, Yasar H, Becker J, Thiyagarajan D, Loretz B, Kalinke U, Lehr C-M. Preferential uptake of chitosan-coated PLGA nanoparticles by primary 
human antigen presenting cells. Nanomed Nanotechnol Biol Med. 2019;21:102073. https://doi.org/10.1016/j.nano.2019.102073.

91. Makadia HK, Siegel SJ. Poly lactic-co-glycolic acid (PLGA) as biodegradable controlled drug delivery carrier. Polymers. 2011;3:1377-97. https:// doi.org/10.3390/polym3031377.

92. Sabir F, Asad MI, Qindeel M, Afzal I, Dar MJ, Shah KU, Zeb A, Khan GM, Ahmed N, Din F-U. Polymeric nanogels as versatile nanoplatforms for biomedical applications. J Nanomater. 2019. https://doi.org/10.1155/ 2019/1526186.

93. Jose S, Sowmya S, Cinu TA, Aleykutty NA, Thomas S, Souto EB. Surface modified PLGA nanoparticles for brain targeting of Bacoside-A. Eur J Pharm Sci. 2014;63:29-35. https://doi.org/10.1016/j.ejps.2014.06.024.

94. Kumari A, Yadav SK, Yadav SC. Biodegradable polymeric nanoparticles based drug delivery systems. Colloids Surf B. 2010;75:1-18. https://doi. org/10.1016/j.colsurfb.2009.09.001

95. Zanetti M, Mazon LR, de Meneses AC, Silva LL, de Araújo PHH, Fiori MA, de Oliveira D. Encapsulation of geranyl cinnamate in polycaprolactone nanoparticles. Mater Sci Eng C. 2019;97:198-207. https://doi.org/10. 1016/j.msec.2018.12.005.

96. Shukla SK, Mishra AK, Arotiba OA, Mamba BB. Chitosan-based nanomaterials: a state-of-the-art review. Int J Biol Macromol. 2013;59:46-58. https://doi.org/10.1016/j.ijbiomac.2013.04.043.

97. Jin SG, Choi H-G. Particle and gel characterization of irinotecan-loaded double-reverse thermosensitive hydrogel. Polymers. 2021;13:551. https://doi.org/10.3390/polym13040551.

98. Li Z, Barnes JC, Bosoy A, Stoddart JF, Zink Jl. Mesoporous silica nanoparticles in biomedical applications. Chem Soc Rev. 2012;41:2590-605. https://doi.org/10.1039/c1cs15246g.

99. He H, Pham-Huy LA, Dramou P, Xiao D, Zuo P, Pham-Huy C. Carbon nanotubes: applications in pharmacy and medicine. BioMed Res Int. 2013. https://doi.org/10.1155/2013/578290.

100. Mohning MP, Thomas SM, Barthel L, Mould KJ, McCubbrey AL, Frasch SC, Bratton DL, Henson PM, Janssen WJ. Phagocytosis of microparticles by alveolar macrophages during acute lung injury requires MerTK. Am J Physiol Lung Cell Mol Physiol. 2018;314:L69-82. https://doi.org/10. 1152/ajplung.00058.2017.

101. Khan N, Shah FA, Rana I, Ansari MM, Ud Din F, Rizvi SZH, Aman W, Lee G-Y, Lee E-S, Kim J-K. Nanostructured lipid carriers-mediated brain delivery of carbamazepine for improved in vivo anticonvulsant and anxiolytic activity. Int J Pharm. 2020;577:1 19033. https://doi.org/10. 1016/j.jpharm.2020.119033.

102. Panariti A, Miserocchi G, Rivolta I. The effect of nanoparticle uptake on cellular behavior: disrupting or enabling functions? Nanotechnol Sci Appl. 2012;5:87. https://doi.org/10.2147/NSA.S25515.

103. Foroozandeh P, Aziz AA. Insight into cellular uptake and intracellular trafficking of nanoparticles. Nanoscale Res Lett. 2018;13:339. https://doi. org/10.1186/s11671-018-2728-6.

104. Behzadi S, Serpooshan V, Tao W, Hamaly MA, Alkawareek MY, Dreaden EC, Brown D, Alkilany AM, Farokhzad OC, Mahmoudi M. Cellular uptake of nanoparticles: journey inside the cell. Chem Soc Rev. 2017;46:421844. https://doi.org/10.1039/C6CS00636A.

105. McMahon HT, Boucrot E. Molecular mechanism and physiological functions of clathrin-mediated endocytosis. Nat Rev Mol Cell Biol. 2011;12:517. https://doi.org/10.1038/nrm3151.

106. Kim JH, Singh A, Del Poeta M, Brown DA, London E. The effect of sterol structure upon clathrin-mediated and clathrin-independent endocytosis. J Cell Sci. 2017;130:2682-95. https://doi.org/10.1242/jcs.201731.

107. Goldstein JL, Brown MS. Progress in understanding the LDL receptor and $\mathrm{HMG}-\mathrm{Co}$ A reductase, two membrane proteins that regulate the plasma cholesterol. J Lipid Res. 1984;25:1450-61.

108. Cocucci E, Aguet F, Boulant S, Kirchhausen T. The first five seconds in the life of a clathrin-coated pit. Cell. 2012;150:495-507. https://doi.org/ 10.1016/j.cell.2012.05.047.

109. Sahay G, Alakhova DY, Kabanov AV. Endocytosis of nanomedicines. Control Release. 2010;145:182-95. https://doi.org/10.1016/j.jconrel. 2010.01.036.

110. Rivolta I, Panariti A, Lettiero B, Sesana S, Gasco P, Gasco MR, Masserini M, Miserocchi G. Cellular uptake of coumarin-6 as a model drug loaded in solid lipid nanoparticles. J Physiol Pharmacol. 2011;62:45.
111. Wang Z, Tiruppathi C, Minshall RD, Malik AB. Size and dynamics of caveolae studied using nanoparticles in living endothelial cells. ACS Nano. 2009;3:4110-6. https://doi.org/10.1021/nn9012274.

112. Pelkmans L, Kartenbeck J, Helenius A. Caveolar endocytosis of simian virus 40 reveals a new two-step vesicular-transport pathway to the ER. Nat Cell Biol. 2001;3:473-83. https://doi.org/10.1038/35074539.

113. Kou L, Sun J, Zhai Y, He Z. The endocytosis and intracellular fate of nanomedicines: implication for rational design. Asian J Pharm Sci. 2013:8:1-10. https://doi.org/10.1016/j.ajps.2013.07.001.

114. Parton RG, Simons K. The multiple faces of caveolae. Nat Rev Mol Cell Biol. 2007;8:185-94. https://doi.org/10.1038/nrm2122.

115. Sandvig K, Pust S, Skotland T, van Deurs B. Clathrin-independent endocytosis: mechanisms and function. Curr Opin Cell Biol. 2011;23:413-20. https://doi.org/10.1016/j.ceb.2011.03.007.

116. Sahay G, Kim JO, Kabanov AV, Bronich TK. The exploitation of differential endocytic pathways in normal and tumor cells in the selective targeting of nanoparticulate chemotherapeutic agents. Biomaterials. 2010;31:923-33. https://doi.org/10.1016/j.biomaterials.2009.09.101.

117. Gradishar WJ. Albumin-bound paclitaxel: a next-generation taxane. Expert Opin Pharmacother. 2006;7:1041-53. https://doi.org/10.1517/ 14656566.7.8.1041.

118. Zhang LW, Monteiro-Riviere NA. Mechanisms of quantum dot nanoparticle cellular uptake. Toxicol Sci. 2009;110:138-55. https://doi.org/10. 1093/toxsci/kfp087.

119. Nishikawa T, Iwakiri N, Kaneko Y, Taguchi A, Fukushima K, Mori H, Morone N, Kadokawa J-I. Nitric oxide release in human aortic endothelial cells mediated by delivery of amphiphilic polysiloxane nanoparticles to caveolae. Biomacromol. 2009;10:2074-85. https://doi.org/10.1021/ bm900128x.

120. Nel AE, Mädler L, Velegol D, Xia T, Hoek EMV, Somasundaran P, Klaessig F, Castranova V, Thompson M. Understanding biophysicochemical interactions at the nano-bio interface. Nat Mater. 2009;8:543-57. https://doi. org/10.1038/nmat2442.

121. Rejman J, Oberle V, Zuhorn IS, Hoekstra D. Size-dependent internalization of particles via the pathways of clathrin-and caveolae-mediated endocytosis. Biochem J. 2004;377:159-69. https://doi.org/10.1042/ bj20031253.

122. Chithrani BD, Ghazani AA, Chan WCW. Determining the size and shape dependence of gold nanoparticle uptake into mammalian cells. Nano Lett. 2006;6:662-8. https://doi.org/10.1021/nl052396o.

123. Banerjee A, Qi J, Gogoi R, Wong J, Mitragotri S. Role of nanoparticle size, shape and surface chemistry in oral drug delivery. J Control Release. 2016;238:176-85. https://doi.org/10.1016/j.jconrel.2016.07.051.

124. Ruan G, Agrawal A, Marcus Al, Nie S. Imaging and tracking of tat peptide-conjugated quantum dots in living cells: new insights into nanoparticle uptake, intracellular transport, and vesicle shedding. J Am Chem Soc. 2007;129:14759-66. https://doi.org/10.1021/ja074936k.

125. Rai S, Pandey V, Rai G. Transfersomes as versatile and flexible nanovesicular carriers in skin cancer therapy: the state of the art. Nano Rev Exp. 2017;8:1325708. https://doi.org/10.1080/20022727.2017.1325708.

126. Zeb A, Arif ST, Malik M, Shah FA, Din FU, Qureshi OS, Lee E-S, Kim J-K. Potential of nanoparticulate carriers for improved drug delivery via skin. J Pharm Investig. 2019:49:485-517.

127. Batool S, Zahid F, Din FU, Naz S, Dar J, Khan M, Khan GM. Macrophage targeting with the novel carbopol-based miltefosine-loaded transfersomal gel for the treatment of cutaneous leishmaniasis: in vitro and in vivo analyses. Drug Dev Ind Pharm. 2021. https://doi.org/10.1080/ 03639045.2021 .1890768$.

128. Meyerhoff A. US Food and Drug Administration approval of Am Bisome (liposomal amphotericin B) for treatment of visceral leishmaniasis. Clin Infect Dis. 1999;28:42-8. https://doi.org/10.1086/515085.

129. Wortmann G, Zapor M, Ressner R, Fraser S, Hartzell J, Pierson J, Weintrob A, Magill A. Lipsosomal amphotericin B for treatment of cutaneous leishmaniasis. Am J Trop Med Hyg. 2010;83:1028-33. https://doi.org/10. 4269/ajtmh.2010.10-0171.

130. Miceli MH, Chandrasekar P. Safety and efficacy of liposomal amphotericin B for the empirical therapy of invasive fungal infections in immunocompromised patients. Infect Drug Resist. 2012;5:9. https://doi. org/10.2147/idr.s22587.

131. Azevedo EG, Ribeiro RR, da Silva SM, Ferreira CS, de Souza LE, Ferreira AAF, de Oliveira e Castro RA, Demicheli C, Rezende SA, Frézard F. Mixed 
formulation of conventional and pegylated liposomes as a novel drug delivery strategy for improved treatment of visceral leishmaniasis. Expert Opin Drug Deliv. 2014;11:1551-60. https://doi.org/10.1517/ 17425247.2014.932347.

132. Khan AS, ud Din F, Ali Z, Bibi M, Zahid F, Zeb A, Khan GM. Development, In vitro and in vivo evaluation of miltefosine loaded nanostructured lipid carriers for the treatment of cutaneous leishmaniasis. Int J Pharm. 2020. https://doi.org/10.1016/j.jpharm.2020.120109.

133. Hanna E, Abadi R, Abbas O. Imiquimod in dermatology: an overview. Int J Dermatol. 2016;55:831-44.

134. Zhou HF, Ma QH, Xia Q, Lu YY, Gu N, Miao X, Luo D. Preparation and cytotoxicity of imiquimod-loaded solid lipid nanoparticles. Solid State Phenom. 2007;121:271-4.

135. Jabeen M, Boisgard A-S, Danoy A, El Kholti N, Salvi J-P, Boulieu R, Fromy B, Verrier B, Lamrayah M. Advanced characterization of imiquimodinduced psoriasis-like mouse model. Pharmaceutics. 2020;12:789. https://doi.org/10.3390/pharmaceutics12090789.

136. Banik BL, Fattahi P, Brown JL. Polymeric nanoparticles: the future of nanomedicine. Wiley Interdiscip Rev Nanomed Nanobiotechnol. 2016:8:271-99. https://doi.org/10.1002/wnan.1364.

137. Zeb A, Rana I, Choi H-I, Lee C-H, Baek S-W, Lim C-W, Khan N, Arif ST, Alvi AM, Shah FA. Potential and applications of nanocarriers for efficient delivery of biopharmaceuticals. Pharmaceutics. 2020;12:1184. https:// doi.org/10.3390/pharmaceutics12121184.

138. Ribeiro TG, Chávez-Fumagalli MA, Valadares DG, França JR, Rodrigues LB, Duarte MC, Lage PS, Andrade PHR, Lage DP, Arruda LV. Novel targeting using nanoparticles: an approach to the development of an effective anti-leishmanial drug-delivery system. Int J Nanomed. 2014;9:877. https://doi.org/10.2147/IJN.S55678.

139. de Castro Spadari C. Alginate nanoparticles as non-toxic delivery system for miltefosine in the treatment of candidiasis and cryptococcosis. Int J Nanomed. 2019;14:5187. https://doi.org/10.2147/IJN.S205350.

140. Barazesh A, Motazedian MH, Sattarahmady N, Morowvat MH, Rashidi S. Preparation of meglumine antimonate loaded albumin nanoparticles and evaluation of its anti-leishmanial activity: an in vitro assay. J Parasitic Dis. 2018:42:416-22. https://doi.org/10.1007/s12639-018-1018-7.

141. Casa DM, Scariot DB, Khalil NM, Nakamura CV, Mainardes RM. Bovine serum albumin nanoparticles containing amphotericin B were effective in treating murine cutaneous leishmaniasis and reduced the drug toxicity. Exp Parasitol. 2018;192:12-8. https://doi.org/10.1016/j.exppara. 2018.07.003.

142. Prajapati VK, Awasthi K, Gautam S, Yadav TP, Rai M, Srivastava ON, Sundar S. Targeted killing of Leishmania donovani in vivo and in vitro with amphotericin B attached to functionalized carbon nanotubes. J Antimicrob Chemother. 2011;66:874-9. https://doi.org/10.1093/jac/ dkro02.

143. Peretti E, Miletto I, Stella B, Rocco F, Berlier G, Arpicco S. Strategies to obtain encapsulation and controlled release of pentamidine in mesoporous silica nanoparticles. Pharmaceutics. 2018;10:195. https:// doi.org/10.3390/pharmaceutics10040195.

144. Stone NRH, Bicanic T, Salim R, Hope W. Liposomal amphotericin B (AmBisome $\left.{ }^{\circledR}\right)$ : a review of the pharmacokinetics, pharmacodynamics, clinical experience and future directions. Drugs. 2016;76:485-500. https://doi. org/10.1007/s40265-016-0538-7.

145. Rashid R, Kim DW, ud Din F, Mustapha O, Yousaf AM, Park JH, Kim JO, Yong CS, Choi H-G. Effect of hydroxypropylcellulose and Tween 80 on physicochemical properties and bioavailability of ezetimibe-loaded solid dispersion. Carbohydr Polym. 2015;130:26-31. https://doi.org/10. 1016/j.carbpol.2015.04.071.

146. Italia JL, Ravi Kumar MNV, Carter KC. Evaluating the potential of polyester nanoparticles for per oral delivery of amphotericin B in treating visceral leishmaniasis. J Biomed Nanotechnol. 2012;8:695-702. https:// doi.org/10.1166/jbn.2012.1414.

147. Radwan MA, AlQuadeib BT, Šiller L, Wright MC, Horrocks B. Oral administration of amphotericin $B$ nanoparticles: antifungal activity, bioavailability and toxicity in rats. Drug Deliv. 2017;24:40-50. https://doi.org/10. 1080/10717544.2016.

148. Jansook P, Pichayakorn W, Ritthidej GC. Amphotericin B-loaded solid lipid nanoparticles (SLNs) and nanostructured lipid carrier (NLCs): effect of drug loading and biopharmaceutical characterizations. Drug Dev
Ind Pharm. 2018;44:1693-700. https://doi.org/10.1080/03639045.2019. 1569023.

149. Valle IV, Machado ME, Araujo CD, da Cunha-Junior EF, da Silva Pacheco J, Torres-Santos EC, da Silva LC, Cabral LM, do Carmo FA, Sathler PC. Oral pentamidine-loaded poly (lactic-co-glycolic) acid nanoparticles: an alternative approach for leishmaniasis treatment. Nanotechnology. 2019:30:4502. https://doi.org/10.1088/1361-6528/ab373e.

150. Patel VR, Agrawal YK. Nanosuspension: an approach to enhance solubility of drugs. J Adv Pharm Technol Res. 2011;2:81. https://doi.org/10. 4103/2231-4040.82950.

151. Yang Z, Liu M, Chen J, Fang W, Zhang Y, Yuan M, Gao J. Development and characterization of amphotericin $B$ nanosuspensions for oral administration through a simple top-down method. Curr Pharm Biotechnol. 2014;15:569-76. https://doi.org/10.2174/138920101566614 0706160709.

152. Zhou Y, Fang Q, Niu B, Wu B, Zhao Y, Quan G, Pan X, Wu C. Comparative studies on amphotericin $B$ nanosuspensions prepared by a high pressure homogenization method and an antisolvent precipitation method. Colloids Surf B. 2018;172:372-9. https://doi.org/10.1016/j.colsurfb.2018. 08.016.

153. Liu M, Chen M, Yang Z. Design of amphotericin B oral formulation for antifungal therapy. Drug Deliv. 2017;24:1-9. https://doi.org/10.1080/ 10717544.2016.1225852.

154. Parvez S, Yadagiri G, Gedda MR, Singh A, Singh OP, Verma A, Sundar S, Mudavath SL. Modified solid lipid nanoparticles encapsulated with Amphotericin B and Paromomycin: an effective oral combination against experimental murine visceral leishmaniasis. Sci Rep. 2020;10:114. https://doi.org/10.1038/s41598-020-69276-5.

155. Afzal I, Sarwar HS, Sohail MF, Varikuti S, Jahan S, Akhtar S, Yasinzai M, Satoskar AR, Shahnaz G. Mannosylated thiolated paromomycin-loaded PLGA nanoparticles for the oral therapy of visceral leishmaniasis. Nanomedicine. 2019;14:387-406. https://doi.org/10.2217/nnm-2018-0038.

156. Patel BK, Parikh RH, Aboti PS. Development of oral sustained release rifampicin loaded chitosan nanoparticles by design of experiment. J Drug Deliv. 2013. https://doi.org/10.1155/2013/370938.

157. Al-Quadeib BT, Radwan MA, Siller L, Horrocks B, Wright MC. Stealth Amphotericin B nanoparticles for oral drug delivery: in vitro optimization. Saudi Pharm J. 2015;23:290-302. https://doi.org/10.1016/j.jsps. 2014.11.004.

158. Bazak R, Houri M, El Achy S, Kamel S, Refaat T. Cancer active targeting by nanoparticles: a comprehensive review of literature. J Cancer Res Clin Oncol. 2015;141:769-84. https://doi.org/10.1007/s00432-014-1767-3.

159. Bertrand N, Wu J, Xu X, Kamaly N, Farokhzad OC. Cancer nanotechnology: the impact of passive and active targeting in the era of modern cancer biology. Adv Drug Deliv Rev. 2014;66:2-25. https://doi.org/10. 1016/j.addr.2013.11.009.

160. Attia MF, Anton N, Wallyn J, Omran Z, Vandamme TF. An overview of active and passive targeting strategies to improve the nanocarriers efficiency to tumour sites. J Pharm Pharmacol. 2019;71:1185-98. https:// doi.org/10.1111/jphp.13098.

161. Azad AK, Rajaram MVS, Schlesinger LS. Exploitation of the macrophage mannose receptor (CD206) in infectious disease diagnostics and therapeutics. J Cytol Mol Biol. 2014. https://doi.org/10.13188/2325-4653. 1000003.

162. Shahnaz G, Edagwa BJ, McMillan J, Akhtar S, Raza A, Qureshi NA, Yasinzai M, Gendelman HE. Development of mannose-anchored thiolated amphotericin B nanocarriers for treatment of visceral leishmaniasis. Nanomedicine. 2017;12:99-115. https://doi.org/10.2217/ nnm-2016-0325.

163. Dar MJ, Din FU, Khan GM. Sodium stibogluconate loaded nano-deformable liposomes for topical treatment of leishmaniasis: macrophage as a target cell. Drug Deliv. 2018;25:1595-606. https://doi.org/10.1080/ 10717544.2018.1494222.

164. Kumar R, Sahoo GC, Pandey K, Das VNR, Das P. Study the effects of PLGA-PEG encapsulated amphotericin B nanoparticle drug delivery system against Leishmania donovani. Drug Deliv. 2015;22:383-8. https:// doi.org/10.3109/10717544.2014.891271.

165. Sarwar HS, Ashraf S, Akhtar S, Sohail MF, Hussain SZ, Rafay M, Yasinzai M, Hussain I, Shahnaz G. Mannosylated thiolated polyethylenimine nanoparticles for the enhanced efficacy of antimonial drug against 
Leishmaniasis. Nanomedicine. 2018;13:25-41. https://doi.org/10.2217/ nnm-2017-0255.

166. Vieira ACC, Magalhães J, Rocha S, Cardoso MS, Santos SG, Borges M, Pinheiro M, Reis $S$. Targeted macrophages delivery of rifampicin-loaded lipid nanoparticles to improve tuberculosis treatment. Nanomedicine. 2017;12:2721-36. https://doi.org/10.2217/nnm-2017-0248.

167. Asthana S, Gupta PK, Jaiswal AK, Dube A, Chourasia MK. Targeted chemotherapy of visceral leishmaniasis by lactoferrin-appended amphotericin B-loaded nanoreservoir: in vitro and in vivo studies. Nanomedicine. 2015;10:1093-109. https://doi.org/10.2217/nnm.14.182.

168. Chaubey P, Mishra B. Mannose-conjugated chitosan nanoparticles loaded with rifampicin for the treatment of visceral leishmaniasis. Carbohydr Polym. 2014;101:1101-8. https://doi.org/10.1016/j.carbpol. 2013.10.044.

169. Borborema SET, Schwendener RA, Junior JAO, de Andrade Junior HF, do Nascimento N. Uptake and antileishmanial activity of meglumine antimoniate-containing liposomes in Leishmania (Leishmania) majorinfected macrophages. Int J Antimicrob Agents. 2011;38:341-7. https:// doi.org/10.1016/j.ijantimicag.2011.05.012.

170. Esfandiari F, Motazedian MH, Asgari Q, Morowvat MH, Molaei M, Heli H. Paromomycin-loaded mannosylated chitosan nanoparticles: synthesis, characterization and targeted drug delivery against leishmaniasis. Acta Trop. 2019;197:105072. https://doi.org/10.1016/j.actatropica.2019. 105045.

171. Nahar M, Dubey V, Mishra D, Mishra PK, Dube A, Jain NK. In vitro evaluation of surface functionalized gelatin nanoparticles for macrophage targeting in the therapy of visceral leishmaniasis. J Drug Target. 2010;18:93-105. https://doi.org/10.3109/10611860903115290.

172. Tempone AG, Perez D, Rath S, Vilarinho AL, Mortara RA, de Andrade Jr HF. Targeting Leishmania (L.) chagasi amastigotes through macrophage scavenger receptors: the use of drugs entrapped in liposomes containing phosphatidylserine. J Antimicrob Chemother. 2004;54:60-8. https:// doi.org/10.1093/jac/dkh281.

173. Kansal S, Tandon R, Dwivedi P, Misra P, Verma PRP, Dube A, Mishra PR. Development of nanocapsules bearing doxorubicin for macrophage targeting through the phosphatidylserine ligand: a system for intervention in visceral leishmaniasis. J Antimicrob Chemother. 2012;67:265060. https://doi.org/10.1093/jac/dks286.

174. Torchilin VP. Passive and active drug targeting: drug delivery to tumors as an example, in Drug delivery. Berlin: Springer; 2010. p. 3-53. https:// doi.org/10.1007/978-3-642-00477-3_1.

175. Ruela ALM, Perissinato AG, Lino MEDS, Mudrik PS, Pereira GR. Evaluation of skin absorption of drugs from topical and transdermal formulations. Braz J Pharm Sci. 2016;52:527-44. https://doi.org/10.1590/s1984-82502 016000300018

176. Rajan R, Jose S, Mukund VPB, Vasudevan DT. Transferosomes-A vesicular transdermal delivery system for enhanced drug permeation. J Adv Pharm Technol Res. 2011;2:138. https://doi.org/10.4103/2231-4040. 85524.

177. Rabia S, Khaleeq N, Batool S, Dar MJ, Kim DW, Din F-U, Khan GM. Rifampicin-loaded nanotransferosomal gel for treatment of cutaneous leishmaniasis: passive targeting via topical route. Nanomedicine. 2020:15:183-203.

178. Nazari-Vanani R, Vais RD, Sharifi F, Sattarahmady N, Karimian K, Motazedian $\mathrm{MH}$, Heli $\mathrm{H}$. Investigation of anti-leishmanial efficacy of miltefosine and ketoconazole loaded on nanoniosomes. Acta Trop. 2018;185:69-76. https://doi.org/10.1016/j.actatropica.2018.05.002.

179. Mahtab A, Anwar M, Mallick N, Naz Z, Jain GK, Ahmad FJ. Transungual delivery of ketoconazole nanoemulgel for the effective management of onychomycosis. AAPS PharmSciTech. 2016;17:1477-90. https://doi.org/ 10.1208/s12249-016-0488-0

180. Telò I, Pescina S, Padula C, Santi P, Nicoli S. Mechanisms of imiquimod skin penetration. Int J Pharm. 2016;511:516-23. https://doi.org/10. 1016/j.ijpharm.2016.07.043.

181. Kalat SAM, Khamesipour A, Bavarsad N, Fallah M, Khashayarmanesh Z, Feizi E, Neghabi K, Abbasi A, Jaafari MR. Use of topical liposomes containing meglumine antimoniate (Glucantime) for the treatment of L. major lesion in BALB/c mice. Exp Parasitol. 2014;143:5-10. https://doi. org/10.1016/j.exppara.2014.04.013.

182. Jaafari MR, Hatamipour M, Alavizadeh SH, Abbasi A, Saberi Z, Rafati S, Taslimi Y, Mohammadi AM, Khamesipour A. Development of a topical liposomal formulation of Amphotericin B for the treatment of cutaneous leishmaniasis. Int J Parasitol Drugs Drug Resist. 2019;11:156-65. https://doi.org/10.1016/j.ijpddr.2019.09.004.

183. Kavian Z, Alavizadeh SH, Golmohamadzadeh S, Badiee A, Khamesipour A, Jaafari MR. Development of topical liposomes containing miltefosine for the treatment of Leishmania major infection in susceptible BALB/C mice. Acta Trop. 2019;196:142-9. https://doi.org/10.1016/j.actatropica. 2019.05.018.

184. Weiss F, Vogenthaler N, Franco-Paredes C, Parker SRS. Leishmania tropica-induced cutaneous and presumptive concomitant viscerotropic Leishmaniasis with prolonged incubation. Arch Dermatol. 2009;145:1023-6. https://doi.org/10.1001/archdermatol.2009.181.

185. Riaz A, Hendricks S, Elbrink K, Guy C, Maes L, Ahmed N, Kiekens F, Khan GM. Preparation and characterization of nanostructured lipid carriers for improved topical drug delivery: evaluation in cutaneous leishmaniasis and vaginal candidiasis animal models. AAPS PharmSciTech. 2020;21:1-14. https://doi.org/10.1208/s12249-020-01717-w.

186. Baiocco P, llari A, Ceci P, Orsini S, Gramiccia M, Di Muccio T, Colotti G. Inhibitory effect of silver nanoparticles on trypanothione reductase activity and Leishmania infantum proliferation. ACS Med Chem Lett. 2011;2:230-3. https://doi.org/10.1021/ml1002629.

187. Singh OP, Singh B, Chakravarty J, Sundar S. Current challenges in treatment options for visceral leishmaniasis in India: a public health perspective. Infect Dis Poverty. 2016;5:19. https://doi.org/10.1186/ s40249-016-0112-2

188. Tiwari B, Pahuja R, Kumar P, Rath SK, Gupta KC, Goyal N. Nanotized curcumin and miltefosine, a potential combination for treatment of experimental visceral leishmaniasis. Antimicrob Agents Chemother. 2017;61:e01169-e1216. https://doi.org/10.1128/AAC.01169-16.

189. Varshosaz J, Arbabi B, Pestehchian N, Saberi S, Delavari M. Chitosan-titanium dioxide-glucantime nanoassemblies effects on promastigote and amastigote of Leishmania major. Int J Biol Macromol. 2018;107:212-21. https://doi.org/10.1016/j.jibiomac.2017.08.177.

190. Dar MJ, Khalid S, Varikuti S, Satoskar AR, Khan GM. Nano-elastic liposomes as multidrug carrier of sodium stibogluconate and ketoconazole: a potential new approach for the topical treatment of cutaneous Leishmaniasis. Eur J Pharm Sci. 2020;145:105256. https://doi. org/10.1016/j.ejps.2020.105256.

191. Dar MJ, Khalid S, McElroy CA, Satoskar AR, Khan GM. Topical treatment of cutaneous leishmaniasis with novel amphotericin B-miltefosine co-incorporated second generation ultra-deformable liposomes. Int J Pharm. 2020:573:1 18900. https://doi.org/10.1016/j.jpharm.2019. 118900.

192. Salim MW, Shabbir K, Yousaf AM, Choi H-G, Khan GM. Preparation, invitro and in-vivo evaluation of Rifampicin and Vancomycin Co-loaded transfersomal gel for the treatment of cutaneous leishmaniasis. J Drug Deliv Sci Technol. 2020;60:101996. https://doi.org/10.1016/j.jddst.2020. 101996.

193. Banerjee A, De M, Ali N. Complete cure of experimental visceral leishmaniasis with amphotericin B in stearylamine-bearing cationic liposomes involves down-regulation of IL-10 and favorable T cell responses. J Immunol. 2008;181:1386-98. https://doi.org/10.4049/ jimmunol.181.2.1386.

194. Banerjee A, De M, Ali N. Combination therapy with paromomycinassociated stearylamine-bearing liposomes cures experimental visceral leishmaniasis through Th1-biased immunomodulation. Antimicrob Agents Chemother. 2011;55:1661-70. https://doi.org/10.1128/AAC. 00524-10.

195. Roychoudhury J, Sinha R, Ali N. Therapy with sodium stibogluconate in stearylamine-bearing liposomes confers cure against SSG-resistant Leishmania donovani in BALB/c mice. PLoS ONE. 2011. https://doi.org/ 10.1371/journal.pone.0017376.

196. Dar MJ, McElroy CA, Khan MI, Satoskar AR, Khan GM. Development and evaluation of novel miltefosine-polyphenol co-loaded second generation nano-transfersomes for the topical treatment of cutaneous leishmaniasis. Expert Opin Drug Deliv. 2020;17:97-110. https://doi.org/ 10.1080/17425247.2020.1700227.

197. Allahverdiyev AM, Abamor ES, Bagirova M, Ustundag CB, Kaya C, Kaya F, Rafailovich M. Antileishmanial effect of silver nanoparticles and their enhanced antiparasitic activity under ultraviolet light. Int J Nanomed. 2011;6:2705. https://doi.org/10.2147/ijn.s23883. 
198. Nadhman A, Nazir S, Khan Ml, Ayub A, Muhammad B, Khan M, Shams DF, Yasinzai M. Visible-light-responsive ZnCuO nanoparticles: benign photodynamic killers of infectious protozoans. Int J Nanomed. 2015;10:6891. https://doi.org/10.2147/ijn.s91666.

199. Sepúlveda AAL, Velásquez AMA, Linares IAP, de Almeida L, Fontana CR, Garcia C, Graminha MAS. Efficacy of photodynamic therapy using TiO2 nanoparticles doped with $\mathrm{Zn}$ and hypericin in the treatment of cutaneous Leishmaniasis caused by Leishmania amazonensis. Photodiagn Photodyn Ther. 2020;30:101676. https://doi.org/10.1016/j.pdpdt.2020. 101676.

200. Ahmad A, Wei Y, Syed F, Khan S, Khan GM, Tahir K, Khan AU, Raza M, Khan FU, Yuan Q. Isatis tinctoria mediated synthesis of amphotericin B-bound silver nanoparticles with enhanced photoinduced antileishmanial activity: a novel green approach. J Photochem Photobiol B. 2016;161:17-24

201. Abamor ES, Allahverdiyev AM. A nanotechnology based new approach for chemotherapy of cutaneous leishmaniasis:TIO2@ AG nanoparticles-Nigella sativa oil combinations. Exp Parasitol. 2016;166:150-63. https://doi.org/10.1016/j.exppara.2016.04.008.

202. Mehrizi TZ, Ardestani MS, Hoseini MHM, Khamesipour A, Mosaffa N, Ramezani A. Novel nanosized chitosan-betulinic acid against resistant Leishmania major and first clinical observation of such parasite in kidney. Sci Rep. 2018;8:1-19. https://doi.org/10.1038/s41598-018-30103-7.

203. Tavakoli P, Ghaffarifar F, Delavari H, Shahpari N. Efficacy of manganese oxide (Mn2O3) nanoparticles against Leishmania major in vitro and in vivo. J Trace Elem Med Biol. 2019;56:162-8.

204. Parveen K, Banse V, Ledwani L. Green synthesis of nanoparticles: their advantages and disadvantages. AIP Publishing LLC. https://doi.org/10. $1063 / 1.4945168$.

205. Griffin S, Masood MI, Nasim MJ, Sarfraz M, Ebokaiwe AP, Schäfer K-H, Keck CM, Jacob C. Natural nanoparticles: a particular matter inspired by nature. Antioxidants. 2018;7:3. https://doi.org/10.3390/antiox7010003.

206. Tagousop CN, Kengne IC, Ngnokam D, Voutquenne-Nazabadioko L. Antimicrobial activities of saponins from Melanthera elliptica and their synergistic effects with antibiotics against pathogenic phenotypes. Chem Cent J. 2018;12:97. https://doi.org/10.1186/s13065-018-0466-6.

207. Anderson O, Beckett J, Briggs CC, Natrass LA, Cranston CF, Wilkinson EJ, Owen JH, Williams RM, Loukaidis A, Bouillon ME. An investigation of the antileishmanial properties of semi-synthetic saponins. RSC Med Chem. 2020;11:833-42. https://doi.org/10.1039/D0MD00123F.

208. Van de Ven H, Vermeersch M, Vandenbroucke RE, Matheeussen A, Apers S, Weyenberg W, De Smedt SC, Cos P, Maes L, Ludwig A. Intracellular drug delivery in Leishmania-infected macrophages: evaluation of saponin-loaded PLGA nanoparticles. J Drug Target. 2012;20:142-54. https://doi.org/10.3109/1061186X.2011.595491.

209. Do Nascimento TG, Da Silva PF, Azevedo LF, Da Rocha LG, de Moraes Porto ICC, e Moura TFAL, Basílio-Júnior ID, Grillo LAM, Dornelas CB, da Silva Fonseca EJ. Polymeric nanoparticles of Brazilian red propolis extract: preparation, characterization, antioxidant and leishmanicidal activity. Nanoscale Res Lett. 2016;11:301. https://doi.org/10.1186/ s11671-016-1517-3.

210. Monzote L, Piñón A, Scull R, Setzer WN. Chemistry and leishmanicidal activity of the essential oil from Artemisia absinthium from Cuba. Nat Prod Commun. 2014;9:1799-804.

211. Tamargo B, Monzote L, Piñón A, Machín L, García M, Scull R, Setzer WN. In vitro and in vivo evaluation of essential oil from Artemisia absinthium L. formulated in nanocochleates against cutaneous leishmaniasis. Medicines. 2017;4:38. https://doi.org/10.3390/medicines4020038.

212. Marquele-Oliveira F, Torres EC, da Silva Barud H, Zoccal KF, Faccioli LH, Hori II, Berretta AA. Physicochemical characterization by AFM, FT-IR and DSC and biological assays of a promising antileishmania delivery system loaded with a natural Brazilian product. J Pharm Biomed Anal. 2016;123:195-204. https://doi.org/10.1016/j.jpba.2016.01.045.

213. Hewlings SJ, Kalman DS. Curcumin: a review of its' effects on human health. Foods. 2017;6:92. https://doi.org/10.3390/foods6100092.

214. Riaz A, Ahmed N, Khan MI, Haq I-U, Ur Rehman A, Khan GM. Formulation of topical NLCs to target macrophages for cutaneous leishmaniasis. J Drug Deliv Sci Technol. 2019;54:101232. https://doi.org/10.1016/j. jddst.2019.101232.

215. Kar N, Chakraborty S, De AK, Ghosh S, Bera T. Development and evaluation of a cedrol-loaded nanostructured lipid carrier system for in vitro and in vivo susceptibilities of wild and drug resistant Leishmania donovani amastigotes. Eur J Pharm Sci. 2017;104:196-211. https://doi. org/10.1016/j.ejps.2017.03.046.

216. Yamamoto ES, Campos BLS, Jesus JA, Laurenti MD, Ribeiro SP, Kallás EG, Rafael-Fernandes M, Santos-Gomes G, Silva MS, Sessa DP. The effect of ursolic acid on Leishmania (Leishmania) amazonensis is related to programed cell death and presents therapeutic potential in experimental cutaneous leishmaniasis. PLoS ONE. 2015;10:e0144946. https://doi.org/ 10.1371/journal.pone.0144946.

217. Das S, Ghosh S, De AK, Bera T. Oral delivery of ursolic acid-loaded nanostructured lipid carrier coated with chitosan oligosaccharides: development, characterization, in vitro and in vivo assessment for the therapy of leishmaniasis. Int J Biol Macromol. 2017;102:996-1008. https://doi. org/10.1016/j.ijbiomac.2017.04.098.

218. Zia Q, Mohammad O, Rauf MA, Khan W, Zubair S. Biomimetically engineered Amphotericin B nano-aggregates circumvent toxicity constraints and treat systemic fungal infection in experimental animals. Sci Rep. 2017;7:1-19. https://doi.org/10.1038/s41598-017-11847-0.

219. Baranwal A, Mahato K, Srivastava A, Maurya PK, Chandra P. Phytofabricated metallic nanoparticles and their clinical applications. RSC Adv. 2016;6:105996-6010. https://doi.org/10.1039/C6RA23411A.

220. Slepička P, Elashnikov R, Ulbrich P, Staszek M, Kolská Z, Švorčík V. Stabilization of sputtered gold and silver nanoparticles in PEG colloid solutions. J Nanopart Res. 2015;17:11. https://doi.org/10.1007/ s11051-014-2850-z.

221. Zahir AA, Chauhan IS, Bagavan A, Kamaraj C, Elango G, Shankar J, Arjaria N, Roopan SM, Rahuman AA, Singh N. Green synthesis of silver and titanium dioxide nanoparticles using Euphorbia prostrata extract shows shift from apoptosis to G0/G1 arrest followed by necrotic cell death in Leishmania donovani. Antimicrob Agents Chemother. 2015;59:4782-99. https://doi.org/10.1128/aac.00098-15.

222. Kalangi SK, Dayakar A, Gangappa D, Sathyavathi R, Maurya RS, Rao DN. Biocompatible silver nanoparticles reduced from Anethum graveolens leaf extract augments the antileishmanial efficacy of miltefosine. Exp Parasitol. 2016;170:184-92. https://doi.org/10.1016/j.exppara.2016.09. 002.

223. Ovais M, Nadhman A, Khalil AT, Raza A, Khuda F, Sohail MF, Islam NU, Sarwar HS, Shahnaz G, Ahmad I. Biosynthesized colloidal silver and gold nanoparticles as emerging leishmanicidal agents: an insight. Nanomedicine. 2017;12:2807-19. https://doi.org/10.2217/nnm-2017-0233.

224. Ahmad A, Syed F, Shah A, Khan Z, Tahir K, Khan AU, Yuan Q. Silver and gold nanoparticles from Sargentodoxa cuneata: synthesis, characterization and antileishmanial activity. RSC Adv. 2015;5:73793-806. https:// doi.org/10.1039/C5RA13206A.

225. Bagirova M, Dinparvar S, Allahverdiyev AM, Unal K, Abamor ES, Novruzova M. Investigation of antileshmanial activities of Cuminum cyminum based green silver nanoparticles on L. tropica promastigotes and amastigotes in vitro. Acta Trop. 2020;208:105498. https://doi.org/10. 1016/j.actatropica.2020.105498.

226. Werle M. Natural and synthetic polymers as inhibitors of drug efflux pumps. Pharm Res. 2008;25:500-11. https://doi.org/10.1007/ s11095-007-9347-8.

227. Ghosh S, Kar N, Bera T. Oleanolic acid loaded poly lactic co-glycolic acid-vitamin ETPGS nanoparticles for the treatment of Leishmania donovani infected visceral leishmaniasis. Int J Biol Macromol. 2016;93:961-70. https://doi.org/10.1016/j.ijbiomac.2016.09.014.

228. Cabral FV, Pelegrino MT, Sauter IP, Seabra AB, Cortez M, Ribeiro MS. Nitric oxide-loaded chitosan nanoparticles as an innovative antileishmanial platform. Nitric Oxide. 2019;93:25-33. https://doi.org/10.1016/j. niox.2019.09.007.

229. Saleem K, Khursheed Z, Hano C, Anjum I, Anjum S. Applications of nanomaterials in leishmaniasis: a focus on recent advances and challenges. Nanomaterials. 2019;9:1749. https://doi.org/10.3390/nano9 121749.

230. Sharma R, Agrawal U, Mody N, Vyas SP. Polymer nanotechnology based approaches in mucosal vaccine delivery: challenges and opportunities. Biotechnol Adv. 2015;33:64-79. https://doi.org/10.1016/j.biotechadv. 2014.12.004.

231. Margaroni M, Agallou M, Athanasiou E, Kammona O, Kiparissides C, Gaitanaki C, Karagouni E. Vaccination with poly (D, L-lactide-coglycolide) nanoparticles loaded with soluble Leishmania antigens and 
modified with a TNFa-mimicking peptide or monophosphoryl lipid A confers protection against experimental visceral leishmaniasis. Int J Nanomed. 2017;12:6169. https://doi.org/10.2147/ijn.s141069.

232. Zutshi S, Kumar S, Chauhan P, Bansode Y, Nair A, Roy S, Sarkar A, Saha B. Anti-Leishmanial vaccines: assumptions, approaches, and annulments. Vaccines. 2019;7:156. https://doi.org/10.3390/vaccines7040156.

233. Schwendener RA. Liposomes as vaccine delivery systems: a review of the recent advances. Ther Adv Vaccines. 2014;2:159-82. https://doi.org/ 10.1177/2051013614541440.

234. Askarizadeh A, Badiee A, Khamesipour A. Development of nano-carriers for Leishmania vaccine delivery. Expert Opin Drug Deliv. 2020;17:16787. https://doi.org/10.1080/17425247.2020.1713746.

235. Mehravaran A, Nasab MR, Mirahmadi H, Sharifi I, Alijani E, Nikpoor AR, Akhtari J. Protection induced by Leishmania major antigens and the imiquimod adjuvant encapsulated on liposomes in experimental cutaneous leishmaniasis. Infect Genet Evol. 2019;70:27-35. https://doi. org/10.1016/j.meegid.2019.01.005.

236. Katebi A, Varshochian R, Riazi-Rad F, Ganjalikhani-Hakemi M, Ajdary S. Combinatorial delivery of antigen and TLR agonists via PLGA nanoparticles modulates Leishmania major-infected-macrophages activation. Biomed Pharmacother. 2021;137:111276. https://doi.org/10.1016/j. biopha.2021.111276.

237. Trovato M, De Berardinis P. Novel antigen delivery systems. World J Virol. 2015:4:156. https://doi.org/10.5501/wjv.v4.i3.156.

238. Ribeiro PAF, Dias DS, Novais MVM, Lage DP, Tavares GSV, Mendonça DVC, Oliveira JS, Chávez-Fumagalli MA, Roatt BM, Duarte MC. A Leishmania hypothetical protein-containing liposome-based formulation is highly immunogenic and induces protection against visceral leishmaniasis. Cytokine. 2018;111:131-9. https://doi.org/10.1016/j.cyto.2018.08. 019.

239. Firouzmand H, Sahranavard M, Badiee A, Khamesipour A, Alavizadeh SH, Samiei A, Soroush D, Tavassoti Kheiri M, Mahboudi F, Jaafari MR. The role of LPD-nanoparticles containing recombinant major surface glycoprotein of Leishmania (rgp63) in protection against leishmaniasis in murine model. Immunopharmacol Immunotoxicol. 2018;40:72-82. https://doi.org/10.1080/08923973.2017.1407941.

240. Hojatizade M, Badiee A, Khamesipour A, Mirshafiey A, Akhtari J, Mehravaran A, Alavizadeh SH, Abbasi A, Saberi Z, Nikpoor AR. DDA/ TDB liposomes containing soluble Leishmania major antigens induced a mixed Th1/Th2 immune response in BALB/C mice. Nanomed J. 2017:4:71-82. https://doi.org/10.22038/nmj.2017.8408.

241. Fakhraee F, Badiee A, Alavizadeh SH, Jalali SA, Chavoshian O, Khamesipour A, Mahboudi F, Jaafari MR. Coadminstration of L. major amastigote class I nuclease (rLmaCIN) with LPD nanoparticles delays the progression of skin lesion and the L. major dissemination to the spleen in BALB/c mice-based experimental setting. Acta Trop. 2016;159:211-8. https://doi.org/10.1016/j.actatropica.2016.04.004.

242. Thakur A, Kaur H, Kaur S. Studies on the protective efficacy of freeze thawed promastigote antigen of Leishmania donovani along with various adjuvants against visceral leishmaniasis infection in mice. Immunobiology. 2015;220:1031-8. https://doi.org/10.1016/j.imbio.2015.05.014.

243. Das A, Ali N. Combining cationic liposomal delivery with MPL-TDM for cysteine protease cocktail vaccination against Leishmania donovani: evidence for antigen synergy and protection. PLoS Negl Trop Dis. 2014;8:e3091. https://doi.org/10.1371/journal.pntd.0003091.

244. Eskandari F, Talesh GA, Parooie M, Jaafari MR, Khamesipour A, Saberi Z, Abbasi A, Badiee A. Immunoliposomes containing Soluble Leishmania Antigens (SLA) as a novel antigen delivery system in murine model of leishmaniasis. Exp Parasitol. 2014;146:78-86. https://doi.org/10.1016/j. exppara.2014.08.016.

245. Moura APV, Santos LCB, Brito CRN, Valencia E, Junqueira C, Filho AAP, Sant'Anna MRV, Gontijo NF, Bartholomeu DC, Fujiwara RT. Virus-like particle display of the a-Gal carbohydrate for vaccination against Leishmania infection. ACS Central Sci. 2017;3:1026-31. https://doi.org/ 10.1021/acscentsci.7b00311.

246. Tosyali OA, Allahverdiyev A, Bagirova M, Abamor ES, Aydogdu M, Dinparvar S, Acar T, Mustafaeva Z, Derman S. Nano-co-delivery of lipophosphoglycan with soluble and autoclaved leishmania antigens into PLGA nanoparticles: Evaluation of in vitro and in vivo immunostimulatory effects against visceral leishmaniasis. Mater Sci Eng C. 2020. https://doi. org/10.1016/j.msec.2020.111684.
247. Ospina-Villa JD, Gómez-Hoyos C, Zuluaga-Gallego R, Triana-Chávez O. Encapsulation of proteins from Leishmania panamensis into PLGA particles by a single emulsion-solvent evaporation method. J Microbiol Methods. 2019;162:1-7. https://doi.org/10.1016/j.mimet.2019.05.004.

248. Noormehr H, Hosseini AZ, Soudi S, Beyzay F. Enhancement of Th1 immune response against Leishmania cysteine peptidase A, B by PLGA nanoparticle. Int Immunopharmacol. 2018;59:97-105. https://doi.org/ 10.1016/j.intimp.2018.03.012.

249. Hojatizade M, Soleymani M, Tafaghodi M, Badiee A, Chavoshian O, Jaafari MR. Chitosan nanoparticles loaded with whole and soluble leishmania antigens, and evaluation of their immunogenecity in a mouse model of leishmaniasis. Iran J Immunol. 2018;15:281-93. https:// doi.org/10.22034/iji.2018.39397.

250. Athanasiou E, Agallou M, Tastsoglou S, Kammona O, Hatzigeorgiou A, Kiparissides C, Karagouni E. A poly (lactic-co-glycolic) acid nanovaccine based on chimeric peptides from different Leishmania infantum proteins induces dendritic cells maturation and promotes peptide-specific IFNY-producing CD8+ T cells essential for the protection against experimental visceral leishmaniasis. Front Immunol. 2017;8:684. https:// doi.org/10.3389/fimmu.2017.00684.

251. Zarrati S, Mahdavi M, Tabatabaie F. Immune responses in DNA vaccine formulated with PMMA following immunization and after challenge with Leishmania major. J Parasitic Dis. 2016;40:427-35. https://doi.org/ 10.1007/s12639-014-0521-8.

252. Bates PA, Depaquit J, Galati EAB, Kamhawi S, Maroli M, McDowell MA, Picado A, Ready PD, Salomón OD, Shaw JJ. Recent advances in phlebotomine sand fly research related to leishmaniasis control. Parasit Vectors. 2015;8:131. https://doi.org/10.1186/s13071-015-0712-x.

253. Warburg A, Faiman R. Research priorities for the control of phlebotomine sand flies. J Vector Ecol. 2011;36:S10-6. https://doi.org/10.1111/j. 1948-7134.2011.00107.x.

254. Gomes GM, Bigon JP, Montoro FE, Lona LMF. Encapsulation of N, $\mathrm{N}$-diethyl-meta-toluamide (DEET) via miniemulsion polymerization for temperature controlled release. J Appl Polym Sci. 2019;136:47139. https://doi.org/10.1002/app.47139.

255. Forgearini JC, Michalowski CB, Assumpção E, Pohlmann AR, Guterres SS. Development of an insect repellent spray for textile based on permethrin-loaded lipid-core nanocapsules. J Nanosci Nanotechnol. 2016;16:1301-9. https://doi.org/10.1166/jnn.2016.11665.

256. Balaji APB, Ashu A, Manigandan S, Sastry TP, Mukherjee A, Chandrasekaran N. Polymeric nanoencapsulation of insect repellent: evaluation of its bioefficacy on Culex quinquefasciatus mosquito population and effective impregnation onto cotton fabrics for insect repellent clothing. J King Saud Univ Sci. 2017;29:517-27. https://doi.org/10. 1016/j.jksus.2016.12.005.

257. Dhiman RC, Yadav RS. Insecticide resistance in phlebotomine sandflies in Southeast Asia with emphasis on the Indian subcontinent. Infect Dis Poverty. 2016;5:106. https://doi.org/10.1186/s40249-016-0200-3.

258. Patil S, Chandrasekaran R. Biogenic nanoparticles: a comprehensive perspective in synthesis, characterization, application and its challenges. J Genet Eng Biotechnol. 2020;18:1-23. https://doi.org/10.1186/ s43141-020-00081-3.

259. Benelli G, Caselli A, Canale A. Nanoparticles for mosquito control: challenges and constraints. J King Saud Univ Sci. 2017;29:424-35. https:// doi.org/10.1016/j.jksus.2016.08.006.

260. Bobo D, Robinson KJ, Islam J, Thurecht KJ, Corrie SR. Nanoparticlebased medicines: a review of FDA-approved materials and clinical trials to date. Pharm Res. 2016;33:2373-87. https://doi.org/10.1007/ s11095-016-1958-5.

261. Anselmo AC, Mitragotri S. Nanoparticles in the clinic: an update. Bioeng Transl Med. 2019;4:e10143. https://doi.org/10.1002/btm2.10143.

262. Drasler B, Sayre P, Steinhäuser KG, Petri-Fink A, Rothen-Rutishauser B. In vitro approaches to assess the hazard of nanomaterials. Nanolmpact. 2017:8:99-116. https://doi.org/10.1016/.impact.2017.08.002.

263. Clift MJD, Raemy DO, Endes C, Ali Z, Lehmann AD, Brandenberger C, Petri-Fink A, Wick P, Parak WJ, Gehr P. Can the Ames test provide an insight into nano-object mutagenicity? Investigating the interaction between nano-objects and bacteria. Nanotoxicology. 2013;7:1373-85. https://doi.org/10.3109/17435390.2012.741725.

264. Accomasso L, Cristallini C, Giachino C. Risk assessment and risk minimization in nanomedicine: a need for predictive, alternative, and 3Rs 
strategies. Front Pharmacol. 2018;9:228. https://doi.org/10.3389/fphar. 2018.00228.

265. Dickinson AM, Godden JM, Lanovyk K, Ahmed SS. Assessing the safety of nanomedicines: a mini review. Appl In Vitro Toxicol. 2019;5:114-22. https://doi.org/10.1089/aivt.2019.0009.

266. Wolfram J, Zhu M, Yang Y, Shen J, Gentile E, Paolino D, Fresta M, Nie G, Chen C, Shen H. Safety of nanoparticles in medicine. Curr Drug Targets. 2015;16:1671-81.

267. Szebeni J, Alving CR, Rosivall L, Bünger R, Baranyi L, Bedöcs P, Tóth $M$, Barenholz Y. Animal models of complement-mediated hypersensitivity reactions to liposomes and other lipid-based nanoparticles. J Liposome Res. 2007;17:107-17. https://doi.org/10.1080/08982100701375118.

268. Bahadar H, Maqbool F, Niaz K, Abdollahi M. Toxicity of nanoparticles and an overview of current experimental models. Iran Biomed J. 2016;20:1-11. https://doi.org/10.7508/ibj.2016.01.001.

269. Farcal L, Andón FT, Di Cristo L, Rotoli BM, Bussolati O, Bergamaschi E, Mech A, Hartmann NB, Rasmussen K, Riego-Sintes J. Comprehensive in vitro toxicity testing of a panel of representative oxide nanomaterials: first steps towards an intelligent testing strategy. PLOS ONE. 2015;10:e0127174. https://doi.org/10.1371/journal.pone.0127174.

270. Hanley C, Thurber A, Hanna C, Punnoose A, Zhang J, Wingett DG. The influences of cell type and $\mathrm{ZnO}$ nanoparticle size on immune cell cytotoxicity and cytokine induction. Nanoscale Res Lett. 2009;4:1409. https://doi.org/10.1007/s11671-009-9413-8.

271. Najafi-Hajivar S, Zakeri-Milani P, Mohammadi H, Niazi M, SoleymaniGoloujeh M, Baradaran B, Valizadeh H. Overview on experimental models of interactions between nanoparticles and the immune system. Biomed Pharmacother. 2016;83:1365-78. https://doi.org/10.1016/j. biopha.2016.08.060

272. Steinberg P. In vitro-in vivo carcinogenicity. In: Steinberg P, editor. In vitro environmental toxicology-concepts, application and assessment. Berlin: Springer; 2016. p. 81-96. https://doi.org/10.1007/10_ 2015 5013.

273. Goode AE, Carter DAG, Motskin M, Pienaar IS, Chen S, Hu S, Ruenraroengsak P, Ryan MP, Shaffer MSP, Dexter DT. High resolution and dynamic imaging of biopersistence and bioreactivity of extra and intracellular MWNTs exposed to microglial cells. Biomaterials. 2015;70:57-70. https://doi.org/10.1016/j.biomaterials.2015.08.019.

274. Vinardell MP, Llanas H, Marics L, Mitjans M. In vitro comparative skin irritation induced by nano and non-nano zinc oxide. Nanomaterials. 2017;7:56. https://doi.org/10.3390/nano7030056.

275. Hashempour S, Ghanbarzadeh S, Maibach HI, Ghorbani M, Hamishehkar H. Skin toxicity of topically applied nanoparticles. Ther Deliv. 2019;10:383-96. https://doi.org/10.4155/tde-2018-0060.

276. Caro C, Egea-Benavente D, Polvillo R, Royo JL, Leal MP, García-Martín ML. Comprehensive toxicity assessment of PEGylated magnetic nanoparticles for in vivo applications. Colloids Surf B. 2019;177:253-9. https://doi. org/10.1016/j.colsurfb.2019.01.051

277. Veintemillas-Verdaguer S, Luengo Y, Serna CJ, Andrés-Vergés M, Varela M, Calero M, Lazaro-Carrillo A, Villanueva A, Sisniega A, Montesinos P. Bismuth labeling for the $\mathrm{CT}$ assessment of local administration of magnetic nanoparticles. Nanotechnology. 2015;26:135101. https://doi. org/10.1080/21691401.2019.1596923.

278. Shahzad K, Mushtaq S, Rizwan M, Khalid W, Atif M, Din FU, Ahmad N, Abbasi R, Ali Z. Field-controlled magnetoelectric core-shell CoFe2O4@ $\mathrm{BaTiO} 3$ nanoparticles as effective drug carriers and drug release in vitro. Mater Sci Eng C. 2021;119:111444. https://doi.org/10.1016/j.msec.2020. 111444.

279. Calderan L, Malatesta M. Imaging techniques in nanomedical research. Eur J Histochem EJH. 2020. https://doi.org/10.4081/ejh.2020.3151.

280. Sharma LR, Subedi A, Shah BK. Anaphylaxis to pegylated liposomal Doxorubicin: a case report. West Indian Med J. 2014;63:376-7. https:// doi.org/10.7727/wimj.2013.270.

281. Mohamed M, Abu Lila AS, Shimizu T, Alaaeldin E, Hussein A, Sarhan HA, Szebeni J, Ishida T. PEGylated liposomes: immunological responses. Sci Technol Adv Mater. 2019;20:710-24. https://doi.org/10. 1080/14686996.2019.1627174.

282. Mishra V, Bansal KK, Verma A, Yadav N, Thakur S, Sudhakar K, Rosenholm JM. Solid lipid nanoparticles: emerging colloidal nano drug delivery systems. Pharmaceutics. 2018;10:191. https://doi.org/10. 3390/pharmaceutics10040191.
283. Lémery E, Briançon S, Chevalier Y, Bordes C, Oddos T, Gohier A, Bolzinger M-A. Skin toxicity of surfactants: structure/toxicity relationships. Colloids Surf A. 2015;469:166-79. https://doi.org/10.1016/j.colsurfa. 2015.01.019.

284. Zielińska A, Carreiró F, Oliveira AM, Neves A, Pires B, Venkatesh DN, Durazzo A, Lucarini M, Eder P, Silva AM. Polymeric nanoparticles: production, characterization, toxicology and ecotoxicology. Molecules. 2020;25:3731. https://doi.org/10.3390/molecules25163731.

285. Yao Y, Zang Y, Qu J, Tang M, Zhang T. The toxicity of metallic nanoparticles on liver: the subcellular damages, mechanisms, and outcomes. Int J Nanomed. 2019;14:8787. https://doi.org/10.2147/IJN.S212907.

286. Lopez-Chaves C, Soto-Alvaredo J, Montes-Bayon M, Bettmer J, Llopis J, Sanchez-Gonzalez C. Gold nanoparticles: distribution, bioaccumulation and toxicity. In vitro and in vivo studies. Nanomed Nanotechnol Biol Med. 2018;14:1-12. https://doi.org/10.1016/j.nano.2017.08. 011.

287. Sun X, Wang Z, Zhai S, Cheng Y, Liu J, Liu B. In vitro cytotoxicity of silver nanoparticles in primary rat hepatic stellate cells. Mol Med Rep. 2013;8:1365-72. https://doi.org/10.3892/mmr.2013.1683.

288. Pereira LC, Pazin M, Franco-Bernardes MF, da Cunha Martins Jr A, Barcelos GRM, Pereira MC, Mesquita JP, Rodrigues JL, Barbosa Jr F, Dorta DJ. A perspective of mitochondrial dysfunction in rats treated with silver and titanium nanoparticles (AgNPs and TiNPs). J Trace Elem Med Biol. 2018;47:63-9. https://doi.org/10.1016/j.jtemb.2018.01.007.

289. Hsiao IL, Hsieh YK, Chuang CY, Wang CF, Huang YJ. Effects of silver nanoparticles on the interactions of neuron-and glia-like cells: toxicity, uptake mechanisms, and lysosomal tracking. Environ Toxicol. 2017;32:1742-53. https://doi.org/10.1002/tox.22397.

290. Weldon BA, Park JJ, Hong S, Workman T, Dills R, Lee JH, Griffith WC, Kavanagh TJ, Faustman EM. Using primary organotypic mouse midbrain cultures to examine developmental neurotoxicity of silver nanoparticles across two genetic strains. Toxicol Appl Pharmacol. 2018;354:215-24. https://doi.org/10.1016/j.taap.2018.04.017.

291. Sawicki K, Czajka M, Matysiak-Kucharek M, Fal B, Drop B, MęczyńskaWielgosz S, Sikorska K, Kruszewski M, Kapka-Skrzypczak L. Toxicity of metallic nanoparticles in the central nervous system. Nanotechnol Rev. 2019;8:175-200. https://doi.org/10.1515/ntrev-2019-0017.

292. Pujalté I, Passagne I, Brouillaud B, Tréguer M, Durand E, OhayonCourtès C, I'Azou B. Cytotoxicity and oxidative stress induced by different metallic nanoparticles on human kidney cells. Part Fibre Toxicol. 2011;8:1-16. https://doi.org/10.1186/1743-8977-8-10.

293. Li X, Wang L, Fan Y, Feng Q, Cui F-Z. Biocompatibility and toxicity of nanoparticles and nanotubes. J Nanomater. 2012. https://doi.org/10. 1155/2012/548389.

294. Rodriguez-Yanez Y, Munoz B, Albores A. Mechanisms of toxicity by carbon nanotubes. Toxicol Mech Methods. 2013;23:178-95. https:// doi.org/10.3109/15376516.2012.754534.

295. Guadagnini R, Halamoda Kenzaoui B, Walker L, Pojana G, Magdolenova Z, Bilanicova D, Saunders M, Juillerat-Jeanneret L, Marcomini A, Huk A. Toxicity screenings of nanomaterials: challenges due to interference with assay processes and components of classic in vitro tests. Nanotoxicology. 2015;9:13-24. https://doi.org/10.3109/17435 390.2013.829590

296. Bosetti R, Jones SL. Cost-effectiveness of nanomedicine: estimating the real size of nano-costs. Nanomedicine. 2019;14:1367-70. https://doi. org/10.2217/nnm-2019-0130.

297. Daraee H, Etemadi A, Kouhi M, Alimirzalu S, Akbarzadeh A. Application of liposomes in medicine and drug delivery. Artif Cells Nanomed Biotechnol. 2016;44:381-91. https://doi.org/10.3109/21691401.2014. 953633.

298. Mehnert W, Mäder K. Solid lipid nanoparticles: production, characterization and applications. Adv Drug Deliv Rev. 2012;64:83-101. https://doi. org/10.1016/j.addr.2012.09.021.

299. Lingayat VJ, Zarekar NS, Shendge RS. Solid lipid nanoparticles: a review. Nanosci Nanotechnol Res. 2017;2:67-72. https://doi.org/10.12691/ nnr-4-2-5.

300. Elsabahy M, Wooley KL. Design of polymeric nanoparticles for biomedical delivery applications. Chem Soc Rev. 2012;41:2545-61. https://doi. org/10.1039/c2cs15327k.

301. Farjadian F, Ghasemi A, Gohari O, Roointan A, Karimi M, Hamblin MR. Nanopharmaceuticals and nanomedicines currently on the market: 
challenges and opportunities. Nanomedicine. 2019;14:93-126. https:// doi.org/10.2217/nnm-2018-0120.

302. NIH. Liposomal amphotericin in disseminated leishmaniasis; 2014 https://www.clinicaltrials.gov/ct2/show/NCT02025491?cond=Leish maniasis+liposomes\&draw=2\&rank=1. Accessed 13 Feb 2021.

303. NIH. Single infusion of liposomal amphotericin B in Indian visceral leishmaniasis; 2009. https://www.clinicaltrials.gov/ct2/show/NCT00628719? term=Liposomes\&cond=leishmaniasis\&draw $=2 \&$ rank $=6$. Accessed 13 Feb 2021

304. NIH. Topical liposomal amphotericin B Gel treatment for cutaneous leishmaniasis; 2020. https://www.clinicaltrials.gov/ct2/show/NCT02 656797 ? cond $=$ Leishmaniasis+liposomes\&draw $=2 \&$ rank $=4$. Accessed 09 Feb 2021.
305. NIH. Efficacy of topical liposomal form of drugs in cutaneous leishmaniasis; 2012. https://www.clinicaltrials.gov/ct2/show/NCT01050777? cond=Leishmaniasis + liposomes\&draw $=2 \&$ rank $=6$. Accessed 09 Feb 2021.

306. Yetisgin AA, Cetinel S, Zuvin M, Kosar A, Kutlu O. Therapeutic nanoparticles and their targeted delivery applications. Molecules. 2020;25:2193. https://doi.org/10.3390/molecules25092193.

\section{Publisher's Note}

Springer Nature remains neutral with regard to jurisdictional claims in published maps and institutional affiliations.
Ready to submit your research? Choose BMC and benefit from:

- fast, convenient online submission

- thorough peer review by experienced researchers in your field

- rapid publication on acceptance

- support for research data, including large and complex data types

- gold Open Access which fosters wider collaboration and increased citations

- maximum visibility for your research: over $100 \mathrm{M}$ website views per year

At BMC, research is always in progress.

Learn more biomedcentral.com/submissions 